$$
\begin{gathered}
\text { UNIVERSIDADE DE SÃO PAULO } \\
\text { ESCOLA DE EDUCAÇÃO FÍSICA E ESPORTE }
\end{gathered}
$$

RESPOSTAS CARDIOVASCULARES AGUDAS AO EXERCÍCIO FÍSICO EM PACIENTES COM CLAUDICAÇÃO INTERMITENTE

Gabriel Grizzo Cucato

SÃO PAULO

2013 


\section{RESPOSTAS CARDIOVASCULARES AGUDAS AO EXERCÍCIO FÍSICO EM PACIENTES COM CLAUDICAÇÃO INTERMITENTE}

Gabriel Grizzo Cucato

Tese apresentada à Comissão de PósGraduação da Escola de Educação Física e Esporte da Universidade de São Paulo como requisito parcial para obtenção do título de Doutor em Ciências.

Programa: Educação Física - Biodinâmica do Movimento Humano.

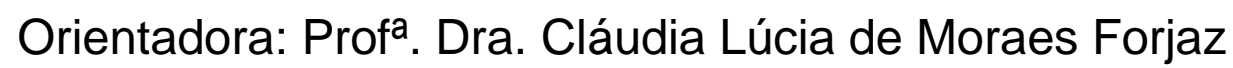

SÃO PAULO

2013 
Nome: Cucato, Gabriel Grizzo

Título: Respostas cardiovasculares agudas ao exercício físico em pacientes com claudicação intermitente.

Tese apresentada à Comissão de Pós-Graduação da Escola de Educação Física e Esporte da Universidade de São Paulo, como requisito parcial para a para a obtenção do título de Doutor em Ciências:

Programa: Educação Física - Biodinâmica do Movimento Humano.

Aprovado em:

Banca examinadora

Prof. Dr. Instituição:

Julgamento: Assinatura:

Prof. Dr. Instituição: Julgamento: Assinatura:

Prof. Dr. Instituição: Julgamento: Assinatura:

Prof. Dr. Instituição: Julgamento: Assinatura:

Prof. Dr. Instituição:

Julgamento: Assinatura: 


\section{AGRADECIMENTOS}

À minha mulher, Mariani Mussi, por ser a melhor companheira, tanto nos melhores quanto nos piores momentos da minha vida. A sua companhia e seu amor fizeram com que eu tivesse sempre mais força para passar por todos os obstáculos encontrados durante a execução desta tese.

À minha orientadora Cláudia Lúcia de Moraes Forjaz por acreditar em meu trabalho desde quando era estagiário do seu laboratório, e por estar sempre à disposição no auxílio acadêmico, profissional e pessoal. Além disso, agradeço por sua amizade e companheirismo construídos ao longo destes anos que ajudaram muito na minha formação profissional e pessoal.

Aos meus pais (Roni e Eliana) e minha irmã por acreditarem em meu potencial e por terem me ajudado em todos os momentos da minha vida, sem eles seria impossível realizar esse sonho.

Ao meu sogro (Venceslau) e sogra (Ana Maria) por terem me acolhido muito bem em sua família e por sempre me tratarem com muita alegria e amor.

A todos meus amigos da cidade de Jaú e, em especial, aos amigos que fizeram ou fazem parte do laboratório de Hemodinâmica da Atividade Motora: Luizinho, Fábio, Natan, Andréia, Dinoélia, Ricardo, Crivaldo, Hélcio, Aluísio, Raphael, Leandro, Fernando, Breno, João, Luis Riani, Teresa, Modesto, Tiago, Rafael. Além disso, agradeço especialmente ao Marcel da Rocha Chehuen por tem sido meu grande companheiro no recrutamento dos voluntários e execução das coletas de dados, sendo que sem a sua ajuda seria impossível a realização desta tese.

Aos médicos do Ambulatório de Cirurgia Vascular do Hospital das Clínicas da Faculdade de Medicina da Universidade de São Paulo, em especial ao Dr. Glauco Saez e Dr. Antônio Zerati pela amizade e parceria construídas durante esses anos e pelo auxílio nos exames clínicos e laboratoriais do estudo.

Aos pacientes do estudo que foram voluntários e tiveram grande comprometimento durante todos estes anos de pesquisa.

Ao Professor Dr. Edilson Serpelony Cyrino por ter sido o primeiro professor a ter me ensinado os valores da pesquisa e por ter me acolhido em seu grupo de pesquisa (GEPEMENE). 
À Dra. Taís Tinucci por ter sido a primeira orientadora deste projeto, e por ter confiado em meu trabalho desde início.

Ao Dr. Nelson Wolosker por ceder os pacientes para a pesquisa e pela amizade e companheirismo construídos ao longo destes anos.

Ao professor Dr. John Saxton que possibilitou que eu realizasse o sonho de fazer o Doutorando Sanduiche em seu laboratório. Com certeza esse período fora do país me ajudou muito no meu amadurecimento profissional e pessoal.

Ao Professor Dr. Raphael Mendes Ritti Dias por ter me aceitado como seu estagiário, fato este que mudou completamente a minha vida. Além disso, agradeço por sua amizade e por todos os seus conselhos científicos e pessoais ao longo destes anos.

Aos funcionários da secretaria de pós-graduação (Márcio, Paulo, Ilza e Mariana) por estarem sempre à disposição no auxílio dos alunos da pós-graduação.

Aos órgãos de fomento CNPq, FAPESP e CAPES por permitirem que eu tivesse dedicação exclusiva ao programa de pós-graduação, fortalecendo a minha formação profissional. 


\section{RESUMO}

CUCATO, G.G. Respostas cardiovasculares agudas ao exercício físico em pacientes com claudicação intermitente. 2013. $113 \mathrm{f}$. Tese (Doutorado) - Escola de Educação Física e Esporte, Universidade de São Paulo, São Paulo.

INTRODUÇÃO: A caminhada é recomendada no tratamento de pacientes com claudicação intermitente $(\mathrm{Cl})$ por aumentar a capacidade funcional. Porém, os efeitos cardiovasculares de uma sessão de caminhada foram pouco estudados nestes pacientes. OBJETIVO: Analisar o efeito de uma sessão de caminhada sobre a função e regulação cardiovascular pós-exercício de pacientes com CI. MATERIAS E MÉTODOS: 20 pacientes com $\mathrm{Cl}$ participaram de duas sessões experimentais realizadas em ordem aleatória: Controle (repouso em pé por 60 minutos) e Exercício (15 séries de dois minutos de caminhada na frequência cardíaca $(F C)$ do limiar de dor, intercaladas por dois minutos de recuperação passiva). Nas duas sessões, a pressão arterial (PA) clínica e de 24 horas, o débito cardíaco (DC - reinalação de $\mathrm{CO}_{2}$ ), o fluxo sanguíneo para os membros ativo e inativo (plestismografia de oclusão venosa), a capacidade vasodilatadora (hiperemia reativa) e a modulação autonômica cardiovascular (análise espectral da variabilidade da FC e da PA) foram medidas antes e após as intervenções. O volume sistólico (VS) e a resistência vascular (RV) sistêmica foram calculados. Os dados foram analisados pela ANOVA de dois fatores para amostras repetidas, post-hoc de Newman-Keuls e $P<0,05$. RESULTADOS: $O$ exercício prévio reduziu a PA clínica ( $\triangle \mathrm{PA}$ média $=-7 \pm 2 \mathrm{mmHg}, \mathrm{P}<0,05)$, mas a $\mathrm{PA}$ ambulatorial não se modificou. Após o exercício, o VS e o DC diminuíram ($5,62 \pm 1,97 \mathrm{ml}$ e $-0,05 \pm 0,13 \mathrm{l} / \mathrm{min}, P<0,05)$. A RV sistêmica não se elevou pósexercício e o exercício prévio impediu o aumento da $R V$ na região ativa e inativa, sem modificar a resposta vasodilatadora. O exercício impediu a redução da FC pósintervenção, pois impediu o aumento da modulação vagal cardíaca. CONCLUSÃO: Uma única sessão de caminhada promoveu hipotensão pós-exercício (HPE) em pacientes com $\mathrm{Cl}$ no ambiente clínico, mas este efeito não perdurou no período ambulatorial. A HPE ocorreu pelo efeito do exercício reduzindo o VS e o DC e, simultaneamente, impedindo o aumento da RV sistêmica.

Palavras chave: Doença Arterial Periférica, Exercício Aeróbico, Função Cardiovascular. 


\begin{abstract}
CUCATO, G.G. Acute cardiovascular responses to walking exercise in patients with intermittent claudication. 2013. 113 f. Thesis (PhD) - Escola de Educação Física e Esporte, Universidade de São Paulo, São Paulo.
\end{abstract}

INTRODUCTION: Walking exercise (WE) is recommended for patients with intermittent claudication (IC) because it improves functional capacity. However, cardiovascular responses after one session of WE has been poor studied. OBJECTIVE: To analyze the post-effects of a WE session on cardiovascular function and regulation in patients with IC. METHODS: Twenty IC patients randomly underwent two experimental sessions: Control (rest on treadmill for $60 \mathrm{~min}$ ) and Exercise (fifteen 2-min bouts of WE at the heart rate $(\mathrm{HR})$ of the onset of claudication pain, interpolated with 2-min rest intervals). Before and after the interventions, clinic and ambulatory blood pressure (BP), cardiac output ( $\mathrm{CO}, \mathrm{CO}_{2}$ rebreathing), blood flow to active and inactive limbs (venous occlusion plethysmography), vasodilatory capacity (reactive hyperemia), cardiovascular autonomic modulation (spectral analysis of HR and BP) were measured in both experimental sessions. Stroke volume (SV) and systemic vascular resistance (VR) were calculated. Data was analyzed by a two-way ANOVA for repeated measures followed by Newman-Keuls post-hoc test, with $P<0.05$. RESULTS: WE significantly decreased clinic BP $(\Delta$ Mean $\mathrm{BP}=-7 \pm 2 \mathrm{mmHg}, \mathrm{P}<0.05)$, but ambulatory BP did not change. After exercise, SV ($5.62 \pm 1.97 \mathrm{ml})$ and $C O(-0.05 \pm 0.13 \mathrm{l} / \mathrm{min})$ decreased $(P<0.05)$, whereas systemic VR did not change. Moreover, previously exercise prevented the increase in VR in the inactive and active limbs without modifying vasodilatory response. Exercise abolished HR decrease after the intervention, because it blunted cardiac vagal modulation increase. CONCLUSION: WE session promoted post-exercise hypotension (PEH) in patients with IC in clinic condition. However, this effect of WE was not maintained during ambulatory period. PEH was promoted by an effect of previous exercise decreasing $\mathrm{CO}$ and SV, and simultaneously, preventing an increase in systemic VR.

Key words: Peripheral artery disease, aerobic exercise, cardiovascular function. 


\section{LISTAS DE FIGURAS}

Página

FIGURA 1 - Risco relativo do desenvolvimento de DAP

FIGURA 2 - Sequência do protocolo experimental.

FIGURA 3 - Desenho experimental.

FIGURA 4 - Fluxograma do estudo.

FIGURA 5 - Resposta $(\Delta)$ da pressão arterial sistólica (PAS, \#103), diastólica (PAD) e média (PAM) avaliadas nas sessões controle (linha tracejada) e exercício (linha contínua) $(\mathrm{n}=20)$

FIGURA 6 Médias horárias da pressão arterial sistólica (PAS, \#103), diastólica (PAD), média (PAM) e da frequência cardíaca (FC) medidas após as intervenções nas duas sessões experimentais, controle (linha tracejada) e exercício (linha contínua) $(n=16)$. Valores = média \pm erro padrão......................

FUGURA 7 Resposta $(\Delta)$ da resistência vascular sistêmica (RVS), débito cardíaco (DC), frequência cardíaca ( $F C$ ) e volume sistólico (VS) e avaliadas nas sessões controle (linha tracejada) e exercício (linha contínua) $(\mathrm{n}=20)$.

* Diferente da pré-intervenção $(P<0,05)$. $†$ Diferente da sessão controle $(P<0,05)$. Valores $=$ média \pm erro padrão......

FIGURA 8 Resposta $(\Delta)$ dos principais parâmetros autonômicos avaliados nas sessões controle (linha tracejada) e exercício (linha contínua).

$\mathrm{RR}=$ Intervalo $\mathrm{R}-\mathrm{R} ; \mathrm{VT}$ = variância total; $\mathrm{BF}=$ banda de 
baixa frequência; $A F=$ banda de alta frequência; $B F / A F=$ balanço simpato-vagal; PAS = Pressão arterial sistólica; OV $=$ nenhuma variação, $2 \mathrm{~V}=$ duas variações, $\mathrm{SBR}=$ sensibilidade barorreflexa.

* Diferente da pré-intervenção $(P<0,05) . \dagger$ Diferente da sessão controle $(P<0,05)$. Valores $=$ média \pm erro padrão.....

FIGURA 9 Resposta $(\Delta)$ do fluxo sanguíneo basal (FSB), resistência vascular $(\mathrm{RV})$, fluxo sanguíneo máximo pós-hiperemia (FSM) e área sob a curva de fluxos pós-hiperemia (AUC) medidos no membro inativo (antebraço - A) e ativo (pernaP) nas sessões controle (linha tracejada) e exercício (linha contínua). * Diferente da pré-intervenção $(P<0,05)$. † Diferente da sessão controle $(P<0,05)$. Valores $=$ média \pm

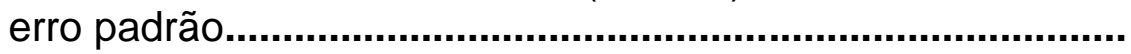




\section{LISTAS DE TABELAS}

Página

TABELA 1 - Características físicas, fatores de risco, medicamentos e perfil sanguíneo da amostra.

TABELA 2 - Pressão arterial de repouso e índice tornozelo-braço no $1^{\circ}$ minuto pós-exercício.................................................................

TABELA 3 - Variáveis cardiorrespiratórias, metabólicas e funcionais medidas no teste ergoespirométrico......................................

TABELA 4 - Variáveis hemodinâmicas medidas em repouso préintervenção nas sessões: controle e exercício.

TABELA 5 - Variáveis autonômicas medidas em repouso préintervenção nas sessões controle e exercício.

TABELA 6 Variáveis vasculares medidas em repouso pré-intervenção nas sessões controle e exercício

TABELA 7 Respostas cardiovasculares e a ocorrência de dor durante a execução da caminhada na sessão de exercício $(n=17) \ldots . . . . .$.

TABELA 8 Pressão arterial sistólica (PAS), pressão arterial diastólica (PAD) e pressão arterial média (PAM) medidas pré e pósintervenção nas sessões experimentais: controle e exercício

TABELA 9 Média da pressão arterial sistólica (PAS), diastólica (PAD), média (PAM) e da frequência cardíaca ( $F C$ ) obtidas no período de 24 horas, vigília e sono pós-intervenção nas sessões controle e exercício $(n=16)$

TABELA 10 Resistência vascular sistêmica (RVS), débito cardíaco (DC), volume sistólico (VS) e frequência cardíaca (FC) medidos pré e pós-intervenção nas sessões experimentais: controle

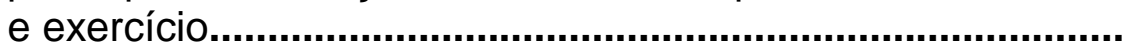


TABELA 11 Parâmetros autonômicos avaliados pelo modelo linear e não- linear de variabilidade da frequência cardíaca, pela variabilidade da pressão arterial e pela sensibilidade barorreflexa espontânea medidos no período pré e pósintervenção das sessões experimentais controle e exercício.

TABELA 12 Fluxo sanguíneo basal (FSB), resistência vascular (RV), fluxo sanguíneo máximo pós-hiperemia (FSM) e área sob a curva de fluxos pós-hiperemia (AUC) medidos no membro inativo (antebraço - A) e ativo (perna - $P$ ) nos períodos pré e pós-intervenção nas duas sessões experimentais: controle e exercício................................................................................. 


\section{LISTAS DE QUADROS}

Página

QUADRO 1 - Valores e interpretação do Índice Tornozelo-Braço (ITB)..... 25

QUADRO 2 - Sintomas e sinais característicos dos quatro estágios da Doença Arterial Periférica (DAP).......................................... 


\section{LISTAS DE SIGLAS, ABREVIAÇÕES E SÍMBOLOS}

$\begin{array}{cc}\text { A } & \text { Antebraço } \\ \text { AF } & \text { Alta frequência } \\ \text { AUC } & \text { Área sob a curva }\end{array}$

banda de baixa frequência

$\mathrm{Cl}$

Claudicação intermitente

$\mathrm{CO}_{2}$

Dióxido de carbono

DAP

Doença arterial periférica

DC

Débito cardíaco

DIC

Distância inicial de claudicação

DTC

Distância total de claudicação

ES

Entropia de shannon

HPE

IMC

ITB

FC

FSB

Hipotensão pós-exercício

Índice de massa corporal

Índice Tornozelo-Braço

Frequência cardíaca

Fluxo sanguíneo basal

HDL

L

Lipoproteína de alta densidade

LA

LD

Lítros

Limiar anaeróbico

LDL

Limiar de dor

Lipoproteína de baixa densidade

$\mathrm{P}$

Perna

PAS

Pressão arterial sistólica

PAD

Pressão arterial diastólica

PAM

Pressão arterial média 
RV

RVS

SBR

$U$

VS

$\mathrm{VO}_{2}$

VT

$<$

$>$

$\pm$

$\Delta$

*

†
Resistência vascular

Resistência vascular sistêmica

Sensibilidade barorreflexa

Unidades

Volume sistólico

Consumo de oxigênio

variância total

Maior que

Menor que

Mais ou menos

Delta

Diferente da pré-intervenção

Diferente da sessão controle

Unidades

$\begin{array}{cc}\text { bpm } & \text { Batimento por minuto } \\ \mathrm{cm} & \text { centrímetro } \\ \mathrm{Hz} & \text { Hertz } \\ \mathrm{ms} & \text { milisegundo } \\ \mathrm{ml} & \text { mililitro } \\ \mathrm{mmHg} & \text { Milímetros de mercúrio } \\ \mathrm{mg} / \mathrm{dL} & \text { Miligramas por decilitro }\end{array}$




\section{LISTAS DE ANEXOS}

ANEXO 1 - Comitê de ética da Escola de Educação Física e Esporte

ANEXO 2 - Comitê de ética da Faculdade de Medica da Universidade de São Paulo 


\section{SUMÁRIO}

Página

RESUMO

ABSTRACT

LISTA DE FIGURAS

LISTA DE TABELAS

LISTA DE QUADROS

LISTA DE SIGLAS, ABREVIAÇÕES E SÍMBOLOS

LISTA DE ANEXOS

1 INTRODUÇÃO 19

2 OBJETIVOS 23

2.1 Geral 23

2.2 Específico 23

3. REVISÃO DE LITERATURA 24

3.1 Doença Arterial Periférica 24

3.1.1 Diagnóstico e Prevalência da Doença Arterial Periférica 24

3.1.2 Tratamento de Pacientes com Claudicação Intermitente 30

3.1.2.1 Intervenção Cirúrgica 30

3.1.2.2 Tratamento Farmacológico 31

3.1.2.3 Exercício Físico 32

3.2 Respostas Cardiovasculares Após o Exercício Físico Aeróbico 33

3.2.1 Respostas Após uma Sessão de Exercício Físico Dinâmico em 33 indivíduos sem Doença Arterial Periférica

3.2.2 Respostas Após uma Sessão de Exercício Físico Dinâmico em Claudicantes $\quad 39$

4. MÉTODOS 41

4.1 AMOSTRA 41

4.2 EXAMES PRELIMINARES 42

4.2.1 Diagnóstico da Doença Arterial Periférica 42

4.2.2 Avaliação da Pressão Arterial 43

4.2.3 Avaliação Ergoespirométrica 44 
4.2.4 Diagnóstico de Obesidade 45

4.2.5 Diagnóstico de Neuropatia Autonômica Cardiovascular 45

4.3 MEDIDAS 45

4.3.1 Pressão Arterial Auscultatória $\quad 45$

4.3.2 Pressão Arterial Fotopletismográfica 46

4.3.3 Monitorização Ambulatorial da Pressão Arterial 46

4.3.4 Frequência Cardíaca 47

$\begin{array}{lll}\text { 4.3.5 Respiração } & 47\end{array}$

4.3.6 Débito Cardíaco 47

4.3.7 Resistência vascular sistêmica $\quad 48$

4.3.8 Volume Sistólico $\quad 48$

4.3.9 Modulação Autonômica do Sistema Cardiovascular $\quad 48$

4.3.9.1 Coleta de Dados para Avaliação Autonômica 49

4.3.9.2 Avaliação Pelo Modelo Linear 50

4.3.9.3 Análise Pelo Modelo Não-Linear 51

4.3.10 Avaliação do Controle Barorreflexo Espontâneo 53

4.3.11 Fluxo Sanguíneo $\quad 54$

4.3.12 Capacidade Vasodilatadora 55

4.4 PROCEDIMENTOS 55

4.4.1 Sessão de Exercício 55

4.5 PROTOCOLO EXPERIMENTAL 56

4.5.1 Sessão Experimental 57

4.6 ANÁLISE DOS DADOS 60

4.7 ANÁLISE ESTATÍSTICA 60

5. RESULTADOS 62

5.1 Amostra 62

5.2 Execução do Protocolo 65

5.3 Respostas Durante a Sessão de Exercício 68

5.4 Respostas Pós-Exercício 69

5.4.1 Pressão Arterial Clínica e de 24 Horas 70

5.4.2 Variáveis Hemodinâmicas Sistêmicas $\quad 75$

5.4.3 Variáveis Autonômicas $\quad 77$

5.4.4 Variáveis Vasculares 80 
5 DISCUSSÂO 84

5.1 Protocolo Experimental 85

5.2 Efeito da caminhada na Hipotensão Pós-Exercício em Pacientes com Claudicação Intermitente $\quad 87$

5.3 Mecanismos da Hipotensão Pós-Exercício em Pacientes com Claudicação Intermitente 90

5.4 Limitações do Estudo 95

6 CONCLUSÃO 96

$7 \quad$ REFERÊNCIAS $\quad 97$

ANEXOS 


\section{INTRODUÇÃO}

A Doença Arterial Periférica (DAP) compreende uma série de disfunções estruturais e funcionais que ocorrem nas artérias que irrigam as regiões periféricas do corpo, principalmente dos membros inferiores (WOLOSKER et al., 2003). A causa mais comum desta doença é a aterosclerose (HIRSCH et al., 2006; NORGREN et al., 2007). Assim, a DAP se caracteriza pelo estreitamento do calibre arterial, o que promove desequilíbrio entre a oferta e a demanda de oxigênio nas regiões distais à lesão (HIRSCH et al., 2006; NORGREN et al., 2007). Esta doença apresenta uma prevalência que aumenta de forma importante com o avançar da idade, sendo de $1 \%$ na faixa etária de $35-39$ anos, $3 \%$ de $60-64$ anos e $7 \%$ na faixa etária acima de 70 anos (NORGREN et al., 2007).

A DAP é uma doença de evolução progressiva, de modo que seus sinais e sintomas tornam-se mais graves com o passar do tempo. O primeiro sintoma relatado pelos pacientes com DAP é a sensação de dor, câimbra, ardência ou formigamento que ocorre no(s) membro(s) afetado(s), geralmente o(s) inferior(es), durante a execução de atividades físicas. Este sintoma é conhecido como claudicação intermitente (CI) (HIRSCH et al., 2006; NORGREN et al., 2007). Assim, quando o individuo com $\mathrm{Cl}$ realiza um esforço físico, principalmente na forma de caminhada, há a necessidade de oxigênio e, consequentemente, de sangue para os músculos ativos. Contudo, devido à presença da obstrução arterial no membro inferior, a oferta de sangue e oxigênio pode não ser suficiente para a demanda aumentada, produzindo um quadro isquêmico, que leva à dor e impede a continuação do esforço. A interrupção do esforço alivia a dor em poucos minutos, porém o retorno à atividade provoca novamente o sintoma, o que justifica a intermitência desta condição (HIRSCH et al., 2006; NORGREN et al., 2007).

O tratamento inicial e preferencial da DAP é a prática regular de exercício físico, principalmente na forma de caminhada (HIRSCH et al., 2006; NORGREN et al., 2007). Esta preferência ocorre em virtude de já estar bem estabelecido na literatura que a caminhada promove aumento significante na capacidade funcional (GARDNER e POEHLMAN, 1995; PARMENTER et al., 2011) e na qualidade de vida de pacientes com $\mathrm{Cl}$ (BENDERMACHER et al., 2006; SPRONK et al., 2007). Contudo, apesar destes benefícios da caminhada já estarem bem comprovados, 
seus efeitos sobre a função cardiovascular ainda não estão claros (CHEHUEN, CUCATO e FORJAZ, 2012). Esse é um aspecto bastante importante visto que a maioria dos pacientes com DAP apresenta diversos fatores de risco cardiovascular, como dislipidemia, diabetes mellitus, e principalmente, hipertensão arterial (HIRSCH et al., 2006; NORGREN et al., 2007). Adicionalmente, esses pacientes frequentemente apresentam alterações na função e regulação cardiovascular, como aumento na modulação simpática (GOERNIG et al., 2008), disfunção endotelial (BREVETTI, SCHIANO e CHIARIELLO, 2008) e rigidez arterial (ZAGURA et al., 2011). Essa função ineficiente somada à presença de fatores de risco aumenta sobremaneira o risco cardiovascular nessa população (CRIQUI et al., 1992).

Em indivíduos sem DAP, o exercício físico trás importantes benefícios ao sistema cardiovascular (GOLBIDI e LAHER, 2012). Estes efeitos podem ser observados pelas adaptações crônicas a um período de treinamento físico (CHODZKO-ZAJKO et al., 2009) ou pelas respostas agudas decorrentes da execução de uma única sessão de exercício (PESCATELLO et al., 2004). Um dos benefícios agudos do exercício físico é a diminuição das pressões arteriais sistólica (PAS) e diastólica (PAD) no período de recuperação pós-exercício. Esta redução é denominada "hipotensão pós-exercício" (HPE) e se caracteriza pela diminuição da pressão arterial pós-exercício quando comparada aos níveis observados no período pré-exercício ou aos valores medidos em um dia controle, sem a execução do exercício (KENNEY e SEALS, 1993; MACDONALD, 2002; PESCATELLO et al., 2004). Este fenômeno foi observado e analisado por inúmeros estudos desde a década de 1980 (WILCOX et al., 1982; BENNETT, WILCOX e MACDONALD, 1984; HAGBERG, MONTAIN e MARTIN, 1987; FLORAS et al., 1989; PESCATELLO et al., 1991; SOMERS et al., 1991; CLEROUX et al., 1992; CLEROUX et al., 1992; FLORAS e WESCHE, 1992; HARA e FLORAS, 1992; KENNEY e SEALS, 1993; PIEPOLI et al., 1993; HALLIWILL, TAYLOR e ECKBERG, 1996; HALLIWILL et al., 1996; RUECKERT et al., 1996; WALLACE et al., 1997; FORJAZ et al., 1998; FORJAZ et al., 1998; FORJAZ et al., 1998; FORJAZ et al., 1999; MACDONALD et al., 1999; WALLACE et al., 1999; HALLIWILL, MINSON e JOYNER, 2000; MACDONALD, MACDOUGALL e HOGBEN, 2000; HALLIWILL, 2001; BRANDAO RONDON et al., 2002; LEGRAMANTE et al., 2002; MACDONALD et al., 2002; SENITKO, CHARKOUDIAN e HALLIWILL, 2002; FORJAZ et al., 2004; PESCATELLO et al., 2004; PESCATELLO et al., 2004; PRICHER et al., 2004; 
WILKINS, MINSON e HALLIWILL, 2004; BISQUOLO et al., 2005; CARDOSO, 2005; LOCKWOOD et al., 2005; LOCKWOOD, WILKINS e HALLIWILL, 2005; BLANCHARD et al., 2006; DUJIC et al., 2006; MCCORD, BEASLEY e HALLIWILL, 2006; SANTAELLA et al., 2006; ARAUJO, 2007; JONES et al., 2009; CARDOSO et al., 2010; CHEN e BONHAM, 2010; EICHER et al., 2010; ANUNCIAÇÃO e POLITO, 2011; CUCATO et al., 2011; LOBO, 2011; RODRIGUES, 2011; TEIXEIRA et al., 2011; ENDO et al., 2012; LIU et al., 2012; HALLIWILL et al., 2013; RODRIGUES et al., 2013). Estes estudos comprovaram que a HPE ocorre na maior parte das vezes em indivíduos hipertensos, tem magnitude significante e proporcional ao valor inicial da pressão arterial e pode ser mantida por várias horas pós-exercício, o que lhe confere reconhecida importância clínica (PESCATELLO et al., 2004).

A ocorrência da HPE aeróbico tem sido atribuída à interação entre mecanismos hemodinâmicos, neurais e vasculares. Alguns estudos (CLEROUX et al., 1992; PIEPOLI et al., 1993; HALLIWILL, MINSON e JOYNER, 2000; LEGRAMANTE et al., 2002; PRICHER et al., 2004; WILKINS, MINSON e HALLIWILL, 2004; ENDO et al., 2012; BARRETT-O'KEEFE, KAPLON e HALLIWILL, 2013; NEW et al., 2013) relacionam-na à redução da resistência vascular sistêmica (RVS) ocasionada pela manutenção da vasodilatação do território muscular ativo (ENDO et al., 2012) e inativo (BISQUOLO et al., 2005) no período de recuperação do exercício, o que pode ocorrer devido à redução da atividade nervosa simpática periférica e/ou ao aumento da produção de substâncias vasodilatadoras (HALLIWILL et al., 2013). Outros autores (HAGBERG, MONTAIN e MARTIN, 1987; FLORAS e WESCHE, 1992; BRANDAO RONDON et al., 2002; SENITKO, CHARKOUDIAN e HALLIWILL, 2002; TEIXEIRA et al., 2011) atribuem a HPE à redução do débito cardíaco (DC), associada à diminuição do volume sistólico (VS), que não é compensada apesar do aumento da frequência cardíaca (FC) pós-exercício provocado pela manutenção da atividade simpática elevada e da atividade vagal reduzida para o coração no período de recuperação pós-exercício (PIEPOLI et al., 1993; MACDONALD et al., 2002).

Em pacientes com Cl, a HPE foi relatada em dois estudos (CUCATO et al., 2011; RODRIGUES, 2011). Entretanto, nesses estudos, o exercício físico utilizado foi o de força, não havendo, pelo nosso conhecimento, nenhum estudo que tenha investigado a ocorrência da HPE após o exercício de caminhada nesses pacientes. Assim, torna-se interessante investigar se a caminhada, o exercício mais 
recomendado para esses pacientes, é capaz de promover a HPE. Além disso, os mecanismos hemodinâmicos, neurais e vasculares responsáveis pela HPE nesta população precisam ser investigados.

Devido às características dos pacientes com $\mathrm{Cl}$, é possível supor que o exercício de caminhada promova HPE nesses pacientes, pois eles apresentam, em sua maioria, hipertensão arterial (BHATT et al., 2006) e existem evidências de que a HPE é mais pronunciada em indivíduos hipertensos (PESCATELLO et al., 2004). Contudo, a presença nesses pacientes de disfunção endotelial (BREVETTI, SCHIANO e CHIARIELLO, 2008), bem como o aumento dos marcadores próinflamatórios durante a caminhada (SIGNORELLI et al., 2007) podem reduzir a capacidade vasodilatadora pós-exercício, prejudicando a HPE. Além disso, devido à ocorrência do sintoma de dor durante a caminhada, os pacientes com $\mathrm{Cl}$ não conseguem realizar a caminhada com duração prolongada, o que tem se mostrado mais efetivo para potencializar a HPE (FORJAZ et al., 1998). Por outro lado, um estudo (JONES et al., 2009) demonstrou que o exercício aeróbico intermitente, que pode ser executado por pacientes com $\mathrm{Cl}$, promoveu maior redução da pressão arterial no período de recuperação que o exercício contínuo.

Desta forma, a partir dos argumentos anteriores, existem evidências científicas para sustentar duas hipóteses contraditórias: a) o exercício de caminhada promove HPE e b) o exercício de caminhada não promove a HPE em pacientes com $\mathrm{Cl}$. Estas hipóteses, bem como os mecanismos hemodinâmicos, neurais e vasculares responsáveis pela resposta da pressão arterial pós-exercício em pacientes com $\mathrm{Cl}$ ainda não foram estudados e, portanto, serão investigados nesta tese. 


\section{OBJETIVOS}

\subsection{GERAL}

Avaliar se a execução de uma única sessão de caminhada em pacientes com $\mathrm{Cl}$ é capaz de promover a HPE, investigando as características deste fenômeno (magnitude e duração), bem como, os mecanismos hemodinâmicos, autonômicos e vasculares envolvidos na resposta.

\subsection{ESPECÍFICOS}

Investigar os efeitos de uma sessão típica de treinamento de caminhada em pacientes com $\mathrm{Cl}$, sobre as respostas pós-exercício da:

- Pressão arterial (clínica e ambulatorial);

- Determinantes hemodinâmicos (DC, RVS, FC e VS);

- Regulação autonômica cardiovascular (modulação autonômica cardíaca e vasomotora e sensibilidade barorreflexa).

- Função vascular (fluxo sanguíneo do antebraço e da perna e capacidade vasodilatadora destas regiões). 


\section{REVISÃO DE LITERATURA}

\subsection{DOENÇA ARTERIAL PERIFÉRICA}

A DAP é uma síndrome causada por disfunções estruturais e funcionais que afetam as artérias que irrigam as regiões periféricas do corpo humano (HIRSCH et al., 2006; NORGREN et al., 2007). Apesar de inúmeros processos fisiopatológicos poderem contribuir para a estenose da circulação arterial periférica, as mais comuns são as disfunções decorrentes de um processo aterosclerótico crônico, que promove a formação de placas de ateroma, que se depositam na parede das artérias (BREVETTI, SCHIANO e CHIARIELLO, 2008), diminuindo o calibre arterial e, promovendo a redução da oferta de sangue e de oxigênio aos tecidos distais à obstrução (HIRSCH et al., 2006; NORGREN et al., 2007).

Embora possa ocorrer em diferentes territórios, às obstruções mais frequentes em pacientes com DAP estão localizadas nas artérias que irrigam os membros inferiores (HIRSCH et al., 2006; NORGREN et al., 2007), sendo o segmento femoropoplíteo o afetado em mais de $60 \%$ dos casos (HALTMAYER et al., 2001).

\subsubsection{Diagnóstico e Prevalência da Doença Arterial Periférica}

O diagnóstico da DAP pode ser realizado por meio de testes clínicos, tais como o exame físico de palpação arterial, a hiperemia reativa, o tempo de enchimento venoso, entre outros (Normas de Orientação Clínica para Prevenção, Diagnóstico e Tratamento da Doença Arterial Obstrutiva Periférica (DAOP), 2005; HIRSCH et al., 2006; NORGREN et al., 2007). Além disso, há exames mais sofisticados, como a angiorressonância nuclear magnética e a arteriografia (WOLOSKER et al., 2001), que fornecem informações importantes em relação à localização da obstrução, bem como o tamanho da estenose arterial. Contudo, um dos exames mais utilizados no âmbito clínico para diagnosticar e avaliar a gravidade da DAP é a medida do índice tornozelo-braço (ITB). A medida do ITB é um 
procedimento simples, não-invasivo e de baixo custo operacional, que compreende o cálculo do quociente entre a PAS medida no tornozelo e a PAS medida no braço (ABOYANS et al., 2012). A DAP é considerada presente, quando os valores desse índice são menores do que 0,90 (HIRSCH et al., 2006; NORGREN et al., 2007). O quadro 1 apresenta a interpretação do ITB em relação à gravidade da doença.

\section{Quadro 1. Valores e interpretação do Índice Tornozelo-Braço (ITB).}

\begin{tabular}{cc}
$>1,30$ & Não Compreensível \\
$1,00-1,29$ & Normal \\
$0,91-0,99$ & Limítrofe \\
$0,41-0,90$ & Doença Arterial Periférica Leve a Moderada \\
$0,00-0,40$ & Doença Arterial Periférica Grave \\
\hline
\end{tabular}

Fonte: HIRSCH et al.(HIRSCH et al., 2006)

A prevalência da DAP tem sido estabelecida numa série de estudos epidemiológicos. Um estudo conduzido pelo National Health and Nutrition Examination Survey (SELVIN e ERLINGER, 2004) observou que, nos Estados Unidos, a doença atinge cerca de cinco milhões de indivíduos com idade superior aos 55 anos. Do mesmo modo, no Brasil, um estudo multicêntrico, que avaliou 1.170 indivíduos em 72 centros urbanos, também observou uma alta prevalência de DAP, estimando que cerca de seis milhões de indivíduos no país possuam essa doença (MAKDISSE et al., 2008). Adicionalmente, um estudo recente conduzido por BHATT et al. (BHATT et al., 2006) avaliou 67.888 indivíduos ao redor do mundo que eram acometidos por algum tipo de doença de origem aterosclerótica e, desses, 8.273 (14\%) apresentaram DAP. Desta forma, a DAP é uma doença bastante prevalente tanto em países desenvolvidos quanto em desenvolvimento. Além disso, sua prevalência vem aumentando com o passar dos anos, de modo que os gastos públicos para o seu tratamento são cada vez mais altos (MAHONEY et al., 2010).

A aumento da prevalência da DAP está fortemente associado ao avanço da idade. Um estudo conduzido por NORGREN et al. (NORGREN et al., 2007) verificou que prevalência da DAP era de 1,0\% no grupo etário de 35-39 anos, 3,1\% de 60-64 anos e 7,2\% de 70-74 anos. Adicionalmente, a DAP parece ser mais prevalente em homens do que em mulheres. CRIQUI et al. (CRIQUI et al., 2005) observou que a 
prevalência em homens é cerca de duas vezes maior do que em mulheres na faixa etária de 60 a 64 anos. Contudo, em idades mais avançadas, a prevalência DAP parece ser semelhante entre os sexos (MURABITO et al., 1997).

De modo semelhante à prevalência, a incidência de DAP também aumenta com o avançar da idade. Em estudo realizado por MEIJER et al. (MEIJER et al., 2002), essa incidência foi de 4 por 1000 pessoas/ano no grupo etário dos 55-59 anos e de 13 por 1000 pessoas/ano no grupo etário de 85 anos ou mais. Além disso, estima-se que a ocorrência de DAP irá aumentar nos Estados Unidos para 19 milhões nos indivíduos acima de 65 anos no ano de 2050 (FOOT et al., 2000).

Uma característica peculiar observada em pacientes com DAP é a presença concomitante de outras doenças isquêmicas ateroscleróticas. Em um estudo conduzido por BHATT et al. (BHATT et al., 2006) foi observado que, dos pacientes com DAP, 38\% apresentavam, além da DAP, doença arterial coronariana, 10\% doença arterial cerebral e 13\% apresentavam as três doenças associadas. Vale ressaltar ainda que, além das doenças isquêmicas oriundas da aterosclerose, pacientes com DAP também apresentam alta prevalência de outras doenças crônicas não transmissíveis, como a hipertensão arterial (81\%), o diabetes mellitus (44\%), a dislipidemia (67\%) (BHATT et al., 2006) e a síndrome metabólica (58\%) (ZERATI et al., 2010).

Como a principal etiologia da DAP é de origem aterosclerótica, os fatores de riscos dessa doença são similares aos observados em outras doenças arteriais obstrutivas, tais como na doença arterial coronariana e cerebrovascular (IRIBARREN et al., 2000). A figura 1 apresenta os principais fatores de risco para o desenvolvimento de DAP e o risco relativo atribuído a cada um deles. 
Tabagismo

Diabetes

Hipertensäo

Hipercolesterolemia

Hiperhomocisteinemia

Proteina C-Reativa

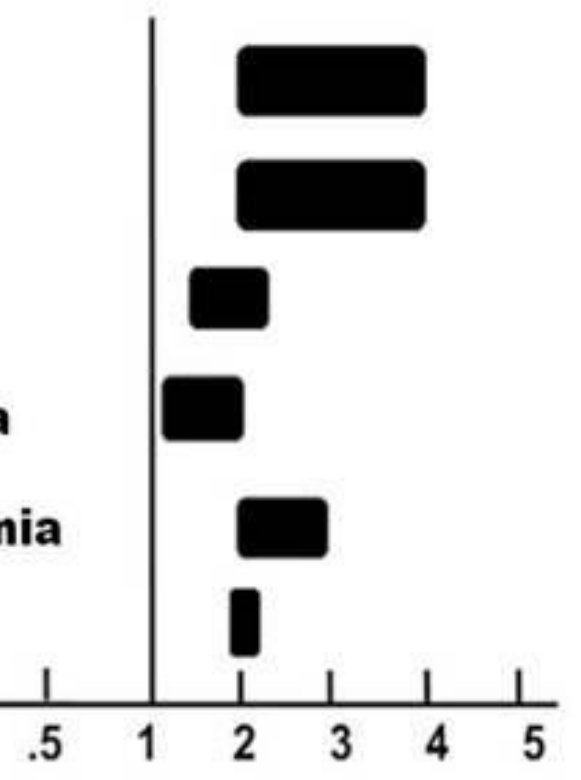

Risco Relativo

Figura 1. Risco relativo do desenvolvimento de Doença Arterial Periférica

Como demonstrado na figura 1 , os principais fatores de risco para 0 desenvolvimento de DAP são o tabagismo e o diabetes mellitus, cujas presenças aumentam em cerca de quatro vezes o risco de se desenvolver a DAP (HIRSCH et al., 2006). Adicionalmente anormalidades lipídicas, como aumento do LDL colesterol, diminuição do HDL colesterol e aumento dos níveis de triglicérides plasmáticos também aumentam os riscos do desenvolvimento de DAP em torno de duas vezes. Além disso, a hipertensão arterial é um importante fator e, apesar de não aumentar de forma tão expressiva o risco de DAP, é altamente prevalente em indivíduos com esta doença, atingindo cerca de $85 \%$ destes pacientes (BHATT et al., 2006). Atualmente, há novos potenciais fatores de risco para o desenvolvimento de DAP, tais como hiperhomocisteinemia, o aumento dos marcadores inflamatórios e aumento de proteína C reativa (HIRSCH et al., 2006). Esses fatores aumentariam de duas a três vezes o risco de desenvolvimento da doença. Entretanto, os estudos identificando a importância desses novos fatores no aumento do risco de desenvolvimento de DAP ainda são incipientes e controversos, de modo que eles ainda necessitam ser melhor investigados.

A evolução da DAP em longo prazo pode resultar em consequências lesivas para o organismo, como a necessidade de amputação do membro afetado e/ou a 
morte por eventos cardiovasculares. Entretanto, a prevalência da segunda consequência é bastante superior à primeira (HIRSCH et al., 2006; NORGREN et al., 2007). Nesse sentido, um estudo conduzido por CRIQUI et al. (CRIQUI et al., 1992) acompanhou durante 10 anos pacientes com DAP e observou que, independente da gravidade da doença, o risco de morte por doenças cardiovasculares foi de 10 a 15 vezes maior em indivíduos com DAP do que em indivíduos sem a doença. Vale ressaltar ainda que 0 risco de eventos cardiovasculares em pacientes com DAP é 30\% maior do que em indivíduos com outras doenças ateroscleróticas, como a doença arterial coronariana e doença arterial cerebral (STEG et al., 2007). Deste modo, estes dados demonstram a alta probabilidade de morte por doença cardiovascular em pacientes com DAP.

Como a maioria das doenças crônicas não transmissíveis, a DAP tem evolução progressiva, de modo que seus sinais e sintomas vão se tornando mais graves quanto maior for o estágio de evolução da doença. Dessa forma, FONTAINE et al. (FONTAINE, KIM e KIENY, 1954) classificaram a DAP em quatro estágios que estão apresentados no Quadro 2.

Quadro 2. Sintomas e sinais característicos dos quatro estágios da Doença Arterial Periférica (DAP).

\begin{tabular}{|l|c|c|c|c|}
\hline \multirow{2}{*}{ Sintoma ou sinal } & \multicolumn{4}{|c|}{ ESTÁGIO } \\
\cline { 2 - 5 } & $\mathrm{I}$ & II & III & IV \\
\hline Parestesia & $+/-$ & ++ & +++ & +++ \\
\hline Dor & Não & AF & R & R \\
\hline$\downarrow$ intensidade da pulsação & $+/-$ & ++ & +++ & ++++ \\
\hline$\downarrow$ da quantidade de pelos & $+/-$ & + & ++ & +++ \\
\hline$\downarrow$ massa muscular & Não & + & ++ & +++ \\
\hline$\downarrow$ temperatura tecidual & Não & $+/-$ & ++ & +++ \\
\hline Lesões tróficas & Não & Não & Não & Sim \\
\hline Lesões vasculares & + & ++ & +++ & ++++ \\
\hline
\end{tabular}

$\downarrow$ - diminuição; AF - Atividade Física; R - Repouso. Fonte: FONTAINE et al. (FONTAINE, KIM e KIENY, 1954)

De forma resumida, o quadro demonstra que no: 
- Estágio I: há ausência de sinais e sintomas, apesar da presença de lesões vasculares.

- Estágio II: há o aparecimento de sintomas, mais especificamente, a presença de dor durante a realização de atividades físicas.

- Estágio III: há a presença de dor em repouso, mas ainda não há o aparecimento de lesões tróficas.

- Estágio IV: há a presença de dor em repouso concomitantemente com o aparecimento de lesões tróficas.

Desta forma, o primeiro e mais prevalente sintoma da DAP é a dor, que ocorre nos membros inferiores durante a caminhada, sendo esta uma característica típica do estágio II da doença. Esta dor é comumente chamada $\mathrm{Cl}$ e pode ocorrer em um ou ambos os membros inferiores, sendo que sua intensidade aumenta proporcionalmente ao aumento da duração e da intensidade do esforço (Normas de Orientação Clínica para Prevenção, Diagnóstico e Tratamento da Doença Arterial Obstrutiva Periférica (DAOP), 2005; HIRSCH et al., 2006; NORGREN et al., 2007).

Quando o indivíduo com $\mathrm{Cl}$ caminha, há necessidade de aumento do fornecimento de oxigênio para os músculos que estão sendo exercitados. Como esses pacientes apresentam obstrução arterial, 0 aporte de sangue e, consequentemente, de oxigênio pode não aumentar de forma proporcional à necessidade, gerando assim um processo isquêmico, que provoca dor e leva o paciente a interromper a caminhada. Com a interrupção do esforço, a dor desaparece em poucos minutos devido à diminuição da necessidade de oxigênio e da isquemia. Contudo, com o reinício da caminhada, inicia-se um novo ciclo de dor, provocado pela nova isquemia, levando novamente à interrupção do esforço (Normas de Orientação Clínica para Prevenção, Diagnóstico e Tratamento da Doença Arterial Obstrutiva Periférica (DAOP), 2005; HIRSCH et al., 2006; NORGREN et al., 2007). Esta alternância entre execução e pausa, dor e alívio, caracteriza a intermitência do sintoma.

A localização do sintoma de Cl está diretamente relacionada ao segmento arterial obstruído (GARDNER, MONTGOMERY e AFAQ, 2007). Nas obstruções aortoilíacas, a dor ocorre nos músculos dos glúteos, da coxa e da parte posterior da perna. Nas obstruções femoropoplíteas, a dor se manifesta nos músculos da parte posterior da perna. Já nas obstruções tíbiofibulares ou das artérias distais do 
membro inferior, a dor acomete os músculos do pé. Contudo, o local do sintoma mais comumente referido pelos pacientes com $\mathrm{Cl}$, é a musculatura da parte posterior da perna, principalmente no músculo gastrocnêmio, sugestivo de obstrução nos segmentos aortoilíacos ou femoropoplíteos (HIRSCH et al., 2006; NORGREN et al., 2007).

3.1.2 Tratamento de Pacientes com Claudicação Intermitente

O tratamento de pacientes com $\mathrm{Cl}$ pode ser realizado por meio de diversas estratégias terapêuticas. Dentre elas, as mais comuns são a revascularização por meio de intervenção cirúrgica e o tratamento clínico, que inclui o tratamento farmacológico e medidas não farmacológicas com a realização do exercício físico.

\subsubsection{Intervenção Cirúrgica}

A intervenção cirúrgica é realizada por meio da reconstrução anatômica da luz arterial que apresenta a obstrução. Essa reconstrução é realizada por meio da colocação de enxertos ou "stents", que aumentam a luz do vaso arterial, promovendo aumento do fluxo sanguíneo para as regiões distais à lesão arterial e, desta forma, melhoram a hemodinâmica do membro (WOLOSKER et al., 2003). Estudos têm observado que a cirurgia de revascularização pode melhorar a capacidade funcional e a qualidade de vida em pacientes com $\mathrm{Cl}$ (MAZARI et al., 2012). Contudo, esta conduta apresenta alto custo operacional e risco elevado, o que faz com sua indicação se restrinja aos pacientes mais graves, em estágios avançados da DAP. 


\subsubsection{Tratamento Farmacológico}

Com relação ao tratamento farmacológico, sua utilização é bem diversificada em pacientes com $\mathrm{Cl}$, pois eles geralmente apresentam outros fatores de risco associados, tais com a hipertensão arterial, o diabetes mellitus e a dislipidemia. Assim, os medicamentos mais utilizados são os para o controle desses fatores de risco, tais como anti-hipertensivos, hipoglicemiantes e, principalmente, as estatinas e antiagregantes plaquetários (DOBESH, STACY e PERSSON, 2009). Nesse sentido, uma meta-análise demonstrou que a utilização destes medicamentos, sobretudo dos antiagregantes plaquetários, pode ser efetiva em prevenir a ocorrência de eventos cardiovasculares agudos, como o infarto agudo do miocárdio e o acidente vascular cerebral (BERGER et al., 2009).

Além do combate aos fatores de risco, existem fármacos específicos para melhorar o fluxo sanguíneo periférico e, consequentemente, aumentar a capacidade de caminhada. Dentre eles, os mais comuns são a pentoxifilina e o cilostazol (DOBESH, STACY e PERSSON, 2009).

A pentoxifilina é considerada um agente hemorreológico, que reduz a viscosidade sanguínea por meio da diminuição da rigidez e aumento da flexibilidade dos eritrócitos. Essa mudança na forma do eritrócito contribui para a melhora da circulação capilar, reduzindo a resistência vascular e, desta forma, melhorando o fluxo sanguíneo (DOBESH, STACY e PERSSON, 2009). Contudo, apesar da pentoxifilina ser um medicamento liberado pela "Food and Drug Administration" desde 1994, a sua indicação no tratamento de pacientes com DAP ainda é controversa, pois os estudos que investigaram sua eficácia e efetividade apresentam muitas limitações, como o número de pacientes envolvidos e diferente dosagens, além de falta de evidências do seu efeito superior na melhoria da capacidade caminhada em comparação ao tratamento placebo (DOBESH, STACY e PERSSON, 2009).

O Cilostazol é um inibidor potente e seletivo da fosfodiesterase III. Além desta função, ele promove aumento da adenosina cíclica monofosfato nos trombócitos e nas células musculares lisas, diminuindo o cálcio intracelular com consequente relaxamento e vasodilatação dos vasos (DOBESH, STACY e PERSSON, 2009). Estudos têm observado que a utilização do cilostazol pode aumentar a capacidade 
de caminhada em 26\% quando comparada à intervenção placebo, além de melhorar a qualidade de vida dos pacientes com DAP (REGENSTEINER et al., 2002). Contudo, o uso do Cilostazol é muito limitado na clínica médica e sua indicação para o tratamento de pacientes com DAP ainda é controversa devido a alguns efeitos colaterais, como cefaleia, diarreia, tontura e palpitações (DOBESH, STACY e PERSSON, 2009). Além disso, alguns estudos (DOBESH, STACY e PERSSON, 2009) não demonstraram superioridade desse medicamento na melhora da capacidade funcional quando comparado ao exercício físico regular.

\subsubsection{Exercício Físico}

Segundo o posicionamento das principais sociedades de cirurgia vascular (Normas de Orientação Clínica para Prevenção, Diagnóstico e Tratamento da Doença Arterial Obstrutiva Periférica (DAOP), 2005; $\mathrm{HIRSCH}$ et al., 2006; NORGREN et al., 2007), o tratamento inicial e preferencial do paciente com Cl é a realização do exercício físico. Um estudo de revisão recente (PARMENTER et al., 2011) sobre o assunto demonstrou que realização de diferentes modalidades de exercício físico pode aumentar de 106 a 151\% a distância inicial de claudicação (DIC

- distância percorrida antes de se iniciar o sintoma de dor) e de 40 a $122 \%$ a distancia total de claudicação (DTC - distância total que se consegue percorrer apesar do sintoma de dor) de pacientes com DAP.

Dentre as várias modalidades de exercício físico, a caminhada é mais utilizada e recomendada no tratamento da DAP (Normas de Orientação Clínica para Prevenção, Diagnóstico e Tratamento da Doença Arterial Obstrutiva Periférica (DAOP), 2005; HIRSCH et al., 2006; NORGREN et al., 2007). A escolha dessa atividade está associada a sua relativa simplicidade de execução, baixo custo e independência de aparelhos específicos ou de profissionais especializados para sua prática. Adicionalmente, em uma metanálise, GARDNER et al. (GARDNER e POEHLMAN, 1995) observaram que a caminhada aumentou significantemente em $180 \%$ a DIC e a $120 \%$ na DTC em pacientes com Cl. Além disso, mais recentemente, um estudo de nosso grupo (GRIZZO CUCATO et al., 2011) demonstrou que o treinamento de caminhada, além de melhorar a capacidade 
funcional, reduziu os níveis de pressão arterial em repouso e durante o exercício submáximo, demonstrando que este tipo de exercício pode aumentar a capacidade funcional e auxiliar no controle de fatores de risco que comumente se associam a DAP.

Os mecanismos envolvidos no aumento na capacidade de caminhada com o treinamento físico em pacientes com $\mathrm{Cl}$ ainda não estão totalmente esclarecidos. A economia de caminhada aumenta após o treinamento (GARDNER et al., 2010; RITTI-DIAS et al., 2010), ou seja, após o treinamento, o consumo de oxigênio necessário para a execução de determinada velocidade de caminhada diminui. Esse efeito sugere que parte do benefício do treinamento na $\mathrm{Cl}$ se deva a melhora na eficiência mecânica. Além disso, é possível que o treinamento promova alterações hemodinâmicas e mudanças no metabolismo muscular do membro que apresenta obstrução (TAN et al., 2000). Dentre estas alterações, as metabólicas parecem ser as mais prováveis, uma vez que o aumento do fluxo sanguíneo e o desenvolvimento de vasos colaterais foram observados, principalmente, em modelos experimentais (NICHOLSON, ANGERSBACH e WILKE, 1992), havendo poucas evidências em humanos (MANNARINO et al., 1991; GARDNER et al., 2005). Desta forma, o treinamento físico promoveria aumento da quantidade de mitocôndrias e das enzimas oxidativas, facilitando o metabolismo aeróbico, o que se refletiria em aumento da diferença arteriovenosa de oxigênio. Estas adaptações diminuiriam a ocorrência de isquemias e a produção de marcadores inflamatórios (TAN et al., 2000), reduzindo a dor e fazendo com ela só fosse deflagrada em intensidades mais elevadas de exercício. Desta forma, o treinamento aumentaria a DIC e DTC.

\subsection{RESPOSTAS CARDIOVASCULAR APÓS O EXERCÍCIO FÍSICO AERÓBICO}

3.2.1 Respostas Após Uma Sessão de Exercício Físico Dinâmico em Indivíduos sem Doença Arterial Periférica

A realização do exercício físico aeróbico promove diversas adaptações fisiológicas que ocorrem durante e após a sua realização. Considerando-se as modificações observadas no período de recuperação do exercício, o que tem 
chamado à atenção é o fenômeno denominado HPE (PESCATELLO et al., 1991; KENNEY e SEALS, 1993; MACDONALD, 2002; PESCATELLO et al., 2004). A HPE caracteriza-se pela redução da pressão arterial durante o período pós-exercício em comparação aos valores pré-exercício ou àqueles medidos em dia controle, sem a realização de exercício prévio.

A HPE já foi relatada em diversos estudos conduzidos com esta finalidade a partir da década de 1980 (WILCOX et al., 1982; BENNETT, WILCOX e MACDONALD, 1984; HAGBERG, MONTAIN e MARTIN, 1987; FLORAS et al., 1989; PESCATELLO et al., 1991; SOMERS et al., 1991; CLEROUX et al., 1992; CLEROUX et al., 1992; HARA e FLORAS, 1992; KENNEY e SEALS, 1993; PIEPOLI et al., 1993; HALLIWILL, DIETZ e JOYNER, 1996; HALLIWILL, TAYLOR e ECKBERG, 1996; RUECKERT et al., 1996; WALLACE et al., 1997; FORJAZ et al., 1998; FORJAZ et al., 1998; FORJAZ et al., 1998; FORJAZ et al., 1999; MACDONALD et al., 1999; WALLACE et al., 1999; FORJAZ et al., 2000; HALLIWILL, MINSON e JOYNER, 2000; MACDONALD, MACDOUGALL e HOGBEN, 2000; HALLIWILL, 2001; BRANDAO RONDON et al., 2002; LEGRAMANTE et al., 2002; MACDONALD, 2002; MACDONALD et al., 2002; FORJAZ et al., 2004; PESCATELLO et al., 2004; PESCATELLO et al., 2004; PRICHER et al., 2004; WILKINS, MINSON e HALLIWILL, 2004; BISQUOLO et al., 2005; CARDOSO, 2005; LOCKWOOD et al., 2005; LOCKWOOD, WILKINS e HALLIWILL, 2005; URAKAWA e YOKOYAMA, 2005; BLANCHARD et al., 2006; MCCORD, BEASLEY e HALLIWILL, 2006; SANTAELLA et al., 2006; FORJAZ, 2007; JONES et al., 2009; CARDOSO et al., 2010; CHEN e BONHAM, 2010; EICHER et al., 2010; ANUNCIAÇÃO e POLITO, 2011; CUCATO et al., 2011; LOBO, 2011; TEIXEIRA et al., 2011; ENDO et al., 2012; LIU et al., 2012). A análise conjunta destes resultados demonstra uma grande variedade de respostas, mas permite a constatação de que a diminuição da pressão arterial após o exercício pode ter magnitude significante e pode ser mantida por várias horas após a intervenção, apresentando reconhecida importância clínica na redução do risco cardiovascular, principalmente em indivíduos hipertensos (PESCATELLO et al., 2004). Assim, apesar da ocorrência da HPE já estar bem estabelecida na literatura, a magnitude e a duração da queda da pressão arterial variam muito entre os estudos. Enquanto alguns autores não observaram reduções significantes pós-exercício tanto em indivíduos normotensos (PESCATELLO et al., 1991) quanto em hipertensos 
(SOMERS et al., 1991), outros verificaram quedas da PAS de até $40 \mathrm{mmHg}$ (WILCOX et al., 1982). De fato, uma meta análise sobre este assunto (MACDONALD, 2002) relatou que após o exercício aeróbico podem ser esperadas reduções das PAS/PAD na ordem de 8/9, 14/9 e 10/7mmHg em indivíduos normotensos, hipertensos limítrofes e hipertensos, respectivamente.

Quanto à duração da HPE, os resultados também são bastante variados. Em indivíduos normotensos e hipertensos, SOMERS et al. (SOMERS et al., 1991) verificaram que a queda da pressão arterial só ocorria na primeira hora após o exercício, enquanto os indivíduos permaneciam no laboratório. Entretanto, estudos posteriores (WALLACE et al., 1999; FORJAZ et al., 2000; MACDONALD, MACDOUGALL e HOGBEN, 2000; QUINN, 2000; BRANDAO RONDON et al., 2002; BLANCHARD et al., 2006) constataram reduções por tempos maiores, tanto em condições laboratoriais quanto ambulatoriais. Em um estudo de nosso laboratório (FORJAZ et al., 2000) verificamos que, em indivíduos normotensos, a média da pressão arterial de 24 horas após uma sessão de exercício aeróbico estava menor que no dia controle sem a execução prévia de exercício. Nesse mesmo sentido, BRANDÃO-RONDON et al. (BRANDAO RONDON et al., 2002) observaram resultados similares em idosos hipertensos. Além disso, em indivíduos hipertensos, a HPE tem sido constantemente observada por até 4 a 16 horas pós-exercício (CARDOSO et al., 2010).

Diversos fatores relacionados ao protocolo de exercício empregado podem explicar a grande variabilidade na magnitude e na duração da HPE no exercício aeróbico. Dentre eles destacam-se: o tipo, a intensidade, a duração, a massa muscular exercitada e o gasto energético total do exercício.

Com relação ao tipo de exercício físico, a HPE tem sido observada após a realização de exercícios aeróbicos contínuos e intermitentes com a utilização de grandes grupos musculares. Na literatura, os principais tipos de exercícios aeróbicos utilizados para estudar a HPE foram a cicloergometria e a caminhada ou corrida na esteira rolante (KENNEY e SEALS, 1993). Além disso, estudos do nosso grupo observaram a HPE também pode ocorrer em após a realização de exercícios resistidos (REZK et al., 2006; QUEIROZ et al., 2009; QUEIROZ et al., 2013) e de relaxamento muscular (SANTAELLA et al., 2006).

Considerando-se o efeito da intensidade do exercício físico realizado, sua influência ainda é controversa. Estudando idosos hipertensos, HAGBERG et al. 
(HAGBERG, MONTAIN e MARTIN, 1987) observaram que a realização do exercício físico de intensidade moderada $\left(70 \%\right.$ do $\left.\mathrm{VO}_{2} \max \right)$ provocava diminuição da pressão arterial maior e mais duradoura que o exercício com intensidade leve $(50 \%$ $\mathrm{VO}_{2} \max$ ). Contrariamente, em indivíduos hipertensos, PESCATELLO et al. (PESCATELLO et al., 2004) demonstraram efeitos similares na diminuição pressão arterial após a realização do exercício físico em 40 e $70 \%$ do $\mathrm{VO}_{2}$ pico. Estudos realizados por nosso grupo também evidenciaram esta controvérsia. Em um estudo inicial (FORJAZ et al., 1998), verificamos que tanto o exercício físico leve (30\% $\mathrm{VO}_{2}$ pico) como o moderado (50\% VO $\mathrm{V}_{2}$ pico) e o intenso $\left(80 \% \mathrm{VO}_{2}\right.$ pico) promoveram diminuições semelhantes na pressão arterial de sujeitos normotensos. Porém, num estudo posterior (FORJAZ et al., 2004), verificamos que a intensidade mais alta (75\% VO $\mathrm{VO}_{2}$ pico) promoveu maior redução de pressão arterial. Adicionalmente, estudo conduzido por EITHER et al. (EICHER et al., 2010) observou que o exercício realizado a $100 \%$ do $\mathrm{VO}_{2}$ pico (após teste máximo em cicloergômetro) promoveu maior redução da PAS e PAD do que o exercício leve $\left(40 \% \mathrm{VO}_{2}\right.$ pico) e moderado $\left(60 \% \mathrm{VO}_{2}\right.$ pico). Contudo, ampliando ainda mais a controvérsia, há estudos com a população hipertensa que o exercício mais leve pode promover maior diminuição da pressão arterial em subgrupos com modificações genéticas (BLANCHARD et al., 2006). Desta forma, embora haja indicadores de que dentro da faixa aeróbica o exercício mais intenso possa apresentar maior efeito hipotensor, em populações específicas, este efeito pode ser oposto, com o exercício de menor intensidade apresentando maior efeito.

Com relação à duração do exercício, seu efeito sobre a resposta da pressão arterial pós-exercício parece estar bem estabelecido. Alguns estudos demonstraram que o exercício mais prolongado promove maior efeito hipotensor (BENNETT, WILCOX e MACDONALD, 1984; FORJAZ et al., 1998). Em indivíduos normotensos FORJAZ et al (FORJAZ et al., 1998) demonstraram que após a realização de uma sessão de exercício físico com 45 minutos de duração havia redução da pressão arterial mais precoce, maior e mais duradoura que após uma sessão de 25 minutos.

O tamanho da massa muscular envolvida no exercício também parece ser um fator importante na HPE. Neste sentido, alguns autores (MACDONALD, MACDOUGALL e HOGBEN, 2000) verificaram que o exercício de membro inferior (maior massa) na cicloergometria provocou HPE mais duradoura que o exercício de membro superior (menor massa) neste ergômetro. Adicionalmente, um estudo de 
nosso grupo (ARAUJO, 2007), comparando o exercício em cicloergômetro pedalando com um ou dois membros inferiores, observou que para a mesma carga relativa, apenas o exercício com maior massa muscular promoveu HPE.

Considerando-se todos os fatores anteriores, massa muscular, duração e intensidade do exercício, é possível observar que o aumento de qualquer um deles sem alterações dos demais implica num maior gasto energético total do exercício, o que pode ser responsável pelo maior efeito hipotensor. De fato, num estudo anterior (ARAUJO, 2007), observamos a necessidade de um gasto energético mínimo durante o exercício para promover a HPE.

Além de todos os fatores supracitados, mais recentemente estudos têm verificado que HPE pode depender da fase do dia em que o exercício é realizado, uma vez foi observado maior efeito hipotensor quando o exercício físico foi realizado no período da tarde quando comparado ao período da manhã (JONES et al., 2009). Porém, num estudo atual (dados não publicados) temos observado maior efeito hipotensor no período da manhã que no final de tarde.

Desta forma, vários aspectos relacionados às características do exercício físico podem afetar a magnitude e duração da HPE, entretanto, ela tem sido consistentemente evidenciada em indivíduos hipertensos em resposta a uma sessão de exercício aeróbico realizada pela manhã ou ao final de tarde, em esteira ou cicloergômetro, com duração entre 20 a 60 min e intensidade variando de 40 a 70\% do $\mathrm{VO}_{2}$ pico (KENNEY e SEALS, 1993; MACDONALD, 2002).

Embora a HPE aeróbico já seja um fenômeno bem definido, seus mecanismos permanecem controversos. Alguns estudos (CLEROUX et al., 1992; PIEPOLI et al., 1993; HALLIWILL, MINSON e JOYNER, 2000; LEGRAMANTE et al., 2002; PRICHER et al., 2004; WILKINS, MINSON e HALLIWILL, 2004; ENDO et al., 2012; BARRETT-O'KEEFE, KAPLON e HALLIWILL, 2013; NEW et al., 2013) atribuem-na à redução da RVS, ocasionada pela manutenção pós-exercício da vasodilatação no território muscular ativo (HALLIWILL, TAYLOR e ECKBERG, 1996; ENDO et al., 2012) e também no território inativo (BISQUOLO et al., 2005). Essa manutenção pode ser explicada pela redução da atividade nervosa simpática periférica, pela redução da resposta vasoconstritora alfa-adrenérgica ou ainda pela liberação de substâncias vasodilatadoras pós-exercício (HOWARD e DICARLO, 1992; HALLIWILL, TAYLOR e ECKBERG, 1996; BARRETT-O'KEEFE, KAPLON e HALLIWILL, 2013; HALLIWILL et al., 2013). Alguns estudos observaram diminuição 
da atividade nervosa simpática periférica, avaliada pela técnica de microneurografia, após a realização uma única sessão de exercício aeróbico em indivíduos normotensos e hipertensos (FLORAS et al., 1989; FORJAZ et al., 1999). HALLIWILL et al. (HALLIWILL, TAYLOR e ECKBERG, 1996) observaram que a resposta vasoconstritora à ativação simpática também estava diminuída após o exercício. Considerando-se as substâncias vasodilatadoras, a liberação de óxido nítrico, de prostaglandina, de histaminas e de opióides tem sido sugerida como relacionada à HPE. JUNGERSTEIN et al. (JUNGERSTEN et al., 1997) verificaram aumento de nitritos/nitratos após o exercício, sugerindo um papel do óxido nítrico na HPE. Porém, outros autores (HALLIWILL, MINSON e JOYNER, 2000) demonstraram que a inibição do óxido nítrico e também das prostaglandina não atenuou a HPE (LOCKWOOD et al., 2005). Por outro lado, BARRETT-O'KEEFE et. (BARRETTO'KEEFE, KAPLON e HALLIWILL, 2013) observaram que o bloqueio dos receptores $\mathrm{H} 1$ e $\mathrm{H} 2$ da histamina atenuou em 65\% a HPE, sugerindo que as histaminas estão envolvidas na manutenção da vasodilatação pós-exercício aeróbico. De forma semelhante, HOFFMANN et al. (HOFFMANN, DELLE e THOREN, 1990) bloquearam a liberação de opióides em ratos e, com isso, impediram a HPE, sugerindo o envolvimento destas substâncias na queda da pressão arterial.

Outros estudos (HAGBERG, MONTAIN e MARTIN, 1987; FLORAS e WESCHE, 1992; BRANDAO RONDON et al., 2002; SENITKO, CHARKOUDIAN e HALLIWILL, 2002; DUJIC et al., 2006; TEIXEIRA et al., 2011), no entanto, atribuíram a HPE à redução do DC associada à diminuição do VS pós-exercício. Esta diminuição, por sua vez, foi atribuída à diminuição da pré-carga, uma vez que RONDON et al. (BRANDAO RONDON et al., 2002) observaram diminuição do volume diastólico final e HALLIWILL et al. (HALLIWILL, MINSON e JOYNER, 2000) relataram redução da pressão venosa central no período pós-exercício. A redução do retorno venoso pós-exercício pode ser explicada pela diminuição do volume plasmático provocada pela perda de líquido na sudorese ou pelo extravasamento do plasma para o interstício, ou ainda essa redução pode se dever ao aumento da complacência venosa, o que foi sugerido por NOSE et al. (NOSE et al., 1988).

Cabe ressaltar que a redução do VS pós-exercício não é compensada apesar do aumento da FC que ocorre no período de recuperação. Este aumento é explicado pela manutenção da atividade nervosa simpática elevada e da atividade vagal reduzida para o coração após o exercício (PIEPOLI et al., 1993; POBER, BRAUN e 
FREEDSON, 2004; TEIXEIRA et al., 2011). No entanto, o fato do aumento da FC não conseguir compensar a diminuição da pressão arterial sugere um efeito do exercício modificando o controle barorreflexo. No entanto, esse aspecto é controverso na literatura, pois alguns estudos verificaram aumento (HALLIWILL et al., 1996) e outros redução (SHI et al., 1993; LIU et al., 2012) da sensibilidade barorreflexa após o exercício físico, mas seu do ponto de ajuste parece estar modificado para níveis mais baixos de pressão arterial após o exercício (CLEROUX et al., 1992; CHANDLER, RODENBAUGH e DICARLO, 1998; CHEN e BONHAM, 2010).

Analisando-se os mecanismos expostos anteriormente, é possível supor que, parar gerar a HPE, o exercício físico aeróbico deve promover alterações nos dois determinantes hemodinâmicos, ou seja, deve promover diminuição da pré-carga e manutenção da vasodilatação periférica. Se a ação ocorresse exclusivamente em um destes mecanismos, o outro se modificaria e compensaria o efeito, impedindo a queda da pressão arterial. Dessa forma, a ação do exercício deve ocorrer simultaneamente nos dois mecanismos, podendo apresentar efeito mais evidente em um deles.

\subsubsection{Respostas Após Uma Sessão de Exercício Físico Dinâmico em Claudicantes}

Em relação a pacientes com $\mathrm{Cl}$, a ocorrência de HPE já foi relatada em dois estudos (CUCATO et al., 2011; RODRIGUES, 2011). No entanto, nesses estudos, empregou-se uma sessão de exercício de força. Em relação ao efeito do exercício aeróbico e, mais especificamente, ao efeito da caminhada, exercício mais recomendado para o paciente com $\mathrm{Cl}$, pelo nosso conhecimento, nenhum estudo investigou a ocorrência da HPE, nem sua duração e nem os mecanismos determinantes da resposta da pressão arterial pós-exercício. Essa questão merece ser investigada, visto que os efeitos cardiovasculares agudos da caminhada podem representar um benefício cardiovascular, que justifique a indicação diária desta prática. Por outro lado, esses efeitos agudos podem revelar um aumento de risco cardiovascular que sugira cuidados com a prática. 
De fato, em função das disfunções observadas nos pacientes com $\mathrm{Cl}$, é possível elaborar hipóteses de que a HPE poderia ser potencializada ou prejudicada nesses pacientes. Devido à presença de dor durante a caminhada, os pacientes com $\mathrm{Cl}$ não conseguem realizar exercícios com prolongada duração. Como exercícios mais longos têm se mostrado mais eficazes em potencializar a HPE (FORJAZ et al., 1998), é possível que a ocorrência dessa hipotensão seja minimizada nesses pacientes. Outro fator é a presença de disfunção endotelial (BREVETTI, SCHIANO e CHIARIELLO, 2008) nestes pacientes que poderia dificultar o efeito vasodilatador do exercício, impedindo a redução da pressão arterial pós-exercício. Além disso, é sabido que após a execução da caminhada em pacientes com $\mathrm{Cl}$ há aumento dos níveis de agentes pró-inflamatórios (SIGNORELLI et al., 2003), o que também pode prejudicar o mecanismo vasodilatador pós-exercício.

Por outro lado, a maioria de pacientes com Cl apresenta hipertensão arterial, o que pode potencializar a ocorrência da HPE, visto que a magnitude de diminuição da pressão arterial no período pós-exercício é maior em indivíduos hipertensos (PESCATELLO et al., 2004). Além disso, JONES et al. (JONES et al., 2009) demonstraram que a execução de um exercício aeróbico realizado de forma intermitente, que pode ser realizado por pacientes com $\mathrm{Cl}$, promove maior HPE que o exercício realizado de forma continua com o mesmo gasto energético. Para completar, há sugestões de que efeito benéfico do exercício seja mais evidente quando as funções do organismo estão alteradas. Neste sentido, como pacientes com $\mathrm{Cl}$ apresentam aumento da modulação simpática em repouso (GOERNIG et al., 2008) e disfunção endotelial (BREVETTI, SCHIANO e CHIARIELLO, 2008), é possível que o exercício promova maior efeito nesses pacientes, corrigindo estas alterações e potencializando a HPE.

Dessa forma, as evidências científicas dão suporte para duas hipóteses conflitantes: 1) o exercício aeróbico promove HPE ou 2) o exercício aeróbico não promove a HPE em pacientes com Cl. Estas hipóteses ainda não foram testadas e os mecanismos envolvidos precisam ser analisados.

Portanto, a presente investigação foi elaborada para verificar os efeitos de uma sessão de exercício aeróbico de caminhada sobre a ocorrência da HPE, investigando suas características (magnitude e duração) e seus mecanismos hemodinâmicos, neurais e vasculares. 


\section{MÉTODOS}

\subsection{AMOSTRA}

A amostra foi composta por homens com DAP que foram recrutados no Ambulatório de Claudicação Intermitente do Hospital das Clínicas da Faculdade de Medicina da Universidade de São Paulo. Para isso, todos os pacientes com DAP de origem aterosclerótica, idade superior a 50 anos e sem membros amputados que frequentaram o ambulatório foram avaliados por um médico, que levantou o histórico da doença, o uso de medicamentos e realizou uma avaliação clínica e ortopédica. Só foram incluídos no estudo, os pacientes com grau II da DAP segundo os critérios de Fontaine (FONTAINE, KIM e KIENY, 1954), sem revascularização ou angioplastia no último ano, que não estavam em uso de $\beta$-bloqueadores, bloqueadores de canal de cálcio não-dihidropiridinico nem vasodilatadores periféricos, que não tivessem problemas ortopédicos que contraindicassem o exercício físico, que não tivessem obesidade e que tivessem níveis de pressão arterial de repouso menores do que 160/105 mmHg para PAS e PAD, respectivamente (CHODZKO-ZAJKO et al., 2009). Os pacientes que preencheram todos esses critérios foram esclarecidos sobre os procedimentos experimentais e foram convidados a assinar o termo de consentimento livre e esclarecido da pesquisa. Aqueles que assinaram foram considerados incluídos no estudo.

Esta tese fez parte de um estudo maior que foi submetido e aprovado pelo Comitê de Ética da Escola de Educação Física e Esporte da Universidade de São Paulo (CEP39-2008/55, anexo 1) e pelo Comitê de Ética do Hospital das Clínicas da Faculdade de Medicina da Universidade de São Paulo (CAPPESp 1179/09 - registro online 4344, anexo 2).

Todos os pacientes incluídos submeteram-se aos procedimentos preliminares e, posteriormente, aos procedimentos experimentais. Nessas etapas do estudo, foram motivos de exclusão: 
- Não conseguir caminhar dois minutos em 3,2 km/h;

- Apresentar arritmias complexas ou isquemia durante o exercício que contraindicassem a realização de exercícios físicos;

- Ter a necessidade de interromper o exercício por motivos outros que não sintoma de $\mathrm{Cl}$;

- Ter potência aeróbica acima da prevista para a idade;

- Não apresentar queda do ITB após o exercício;

- Apresentar neuropatia autonômica diabética;

- Modificar o uso dos medicamentos durante o estudo;

- Não aderir ao protocolo do estudo.

\subsection{EXAMES PRELIMINARES}

\subsubsection{Diagnóstico da Doença Arterial Periférica}

O diagnóstico da DAP foi realizado pelos critérios de FONTAINE (FONTAINE, KIM e KIENY, 1954), pelo valor do ITB em repouso, pela diminuição desse índice após o exercício e pela presença do sintoma de dor, câimbra, ardência ou formigamento nos membros inferiores durante teste em esteira (HIRSCH et al., 2006; NORGREN et al., 2007).

Para a avaliação do ITB de repouso, foram medidas em triplicata a PAS dos braços e dos tornozelos. A aferição da pressão arterial no braço foi feita pelo método auscultatório e no tornozelo por um equipamento de Doppler Vascular Portátil (MEDMEGA, DV-610, São Paulo, Brasil). Para isso, um manguito foi colocado no braço do paciente, dois a três centímetros acima da fossa antecubital, o outro manguito foi posicionado na perna do paciente dois a três centímetros acima do maléolo medial. As medidas foram feitas após o paciente permanecer em repouso 
deitado por pelo menos 10 minutos. Nas medidas, a determinação da PAS foi feita pelo aparecimento do primeiro som audível (fase I de Korotkoff) no método auscultatório e detectável no Doppler. As medidas no braço e tornozelo de cada lado foram realizadas simultaneamente por dois avaliadores experientes. Em posse desses dados, foi calculado o ITB de cada membro inferior por meio da divisão da PAS de cada tornozelo pela maior média da PAS obtida nos braços. Deve-se ressaltar que a medida da PAS por meio do método auscultatório produz resultados similares à medida obtida com o Doppler (GARDNER e MONTGOMERY, 1998).

Foram caracterizados como portadores da DAP, os pacientes que apresentaram sintomas de $\mathrm{Cl}$, ITB $<0,90$ em repouso em um ou em ambos os membros. Além disso, a medida deste índice foi repetida antes e um minuto após o teste de esforço e os pacientes deveriam apresentar queda desse índice após o esforço.

\subsubsection{Avaliação da Pressão Arterial}

Para determinar os níveis de pressão arterial em repouso, a pressão arterial foi medida com os pacientes sentados em repouso por pelo menos cinco minutos. A medida foi feita em ambos os membros superiores utilizando-se o método auscultatório com um esfigmomanômetro de coluna de mercúrio, e empregando-se as fases I e V dos sons de Korotkoff para a identificação dos valores de PAS e PAD, respectivamente. Foram realizadas medidas em cada braço, até que se obtivesse três valores consecutivos com diferença inferior a $5 \mathrm{mmHg}$. Este procedimento foi realizado em duas visitas realizadas em dias distintos. Para a definição do valor da pressão arterial, foram considerados os valores obtidos no braço com maior pressão arterial e foi calculada a média das seis medidas válidas (VI Diretrizes Brasileiras de Hipertensão, 2010). Esta avaliação foi realizada com os pacientes utilizando normalmente sua medicação. Os pacientes deveriam ter níveis de PAS/PAD até $160 / 105 \mathrm{mmHg}$. 


\subsubsection{Avaliação Ergoespirométrica}

Os pacientes foram submetidos a um teste ergoespirométrico máximo. O teste foi realizado em esteira rolante (IMBRASPORT, ATL, Rio Grande do Sul, Brasil) utilizando-se um protocolo escalonado específico para pacientes com DAP (GARDNER et al., 1991). O teste manteve velocidade constante de $3,2 \mathrm{~km} / \mathrm{h}$ (2mph) e teve incrementos de $2 \%$ de inclinação a cada dois minutos até que o sintoma de $\mathrm{Cl}$ impedisse a continuação do exercício. Durante o teste, a FC foi continuamente monitorizada por um eletrocardiógrafo (Medical Graphics Corporation, Cardio Perfect, Minnesota, Estados Unidos) e foi registrada ao final de cada dois minutos. A pressão arterial também foi medida a cada 2 minutos pelo método auscultatório. $O$ consumo de oxigênio $\left(\mathrm{VO}_{2}\right)$ foi continuamente medido a cada ciclo respiratório por um analisador de gases computadorizado (Medical Graphics Corporation, CPX/D, Minnesota, Estados Unidos). $\mathrm{O} \mathrm{VO}_{2}$ pico foi estabelecido pelo valor mais alto obtido durante o esforço em médias de 30 segundos. Durante o teste, o indivíduo foi instruído a relatar o momento do início do sintoma de dor no membro inferior, o que caracteriza o limiar de dor do paciente. Neste momento, foram anotadas a FC do limiar de dor e a DIC. O teste foi interrompido quando o indivíduo não suportou mais o sintoma de $\mathrm{Cl}$ e, neste momento, foi anotada a DTC. Adicionalmente, o ITB foi medido em repouso deitado antes do exercício e após o primeiro minuto pósexercício. A medida deste índice foi feita simultaneamente o braço de maior valor e o tornozelo de menor valor de PAS. Neste teste, os pacientes deveriam: 1) conseguir caminhar pelo menos dois minutos na velocidade do teste $(3,2 \mathrm{~km} / \mathrm{h}), 2)$ interromper o exercício exclusivamente devido à $\mathrm{Cl}, 3$ ) apresentar potência aeróbica abaixo da prevista para a idade, 4) apresentar queda do ITB após o esforço. Em adição eles não deveriam apresentar arritmias complexas ou isquemia durante o exercício que contraindicassem a realização de exercícios físicos. 


\subsubsection{Diagnóstico de Obesidade}

O peso e a estatura foram medidos numa balança (Welmy, 110, São Paulo, Brasil) e o índice de massa corporal (IMC) foi calculado pelo quociente entre o peso e o quadrado da estatura $\left(\mathrm{m}^{2}\right)$. Os pacientes não deveriam apresentar IMC igual ou maior que $30 \mathrm{~kg} / \mathrm{m}^{2}$.

\subsubsection{Diagnóstico de Neuropatia Autonômica Cardiovascular}

A presença da neuropatia foi avaliada pela bateria de testes recomendada pela Diretriz da American Diabetes Association (BOULTON et al., 2005). Foi realizada a avaliação em repouso da FC (>100 bpm) e do intervalo QTc ( $<440 \mathrm{~ms})$. Avaliou-se também a variação da FC frente às manobras de: a) arritmia sinusal $(<10$ bpm); b) teste de levantar (Razão 30\%15 batimento > 1,03); e c) manobra de Valsalva (razão entre a maior - menor intervalo $R R>1,2$ ). Para completar, avaliouse a alteração da pressão arterial frente à manobra de levantar (diminuição da PAS $<10 \mathrm{mmHg}$ ). Nesta bateria, a presença de alteração em um dos testes indica a presença da neuropatia e os pacientes do estudo não deveriam ter nenhuma alteração.

\subsection{MEDIDAS}

\subsubsection{Pressão Arterial Auscultatória}

Nas sessões experimentais, a medida auscultatória da pressão arterial foi realizada no braço dominante do paciente, utilizando-se um estetoscópio e uma coluna de mercúrio e empregando-se as fases I e $\mathrm{V}$ dos sons de Korotkoff para a identificação da PAS e PAD, respectivamente. Esta medida foi sempre realizada 
pelo mesmo avaliador experiente no mesmo paciente. A PAM foi calculada pela fórmula: $P A M=(P A S-P A D) / 3+P A D$.

\subsubsection{Pressão Arterial Fotopletismográfica}

Nas sessões experimentais, a medida da pressão arterial foi também realizada pela técnica fotopletismográfica. Para isso, um manguito de tamanho adequado foi colocado no dedo médio da mão não dominante do paciente e foi acoplado a um monitor automático que obtém medidas da pressão arterial batimento a batimento (FINAPRESS MEDICAL SYSTEM, Finometer Pro, Amsterdam, Holanda). A onda de pressão arterial foi digitalizada e gravada em microcomputador, através do programa Windaq (AKRON, Windaq DI-720, Ohio, Estados Unidos), com frequência de amostragem de $500 \mathrm{~Hz}$ para posterior realização da análise espectral.

\subsubsection{Monitorização Ambulatorial da Pressão Arterial}

Após as sessões experimentais, a medida da pressão arterial ambulatorial foi realizada no braço não dominante do paciente por um monitor automático oscilométrico (SPACELABS, Inc. Redmond, Washington, Estados Unidos), que foi programado para realizar medidas a cada 15 minutos por 24 horas. A calibração do equipamento foi regularmente checada em comparação com a coluna de mercúrio. Foram aceitos para análise apenas os registros com pelo menos $80 \%$ das medidas válidas. Essa análise seguiu a recomendação das V Diretriz Brasileira para Uso da Monitorização Ambulatorial da Pressão Arterial (V Diretrizes Brasileiras de Monitoração Ambulatorial Da Pressão Arterial (MAPA V) e III Diretrizes de Monitoração Residencial da Pressão Arterial (MRPA III), 2011). 


\subsubsection{Frequência Cardíaca}

Durante as sessões experimentais, a FC foi continuamente monitorada por um eletrocardiógrafo (EMG SYSTEM DO BRASIL, EMG-230, São Paulo, Brasil). O traçado eletrocardiográfico foi digitalizado e gravado em microcomputador por meio do programa Windaq (AKRON, Windaq DI-720, Ohio, Estados Unidos) com frequência de amostragem de $500 \mathrm{~Hz}$ para posterior realização da análise espectral.

\subsubsection{Respiração}

Os movimentos respiratórios foram monitorados por uma cinta respiratória piezoelétrica (UFI, Pneumotrace, Califórnia, Estados Unidos) posicionada no tórax do paciente. $O$ sinal obtido com esta cinta foi amplificado, digitalizado e gravado em microcomputador por meio do programa Windaq (AKRON, Windaq DI-720, Ohio, Estados Unidos) com uma frequência de amostragem de $500 \mathrm{~Hz}$ para posterior realização da análise espectral.

\subsubsection{Débito Cardíaco}

O DC foi medido pelo método indireto de Fick, por meio do processo de reinalação de $\mathrm{CO}_{2}$ (JONES et al., 1967), que se baseia na seguinte fórmula: $\mathrm{DC}=$ $\mathrm{VCO}_{2} /\left(\mathrm{CvCO}_{2}-\mathrm{CaCO}_{2}\right)$ onde: $\mathrm{VCO}_{2}$ - produção de $\mathrm{CO}_{2} ; \mathrm{CvCO}_{2}$ - conteúdo venoso de $\mathrm{CO}_{2} ; \mathrm{CaCO}_{2}$ - conteúdo arterial de $\mathrm{CO}_{2}$.

Para tanto, foi utilizado um analisador de gases computadorizado (Medical Graphis Corporation, CPX/D, Minnesota, Estados Unidos), que mediu a produção de $\mathrm{CO}_{2}\left(\mathrm{VCO}_{2}\right)$ e estimou o conteúdo arterial de $\mathrm{CO}_{2}\left(\mathrm{CaCO}_{2}\right)$ por meio da medida da pressão expirada final de $\mathrm{CO}_{2}\left(\mathrm{PetCO}_{2}\right)$. Para o cálculo do $\mathrm{CvCO}_{2}$, o paciente realizou uma manobra de inalação e reinalação do ar obtido em uma bolsa com concentrações de $\mathrm{CO}_{2}$ entre 8 a $10 \%$ e de $\mathrm{O}_{2}$ de $35 \%$. Esta manobra foi realizada 
por, no máximo, vinte segundos e até se que obtivesse um equilíbrio entre o ar inspirado e o expirado, o que permitiu estimar o conteúdo venoso de $\mathrm{CO}_{2}\left(\mathrm{CvCO}_{2}\right)$. A partir destes dados, calculou-se o DC conforme a fórmula exposta acima.

\subsubsection{Resistência Vascular Sistêmica}

A RVS foi calculada pelo quociente entre os valores de pressão arterial média (PAM) medida pelo método auscultatório e do DC obtido pelo método de reinalação de $\mathrm{CO}_{2}$.

\subsubsection{Volume Sistólico}

O VS foi calculado pelo quociente entre o DC (I/min) e a FC (bpm).

\subsubsection{Modulação Autonômica do Sistema Cardiovascular}

A modulação autonômica do sistema cardiovascular foi avaliada pela modelo linear, através da análise espectral da variabilidade da FC e da pressão arterial, utilizando-se o método autorregressivo. Além disso, foi também avaliada pelo modelo não-linear, empregando-se a análise simbólica e a Entropia de Shannon.

A análise espectral da variabilidade da FC e da pressão arterial pelo modelo autorregressivo é uma técnica muito utilizada pela literatura (Heart rate variability: standards of measurement, physiological interpretation and clinical use. Task Force of the European Society of Cardiology and the North American Society of Pacing and Electrophysiology, 1996; HALLIWILL et al., 1996; LIU et al., 2012) e pelo nosso grupo (REZK et al., 2006; LOBO, 2011; TEIXEIRA et al., 2011), na qual é possível distinguir a participação de cada alça autonômica (simpática e parassimpática) sobre a modulação cardíaca e vascular (Heart rate variability: standards of measurement, physiological interpretation and clinical use. Task Force of the European Society of 
Cardiology and the North American Society of Pacing and Electrophysiology, 1996). Adicionalmente, a análise pelo modelo não-linear foi incluída no presente estudo, pois se trata de uma ferramenta nova que necessita de menores pré-requisitos para a execução (PORTA et al., 2001). Dessa forma, sua inclusão possibilitou a comparação com a análise tradicional, permitindo testá-la na situação de pré e pósexercício em pacientes com $\mathrm{Cl}$, o que ainda não foi feito. Por fim, a Entropia de Shannon é uma análise que difere dos índices lineares e simbólicos, pois permite avaliar não a magnitude de modulação autonômica, mas o grau de complexidade dessa modulação. Desta forma, a avaliação da modulação autonômica da variabilidade da FC e da pressão arterial por diferentes métodos permitiu-nos trazer informações complementares sobre o controle cardiovascular pós-exercício em pacientes com $\mathrm{Cl}$, permitindo um entendimento mais amplo do fenômeno e a avaliação da utilidade das ferramentas mais recentes nessa condição experimental.

\subsubsection{Coleta de Dados Para Avaliação Autonômica}

Para a análise espectral da variabilidade da FC e da pressão arterial, foram utilizados os sinais eletrocardiográficos, respiratórios e de pressão arterial que foram coletados a cada batimento cardíaco e digitalizados pelo sistema Windaq (AKRON, Windaq DI-720, Ohio, Estados Unidos), com frequência de amostragem de $500 \mathrm{~Hz} /$ canal.

Estes sinais foram, inicialmente, analisados pelo programa PRÉ (Calcolo Segnali di Variabilitá Cardiovasculari - 20/06/95, Dipartimento di Bioengenharia Del Politécnico di Milano, Milão, Itália), que calculou os intervalos $\mathrm{RR}$, os valores da respiração e da PAS e PAD a cada batimento cardíaco, construindo as séries temporais de cada um destes sinais, que foram utilizadas nas análises subsequentes. 


\subsubsection{Avaliação Pelo Modelo Linear}

A análise linear foi realizada em períodos estacionários de, no mínimo, dois minutos. As séries temporais foram decompostas em seus componentes de alta e de baixa frequência pelo método autorregressivo, empregando-se o recurso de Levinson-Durbin e utilizando-se o critério de Akaike para a escolha da ordem do modelo. Esta análise foi realizada utilizando-se o programa LA (Programma di Analisi Lineare - 14/12/1999, Dipartimento di Scienze Precliniche, Universitá Degli Studi di Milano, Itália) e seguiu as recomendações do TASK FORCE de análise espectral (Heart rate variability: standards of measurement, physiological interpretation and clinical use. Task Force of the European Society of Cardiology and the North American Society of Pacing and Electrophysiology, 1996).

Foram consideradas como fisiologicamente significantes, o sinal obtido entre as frequências entre 0,04 e $0,4 \mathrm{~Hz}$, sendo que foram considerados como componente de:

Muita baixa frequência - oscilações menores que 0,04 Hz.

Baixa frequência - oscilações entre 0,04 e $0,15 \mathrm{~Hz}$

Alta frequência - oscilações entre 0,15 e 0,4 Hz.

Para a análise da banda de baixa frequência, somente os picos que estivessem na faixa adequada e não apresentassem coerência com o sinal da respiração foram considerados. Na banda de alta frequência, foram considerados os picos que estivessem na faixa adequada e apresentassem coerência $>0,5$ com a respiração. Para a análise da variabilidade da pressão arterial foram selecionados apenas os picos na faixa de baixa frequência que não apresentassem coerência com a respiração.

O poder de cada componente espectral foi calculado em termos absoluto e normalizado. A normalização foi realizada dividindo-se o poder de cada banda do espectro pela variância total, da qual foi subtraído o valor da banda de muita baixa frequência, sendo o resultado multiplicado por 100 .

Para a interpretação dos resultados, os componentes de baixa e alta frequência normalizados da variabilidade da FC foram considerados, 
respectivamente, como a modulação predominantemente simpática e parassimpática do coração e a razão entre essas bandas, como o balanço simpatovagal cardíaco (Heart rate variability: standards of measurement, physiological interpretation and clinical use. Task Force of the European Society of Cardiology and the North American Society of Pacing and Electrophysiology, 1996). O componente de baixa frequência da variabilidade da pressão arterial, avaliado em termos absolutos, foi considerado com correspondente à modulação simpática vasomotora.

\subsubsection{Análise pelo Modelo Não-Linear}

O método de avaliação da variabilidade da FC pela modelo não-linear foi realizado pela análise simbólica e pela entropia de Shannon (PORTA et al., 2001). Para a realização da análise simbólica foi utilizado o programa SA (Simbolic Analisi, Dipartimento di Scienze Precliniche, Universitá Degli Studi di Milano, Milão, Itália), que realizou uma transformação da série temporal dos intervalos $R R$ em uma sequência de números inteiros (símbolos). Para isso, foram avaliadas séries temporais de 300 batimentos cardíacos.

Em cada série, a variação máxima dos intervalos $R R$ foi dividida equitativamente de modo a se formassem seis níveis de variação dos intervalos $R R$, aos quais foram atribuídos símbolos de 0 a 5 . Posteriormente, cada intervalo RR foi classificado em um dos níveis e recebeu o símbolo correspondente a este. Por exemplo, se a série temporal variou de 800 a $1100 \mathrm{~ms}$, essa amplitude foi dividida em 6 níveis (símbolos). Assim, um intervalo de 800 a 850 ms foi considerado como nível (símbolo) 0, de 850 a 900 ms como símbolo 1, de 900 a 950 ms como símbolo 2, 950 a 1000 ms como símbolo 3, 1000 a 1050 ms como símbolo 4 e 1050 a 1100 ms como símbolo 5 .

Após a classificação, cada batimento foi agrupado com os dois subsequentes, formando tríades de poderes simbólicos. No exemplo anterior, se o início da série temporal foi $807,848,870,930,940,920$, a tríades formadas foram: 
001

012

122

222

As tríades, então, foram classificadas em famílias segundo sua variação, ou seja: a) Família 0V: padrão sem variação na tríade, ou seja, todos os símbolos são iguais $(3,3,3$ ou $1,1,1)$; b) Família 1V: padrões com uma variação, ou seja, dois símbolos consecutivos iguais e um é diferente (3,3,4 ou 4,2,2); c) Família 2V: padrões com duas variações similares, ou seja, símbolos formando uma rampa ascendente ou descendente $(1,2,4$ ou $4,3,1)$ ou padrões com duas variações diferentes $(2,4,3$ ou $4,1,3)$.

No exemplo anterior, seriam obtidas as seguintes famílias:

$$
\begin{aligned}
& 001-1 V \\
& 012-2 V \\
& 122-1 V \\
& 222-0 V
\end{aligned}
$$

O padrão de variação OV representa a modulação simpática cardíaca, enquanto que o padrão 2V representa a modulação parassimpática. A contribuição relativa da modulação simpática e parassimpática sobre a função cardíaca foi avaliada, respectivamente, pela participação percentual das famílias $0 \mathrm{~V}$ e $2 \mathrm{~V}$ na série temporal. Essa contribuição foi calculada dividindo-se o número de famílias $0 \mathrm{~V}$ e $2 \mathrm{~V}$ pelo número total de famílias na série temporal e multiplicando-se o resultado por 100.

A Entropia de Shannon foi calculada na mesma sequência de 300 batimentos utilizada para a análise simbólica. O programa SA também calculou essa entropia por meio da seguinte fórmula:

$$
\mathrm{SE}(L, \xi)=-\sum p\left(x_{L}^{\xi}\right) \cdot \log p\left(x_{L}^{\xi}\right)
$$

Sendo: $\mathrm{SE}=$ Entropia de Shannon, $\mathrm{p}=$ probabilidade da frequência da amostra, $x=$ amostra de séries; $\xi=$ número de níveis pelos quais a amostra foi distribuída (fixo em 6); $L$ = sequência da amostra (fixo em 3 ). 
Como dito anteriormente, a Entropia de Shannon fornece uma estimativa da complexidade da distribuição de padrões dentro da série temporal, descrevendo a forma de distribuição destes padrões. Assim, avalia-se a presença de picos na distribuição que representam padrões frequentes ou a presença de vales que representa padrões menos frequentes. A Entropia de Shannon é considerada alta quando a distribuição dos padrões for plana, ou seja, todos os padrões são identicamente distribuídos. Assim, quando a série apresenta grande entropia, ou seja grande complexidade, significa que ela transporta o máximo de informações. Pelo contrário, a entropia será considerada baixa, se um determinado conjunto de padrões for mais comum na série, enquanto que outros forem ausentes ou pouco frequentes. Essa distribuição demonstra pouca complexidade na série e, portanto, pouca informação.

\subsubsection{Avaliação do Controle Barorreflexo Espontâneo}

Com o intuito de se obter informações sobre a relação entre as alterações da pressão arterial e da FC, a sensibilidade barorreflexa foi avaliada pelo método sequencial (LA ROVERE, PINNA e RACZAK, 2008).

O método sequencial foi aplicado utilizando-se o programa BRS (Barorreflex Sequence Analysis - versão 1.1, Dipartimento di Scienze Precliniche, Universitá Degli Studi di Milano, Milão, Itália), que selecionou sequências de três ou mais batimentos consecutivos com mudanças no mesmo sentido de PAS (de pelo menos $1 \mathrm{mmHg}$ ) e do intervalo cardíaco (de pelo menos $4 \mathrm{~ms}$ ). Em cada uma dessas sequências foi calculada a regressão linear e só foram aceitas como relacionadas ao controle barorreflexo, as sequências com coeficiente de correlação igual ou maior que 0,8. Para cada sequência válida, foi calculada a inclinação da reta de regressão linear, e foi considerado como representando a sensibilidade do barorreflexo, o valor médio de todas as inclinações. 


\subsubsection{Fluxo Sanguíneo}

O Fluxo sanguíneo da musculatura inativa (antebraço) e ativa (perna) foi medido pela técnica de pletismografia de oclusão venosa (WILKINSON e WEBB, 2001). Para tanto, o fluxo foi medido no antebraço do braço não dominante e na perna com o menor valor de ITB. As medidas de fluxo arterial muscular do antebraço e da perna foram realizadas enquanto os fluxos arteriais para a mão (caso do antebraço) e o pé (caso da perna) foram ocluídos por manguitos colocados em torno do punho e do tornozelo, respectivamente, e inflados com uma pressão de $200 \mathrm{mmHg}$.

Para as medidas, manguitos foram colocados no braço $(2 \mathrm{~cm}$ acima da dobra do cotovelo) e na coxa ( $2 \mathrm{~cm}$ acima da dobra do joelho). Eles foram inflados (Hokanson, AG101 Air Source, Washington, Estados Unidos) por 10 segundos em níveis subdiastólicos, mas um pouco acima da pressão venosa (40 a 60mmHg) para ocluir o retorno venoso, seguidos de 10 segundos de deflação, completando ciclos de 20 segundos cada. Ao serem inflados, estes manguitos impediram a saída do fluxo venoso do membro sem impedir o influxo arterial, o que provocou aumentos do volume do antebraço e da perna proporcionais ao fluxo arterial destas regiões. Estes aumentos foram percebidos por sensores "mercury-in-silastic strain gauges" (Hokanson, Al-6, Washington, Estados Unidos) posicionados na maior circunferência do antebraço e da perna. Os sinais obtidos foram registrados em microcomputador por meio de um software (Hokanson, NIVP3, Washington, Estados Unidos). Os fluxos do antebraço e da perna foram avaliados, respectivamente, pelo aumento do volume do antebraço e da perna durante a oclusão venosa e foram expressos em $\mathrm{mL} .100 \mathrm{~mL}^{-1}$ de tecido. $\mathrm{min}^{-1}$. A medida foi realizada por quatro minutos (12 ciclos), sendo excluídos da análise os dois primeiros e o último ciclo. A média dos noves ciclos restantes foi usada para determinar o fluxo sanguíneo basal. A partir da obtenção do fluxo basal, foi possível calcular a resistência vascular do membro inativo (antebraço) e ativo (perna) por meio do quociente entre o fluxo sanguíneo basal de cada região e a PAM, o que foi expresso em unidades (U). 


\subsubsection{Capacidade Vasodilatadora}

Para avaliar a capacidade vasodilatadora, mediu-se a vasodilatação fluxo mediada, utilizando a técnica de hiperemia reativa (HIGASHI e YOSHIZUMI, 2003). Para esta avaliação, após a medida do fluxo basal, os manguitos posicionados no braço e acima do joelho foram insuflados rapidamente até $200 \mathrm{mmHg}$ e esta oclusão foi mantida por cinco minutos. Durante o último minuto de oclusão arterial, o paciente realizou movimentos com as mãos e com os pés para potencializar o efeito da isquemia. Em seguida, os manguitos do antebraço e o da perna foram desinflados e foi registrado o fluxo sanguíneo por quatro minutos, como descrito no registro de fluxo basal.

A capacidade vasodilatadora foi avaliada de duas formas. Primeiro, o valor do fluxo da primeira onda registrada após a desinflação do manguito arterial foi considerado como fluxo sanguíneo máximo em resposta a hiperemia reativa. Segundo, utilizou-se todas as ondas medidas durante os 4 minutos pós-hiperemia reativa (12 ciclos) para calcular área sob a curva dos fluxos. Para isto utilizou-se o programa Origin (Origin Lab 6.0, Massachusetts, Estados Unidos). Um estudo recente observou que a primeira onda após a hiperemia reativa representa principalmente a vasodilatação endotélio-independente (OLAMAEI et al., 2010). Em contrapartida, a medida da área sob a curva representa, entre outros fatores, a vasodilatação endotélio-dependente (OLAMAEI et al., 2010).

\subsection{PROCEDIMENTOS}

\subsubsection{Sessão de exercício}

A sessão de exercício foi constituída, exclusivamente, por caminhada em esteira ergométrica e durou aproximadamente 60 minutos. A caminhada foi realizada de forma intervalada, com séries de dois minutos de esforço, seguidos de dois minutos de recuperação passiva (repouso em pé na esteira). No total, foram 
realizadas 15 execuções de caminhada, totalizando 30 minutos de ação efetiva. $A$ intensidade do exercício foi monitorada pela FC que foi mantida na FC do limiar de dor que foi atingido no teste ergoespirométrico máximo. Num estudo anterior (RITTIDIAS et al., 2009), verificamos que esta intensidade está acima do limiar anaeróbico desses pacientes e, corresponde a aproximadamente $84 \%$ do $\mathrm{VO}_{2}$ pico. Assim, durante o exercício, a velocidade da esteira foi mantida em 3,2 km/h e a inclinação foi ajustada para que a FC do limiar de dor fosse mantida durante todo o esforço. Foi aceita uma variação de quatro batimentos para cima ou para baixo da FC estipulada.

\subsection{PROTOCOLO EXPERIMENTAL}

A sequência do protocolo experimental está apresentada na figura 2.

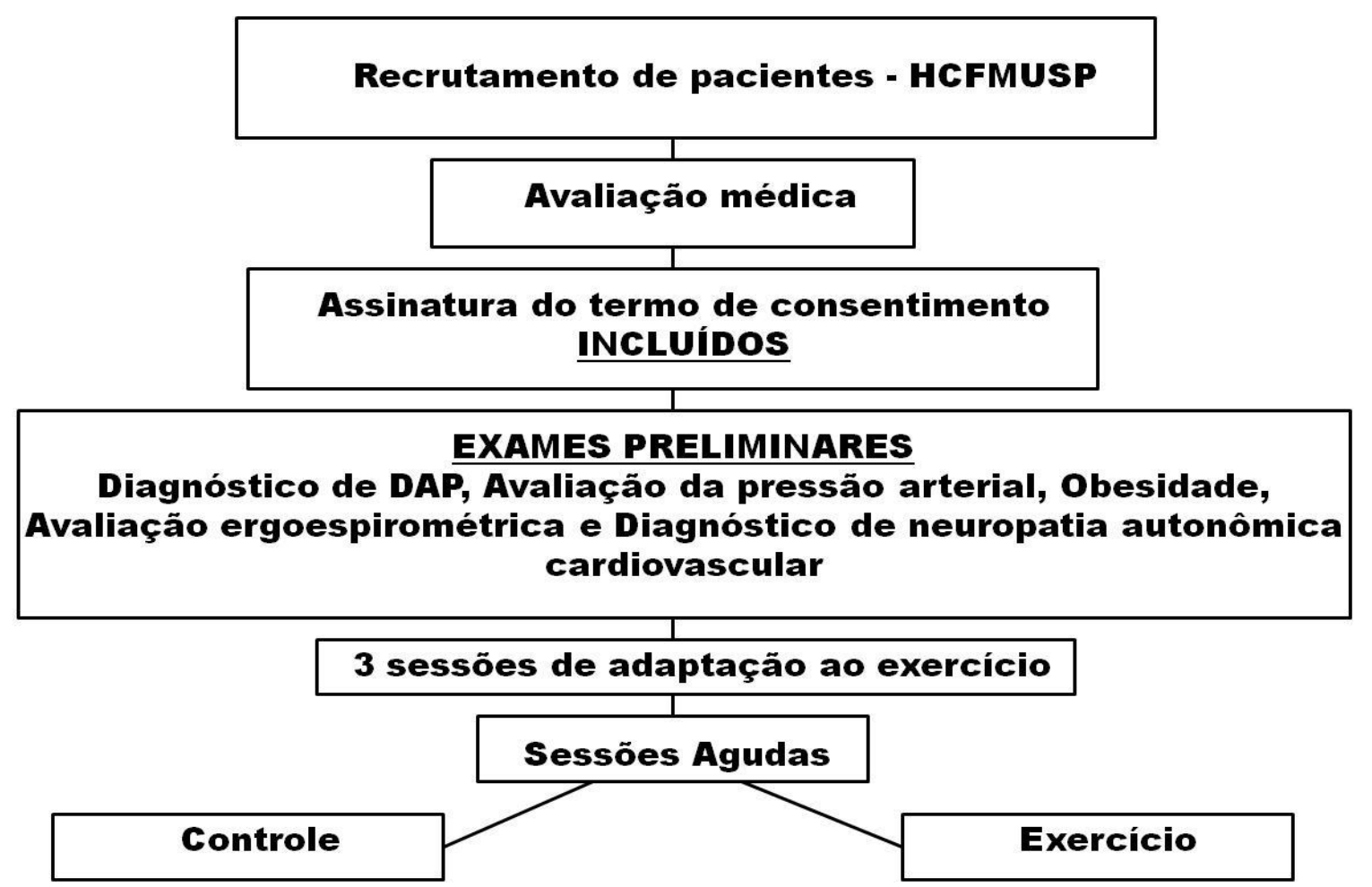

Figura 2. Sequência do protocolo experimental.

Como apresentado na figura 2, todos os pacientes do Ambulatório Vascular do Hospital das Clínicas da Faculdade de Medicina da Universidade de São Paulo 
que apresentassem possibilidade e vontade de participar do estudo passaram a por uma avaliação médica. A partir desta avaliação, aqueles que se encaixaram nos critérios de inclusão assinaram o termo de consentimento e foram considerados incluídos no estudo. Então, eles realizaram os exames preliminares descritos anteriormente e, a partir dos resultados destas avaliações, foram excluídos aqueles que não apresentavam as características estabelecidas para o estudo.

Posteriormente, os pacientes que permaneceram no estudo realizaram três sessões de adaptação ao exercício de caminhada, que foram executadas com o mesmo protocolo das sessões experimentais descrito no tópico 4.5.1. Estas sessões foram realizadas com intervalo mínimo de 48 horas com o intuito de acostumar os pacientes aos procedimentos experimentais, à equipe do estudo e à realização do exercício. Após essas sessões, todos os pacientes submeteram-se, em ordem aleatória, às duas sessões experimentais do estudo: controle e exercício.

Durante todo o período do estudo, os pacientes foram questionados sobre o uso da medicação, sendo que qualquer mudança neste uso foi motivo de exclusão do paciente.

\subsubsection{Sessão experimental}

As sessões experimentais, controle e exercício, seguiram o desenho experimental exposto na figura 3. 


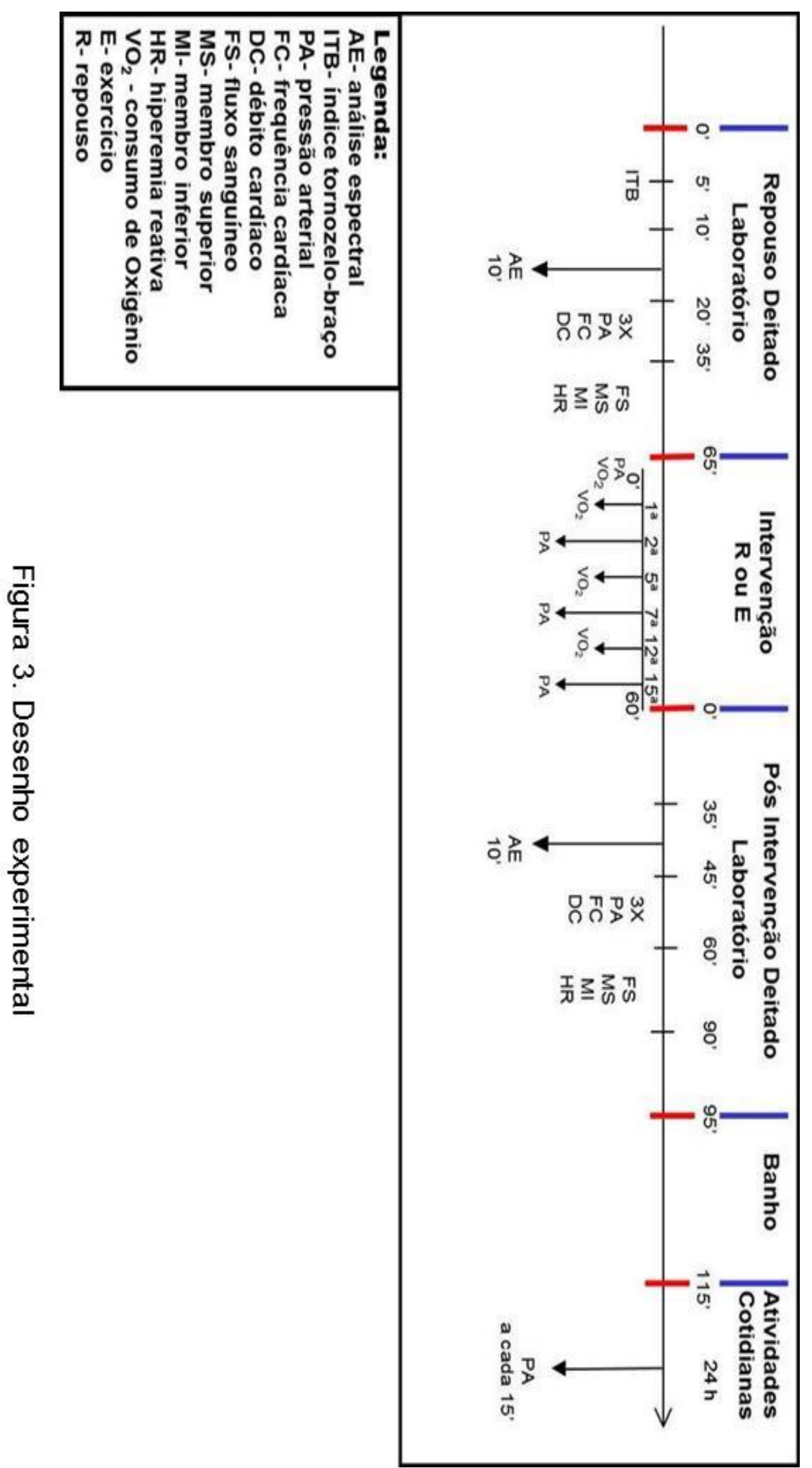


As sessões foram realizadas no mesmo horário do dia, em ordem aleatória, com pelo menos 48 horas de intervalo entre elas. Os pacientes deveriam realizar uma refeição leve pelo menos duas horas antes do início da sessão experimental e não deveriam ingerir estimulantes como café, chá, coca-cola e outros. Além disso, deveriam se abster de qualquer tipo de atividade física por 48 horas e da ingestão de bebidas alcoólicas nas 24 horas anteriores à sessão experimental. Os fumantes não deveriam fumar antes da sessão experimental e a medicação deveria ser tomada de forma cotidiana.

Nas duas sessões, ao chegar ao laboratório, dois manguitos de medida de pressão arterial foram instalados, um no braço dominante (auscultatório) e outro no dedo médio da mão do braço não dominante (fotopletismográfico). Os pacientes permaneceram, inicialmente, deitados por 65 minutos (período pré-intervenção). Nos primeiros 5 a 10 minutos desse período, as PAS do braço e da perna foram medidas para o cálculo do ITB de repouso. Após 10 minutos de repouso foram coletadas as ondas de pressão arterial, do eletrocardiograma e da respiração para a análise espectral. Nos 15 minutos seguintes foram medidos, em triplicata, a pressão arterial auscultatória, o DC e a FC. Nos últimos 30 minutos do período pré-intervenção, foram medidos o fluxo sanguíneo basal para o membro superior e inferior e o fluxo sanguíneo em resposta à manobra de hiperemia reativa.

Posteriormente, iniciou-se o período de intervenção. Neste, os pacientes realizaram o protocolo de caminhada descrito anteriormente na sessão de exercício ou permaneceram em repouso em pé na esteira por 60 minutos na sessão controle. Neste período de intervenção, a FC foi monitorada por meio de um monitor cardíaco (POLAR, A3, Helsinki, Finlândia) para a verificação da intensidade do exercício. O momento do início da dor de claudicação foi anotado em cada série de esforço. A pressão arterial foi medida na $2^{\underline{a}}, 7^{\underline{a}}$ e $15^{\underline{a}}$ séries do exercício, pelo método auscultatório. Além disso, $\mathrm{o} \mathrm{VO}_{2}$ foi medido por meio de um analisador de gases computadorizado (Medical Graphics Corporation, CPX/D, Minnesotta, Estados Unidos) na $1^{\underline{a}}, 5^{\underline{a}}$ e $12^{a}$ séries de exercício.

Após as intervenções, os pacientes retornaram à posição de repouso deitado por mais 90 minutos. Este período foi denominado de período pós-intervenção. Nele, os sinais eletrocardiográficos, respiratórios e da pressão arterial foram coletados para a análise espectral dos 35 aos 45 minutos pós-intervenção. Os valores da pressão arterial auscultatória, do DC e da FC foram medidos, em triplicata, dos 45 
aos 60 minutos. Nos últimos 30 minutos pós-intervenção, o fluxo sanguíneo basal do membro inferior e superior e o fluxo sanguíneo em resposta à manobra de hiperemia reativa foram avaliados.

Os pacientes, então, tiveram 20 minutos para tomar banho e retornar ao laboratório. O monitor ambulatorial de medida de pressão arterial foi colocado no braço não dominante. O primeiro valor medido por esse monitor, ainda no laboratório, foi comparado ao valor obtido simultaneamente pelo método auscultatório para a comparação dos dois métodos. O monitor ambulatorial foi mantido no braço não dominante do voluntário, que foi liberado para suas atividades cotidianas. Durante o período ambulatorial, o monitor foi programado para realizar medidas a cada 15 minutos por 24 horas. Além disso, foi solicitado ao paciente que anotasse suas atividades e horários enquanto estivesse com o monitor e que não ingerisse bebidas alcoólicas, não realizasse exercícios físicos e não dormisse no período diurno. Adicionalmente, foi solicitado que o paciente mantivesse horários e atividades semelhantes após as duas sessões experimentais.

\subsection{ANÁLISE DOS DADOS}

Os dados hemodinâmicos, medidos em triplicata, foram calculados pela média das medidas realizadas.

Os dados de pressão arterial ambulatorial foram avaliados em médias horárias e nas médias obtidas para os períodos de 24 horas, de vigília e de sono relatados pelo paciente.

\subsection{ANÁLISE ESTATÍSTICA}

Previamente ao início da análise, os dados foram avaliados quanto à normalidade de sua distribuição e homogeneidade de sua variância por meio dos testes de Shapiro-Wilks e Levene, respectivamente. Quando a normalidade não foi detectada, foram realizadas transformações logarítmicas para obtê-la. Assim, foi 
realizada transformação logarítmica para as seguintes variáveis: valores absolutos da banda de baixa frequência do intervalo $R R$, valores absolutos da banda de alta frequência do intervalo $R R$, balanço simpatovagal cardíaco, variância total da PAS, valores absolutos da banda de baixa frequência da PAS, variância total da PAD, valores absolutos da banda de baixa frequência da PAD, fluxo sanguíneo basal do antebraço, fluxo sanguíneo máximo no antebraço, fluxo sanguíneo basal na perna, fluxo sanguíneo máximo na perna e área sob a curva de fluxos na perna. Quando não houve diferenças significantes nestas variáveis, elas foram apresentadas nos seus valores originais (sem transformação logarítmica para facilitar a visualização do leitor).

Para se comparar os dados pré-intervenção nas duas sessões experimentais foi empregado o teste t-Student para amostras repetidas.

Para avaliar os comportamentos cardiovasculares durante a realização da caminhada na sessão de exercício, os valores obtidos no momento pré-intervenção e nas diferentes séries do exercício foram comparados pela ANOVA de um fator repetido.

Para a análise inferencial das respostas pós-exercício foi utilizada a ANOVA de dois fatores repetidos, tendo como fatores principais: a sessão (exercício e controle) e o momento (pré e pós-intervenção). Quando necessário, a diferença significante foi localizada por meio do teste de post-hoc de Newman-Keuls.

Para os dados médios da monitorização ambulatorial da pressão arterial, a comparação entre as sessões foi realizada por meio do teste t-Student para amostras repetidas.

Os dados estão apresentados em média \pm erro padrão, e foi considerado significante o valor de $\mathrm{P}<0,05$. 


\section{RESULTADOS}

\subsection{Amostra}

O fluxograma completo do estudo está apresentado na figura 4.
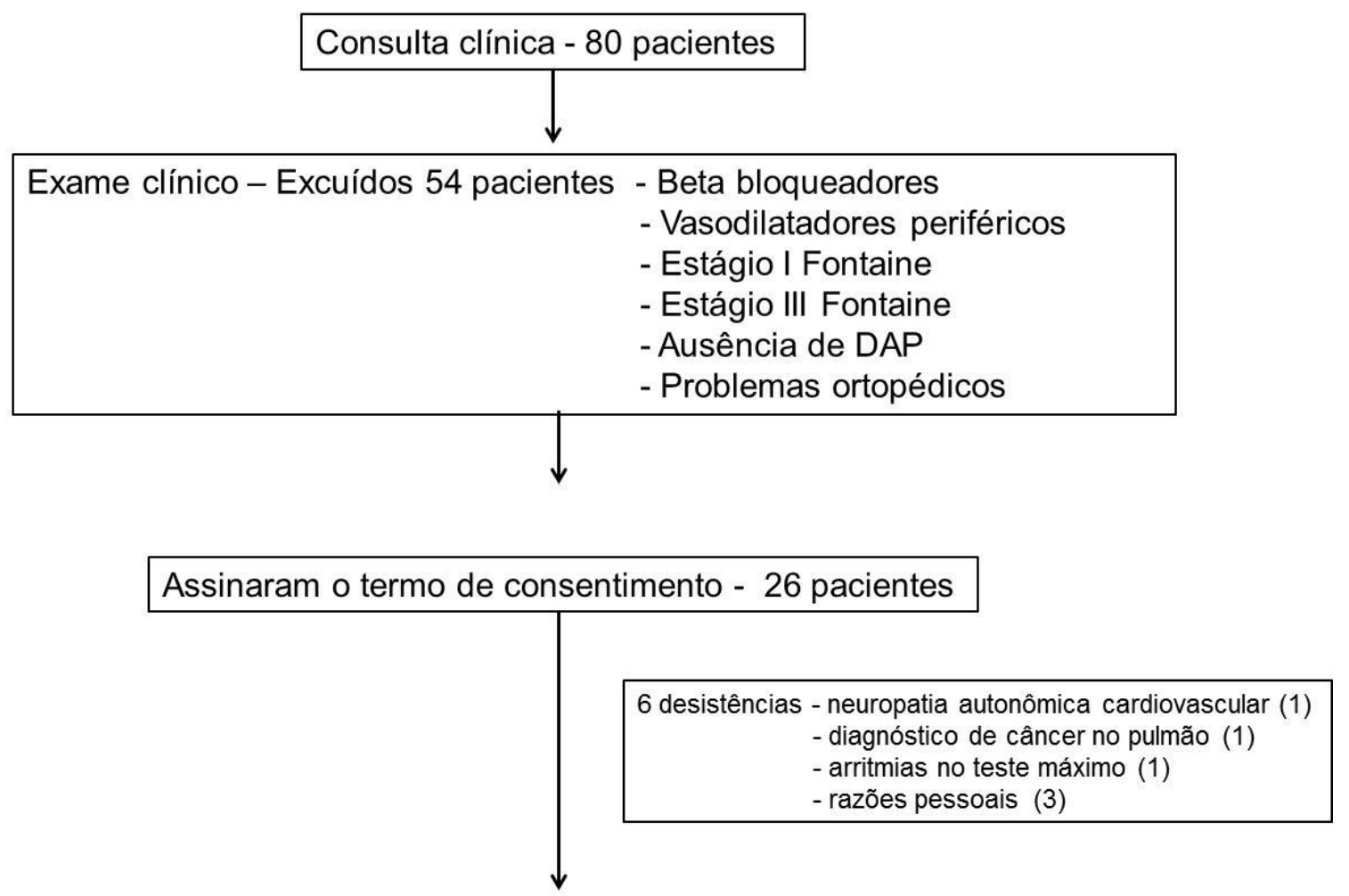

Finalizaram o protocolo experimental - 20 pacientes

Figura 4. Fluxograma do estudo

Inicialmente, 80 pacientes passaram por consulta clínica no Ambulatório de Cirurgia Vascular do Hospital das Clínicas da Faculdade de Medicina da Universidade de São Paulo. Destes, 54 não atendiam os critérios de inclusão (não tinha DAP ou estavam nos estágios I ou III da doença, tinham problemas ortopédicos ou usavam os medicamentos não aceitos na pesquisa). Assim, 26 pacientes apresentaram todos os critérios e assinaram o termo de consentimento livre e esclarecido. Destes, seis foram excluídos pelos seguintes motivos: 
diagnóstico de neuropatia autonômica cardiovascular $(\mathrm{N}=1)$, diagnóstico de câncer no pulmão $(n=1)$, desenvolvimento de arritmias que contraindicaram a realização de exercício físico $(\mathrm{N}=1)$, desistência por razões pessoais $(\mathrm{N}=3)$. Desta forma, 20 pacientes realizaram todos os procedimentos propostos pelo estudo e suas características pessoais, fatores de risco e medicamentos utilizados estão apresentados na tabela 1.

Tabela 1 - Características físicas, fatores de risco, medicamentos e perfil sanguíneo da amostra.

Variáveis $\mathrm{N}=20$

Idade $61,2 \pm 1,7$

Peso $71,5 \pm 2,2$

Índice de Massa Corporal $\left(\mathrm{kg} / \mathrm{m}^{2}\right)$ $25,3 \pm 0,6$

Ex-tababismo (\%) 65

Tabagismo atual (\%) 35

Hipertensão Arterial (\%) 75

Diabetes Mellitus (\%) 20

Dislipidemia (\%) 80

Anti-hipertensivos (\%) 75

Anticoagulantes (\%) 95

Estatinas (\%) 80

Hipoglicemiantes (\%) 20

Glicemia (mg/dL) $112 \pm 7$

Trigliceridemia $(\mathrm{mg} / \mathrm{dL})$ $151 \pm 21$

Colesterolemia total $(\mathrm{mg} / \mathrm{dL})$ $182 \pm 10$

LDL-colesterol ( $\mathrm{mg} / \mathrm{dL}$ ) $110 \pm 9$

HDL-colesterol (mg/dL) $42 \pm 9$

$\overline{\mathrm{LDL}}$ - Lipoproteína de baixa densidade; HDL - lipoproteína de alta densidade. Valores $=$ média \pm erro padrão

É possível observar que a maior parte dos pacientes eram idosos e não obesos. A maioria apresentava ainda vários fatores de risco associados à DAP, sendo a hipertensão e a dislipidemia os mais frequentes. Além disso, a maioria fazia 
uso de medicação anticoagulante (ácido acetilsalicílico) e de agentes antihipertensivos de diferentes classes (inibidores da enzima conversora da angiotensina e diuréticos). Apenas $80 \%$ dos pacientes estavam em uso de estatinas.

A tabela 2 apresenta os valores da pressão arterial e o ITB da amostra do presente estudo.

Tabela 2 - Pressão arterial de repouso e índice tornozelo-braço (ITB) no 1을 minuto pós-exercício.

\begin{tabular}{lc}
\hline Variáveis & $\mathrm{N}=20$ \\
\hline PAS $(\mathrm{mmHg})$ & $130 \pm 3$ \\
PAD $(\mathrm{mmHg})$ & $79 \pm 2$ \\
PAM $(\mathrm{mmHg})$ & $96 \pm 2$ \\
ITB & $0,56 \pm 0,03$ \\
ITB pós-exercício (1ํo min) & $0,22 \pm 0,05$
\end{tabular}

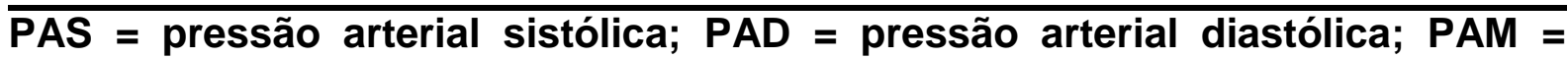
pressão arterial média; ITB = índice tornozelo-braço. Valores = média \pm erro padrão.

Observa-se que os pacientes analisados apresentaram valores médios de pressão arterial controlados, sendo que todos tinham PAS e PAD menores que 160 e $95 \mathrm{mmHg}$, respectivamente. Com relação aos valores de ITB de repouso, todos os pacientes apresentaram valores inferiores a 0,90 e diminuição deste índice após a execução do exercício.

Os resultados obtidos no teste ergoespirométrico estão apresentados na tabela 3. 
Tabela 3 - Variáveis cardiorrespiratórias, metabólicas e funcionais medidas no teste ergoespirométrico.

Variáveis

$\mathrm{N}=20$

$\mathrm{VO}_{2}$ pico $(\mathrm{ml} / \mathrm{min})$

$1318 \pm 80$

$\mathrm{VO}_{2}$ pico $\left(\mathrm{ml} \mathrm{kg}^{-1} \cdot \mathrm{min}^{-1}\right)$

$18,9 \pm 0,8$

FC pico (bpm)

$126 \pm 4$

Razão de troca respiratória

$0,97 \pm 0,02$

PAS máxima $(\mathrm{mmHg})$

$198 \pm 4$

$\mathrm{DIC}(\mathrm{m})$

$297 \pm 38$

$\operatorname{DTC}(\mathrm{m})$

$743 \pm 19$

$\mathrm{VO}_{2}=$ consumo de oxigênio; $\mathrm{FC}$ = frequência cardíaca, $\mathrm{PAS}=$ pressão arterial sistólica; DIC = distância inicial de claudicação; DTC = distância total de claudicação. Valores $=$ média \pm erro padrão

Todos os testes foram interrompidos pela presença do sintoma de dor nos membros inferiores, impedindo a continuação do esforço, o que fez com que o $\mathrm{VO}_{2}$ pico fosse de $52 \pm 3 \%$ do esperado e a FC pico de $79 \pm 3 \%$ da predita para a idade.

5.2 Execução do protocolo

Em função do processo de aleatorização, 10 pacientes iniciaram o protocolo experimental com a sessão controle e 10 com a sessão de caminhada. $O$ intervalo médio entre as sessões foi de $3 \pm 1$ dias.

Para demonstrar a semelhança das condições iniciais nas duas sessões experimentais, a tabela 4 apresenta os dados hemodinâmicos medidos em repouso antes das intervenções nas duas sessões experimentais. As variáveis hemodinâmicas foram obtidas em todos os pacientes. 
Tabela 4 - Variáveis hemodinâmicas medidas em repouso pré-intervenção nas sessões: controle e exercício.

\begin{tabular}{lccc}
\hline & Sessão Controle & Sessão Exercício & $P$ \\
\hline PAS $(\mathrm{mmHg})(\mathrm{N}=20)$ & $130 \pm 3$ & $131 \pm 3$ & 0,14 \\
PAD $(\mathrm{mmHg})(\mathrm{N}=20)$ & $75 \pm 1$ & $77 \pm 2$ & 0,32 \\
PAM $(\mathrm{mmHg})(\mathrm{N}=20)$ & $94 \pm 2$ & $95 \pm 2$ & 0,20 \\
DC $(/ \mathrm{min})(\mathrm{N}=20)$ & $3,028 \pm 0,100$ & $2,926 \pm 0,126$ & 0,28 \\
FC $(\mathrm{bpm})(\mathrm{N}=20)$ & $66 \pm 2$ & $64 \pm 2$ & 0,28 \\
VS (ml) $(\mathrm{N}=20)$ & $44,9 \pm 1,9$ & $44,6 \pm 2,4$ & 0,86 \\
RVS $(\mathrm{U})(\mathrm{N}=20)$ & $31,9 \pm 1,2$ & $34,2 \pm 1,7$ & 0,07
\end{tabular}

PAS = pressão arterial sistólica; PAD = pressão arterial diastólica; PAM = pressão arterial média; $\mathrm{DC}$ = débito cardíaco; FC = frequência cardíaca; VS = volume sistólico; RVS = resistência vascular sistêmica. Valores = média \pm erro padrão.

A tabela 5 apresenta os dados autonômicos medidos em repouso antes das intervenções nas duas sessões experimentais. Nas variáveis autonômicas, devido à presença de arritmias e/ou artefatos, a avaliação não foi possível em alguns pacientes: variáveis de variabilidade da FC pelo modelo linear $=6$, variabilidade da pressão arterial $=10$, sensibilidade barorreflexa $=11$ e variabilidade da FC pelo método não-linear $=7$. 
Tabela 5 - Variáveis autonômicas medidas em repouso pré-intervenção nas sessões controle e exercício.

\begin{tabular}{|c|c|c|c|}
\hline & Sessão Controle & Sessão Exercício & $\mathrm{P}$ \\
\hline $\operatorname{RR}\left(\mathrm{ms}^{2}\right)(\mathrm{N}=14)$ & $935 \pm 33$ & $944 \pm 37$ & 0,52 \\
\hline $\mathrm{VT}_{\mathrm{RR}}\left(\mathrm{ms}^{2}\right)(\mathrm{N}=14)$ & $1431 \pm 331$ & $1337 \pm 275$ & 0,67 \\
\hline $\mathrm{BF}_{\mathrm{RR}}\left(\mathrm{ms}^{2}\right)(\mathrm{N}=14)$ & $319 \pm 79$ & $182 \pm 28$ & 0,20 \\
\hline $\operatorname{AF}_{\mathrm{RR}}\left(\mathrm{ms}^{2}\right)(\mathrm{N}=14)$ & $133 \pm 31$ & $122 \pm 33$ & 0,52 \\
\hline $\mathrm{BF}_{\mathrm{RR}}(\mathrm{un})(\mathrm{N}=14)$ & $59,7 \pm 6,0$ & $56,7 \pm 4,7$ & 0,54 \\
\hline $\mathrm{AF}_{\mathrm{RR}}(\mathrm{un})(\mathrm{N}=14)$ & $30,1 \pm 5,3$ & $34,5 \pm 4,3$ & 0,33 \\
\hline $\mathrm{BF} / \mathrm{AF} \mathrm{RR}_{\mathrm{R}}(\mathrm{N}=14)$ & $3,6 \pm 0,9$ & $3,1 \pm 1,2$ & 0,33 \\
\hline OV (\%) $(\mathrm{N}=13)$ & $30,4 \pm 3,8$ & $36,0 \pm 3,2$ & 0,28 \\
\hline $1 \mathrm{~V}(\%)(\mathrm{N}=13)$ & $47,6 \pm 1,9$ & $47,5 \pm 2,0$ & 0,59 \\
\hline $2 \mathrm{~V}(\%)(\mathrm{N}=13)$ & $22,0 \pm 2,6$ & $16,4 \pm 1,9$ & 0,06 \\
\hline$E S(N=13)$ & $3,4 \pm 0,1$ & $3,2 \pm 0,1$ & 0,22 \\
\hline $\mathrm{VT}_{\text {PAS }}\left(\mathrm{mmHg}^{2}\right)(\mathrm{N}=10)$ & $35,9 \pm 5,7$ & $51,3 \pm 9,4$ & 0,07 \\
\hline $\mathrm{BF}_{\mathrm{PAS}}\left(\mathrm{mmHg} \mathrm{g}^{2}\right)(\mathrm{N}=10)$ & $8,8 \pm 3,0$ & $7,3 \pm 3,5$ & 0,09 \\
\hline $\mathrm{VT}_{\mathrm{PAD}}\left(\mathrm{mmHg} \mathrm{g}^{2}\right)(\mathrm{N}=10)$ & $10,6 \pm 1,0$ & $15,5 \pm 3,5$ & 0,37 \\
\hline $\mathrm{BF}_{\mathrm{PAD}}\left(\mathrm{mmHg} \mathrm{g}^{2}\right)(\mathrm{N}=10)$ & $2,6 \pm 0,8$ & $2,3 \pm 0,9$ & 0,68 \\
\hline $\operatorname{SBR}(\mathrm{ms} / \mathrm{mmHg})(\mathrm{n}=9)$ & $8,0 \pm 1,0$ & $6,1 \pm 1,1$ & 0,18 \\
\hline
\end{tabular}

RR = Intervalo R-R; VT = variância total; $B F$ = banda de baixa frequência; AF =

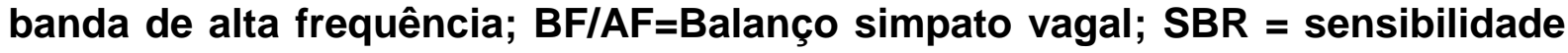
barorreflexa, $0 \mathrm{~V}=$ nenhuma variação, $1 \mathrm{~V}=$ uma variação, $2 \mathrm{~V}=$ duas variações, ES = Entropia de Shannon. Valores = média \pm erro padrão.

A tabela 6 apresenta os dados vasculares medidos em repouso antes das intervenções nas duas sessões experimentais. Nestas variáveis, a avaliação também não foi possível em alguns pacientes: fluxo sanguíneo e resistência vascular do antebraço $=6$, fluxo sanguíneo máximo pós-hiperemia no antebraço $=8$, área sob a curva de fluxos pós-hiperemia do antebraço $=6$, fluxo sanguíneo e resistência vascular da perna $=5$, fluxo sanguíneo máximo pós-hiperemia da perna $=7$ e área sob a curva de fluxos pós-hiperemia da perna $=9$. 
Tabela 6 - Variáveis vasculares medidas em repouso pré-intervenção nas sessões controle e exercício.

\begin{tabular}{|c|c|c|c|}
\hline & Sessão Controle & Sessão Exercício & $P$ \\
\hline $\mathrm{FSB}_{\mathrm{A}}\left(\mathrm{ml} \cdot 100 \mathrm{ml}^{-1} \cdot \mathrm{min}^{-1}\right)(\mathrm{N}=14)$ & $2,4 \pm 0,2$ & $2,2 \pm 0,3$ & 0,50 \\
\hline $\mathrm{FSB}_{\mathrm{P}}\left(\mathrm{ml} \cdot 100 \mathrm{ml}^{-1} \cdot \mathrm{min}^{-1}\right)(\mathrm{N}=15)$ & $2,0 \pm 0,2$ & $1,9 \pm 0,2$ & 0,06 \\
\hline $\mathrm{RV}_{\mathrm{A}}(\mathrm{U}) \quad(\mathrm{N}=14)$ & $47,7 \pm 4,7$ & $50,3 \pm 4,5$ & 0,48 \\
\hline $\mathrm{RV}_{\mathrm{P}}(\mathrm{U})(\mathrm{N}=15)$ & $50,9 \pm 3,9$ & $57,9 \pm 5,5$ & 0,06 \\
\hline $\mathrm{FSM}_{\mathrm{A}}\left(\mathrm{ml} \cdot 100 \mathrm{ml}^{-1} \cdot \mathrm{min}^{-1}\right)(\mathrm{N}=12)$ & $26,4 \pm 1,7$ & $27,0 \pm 1,9$ & 0,76 \\
\hline $\mathrm{FSM}_{\mathrm{P}}\left(\mathrm{ml} \cdot 100 \mathrm{ml}^{-1} \cdot \mathrm{min}^{-1}\right)(\mathrm{N}=13)$ & $7,6 \pm 0,9$ & $7,1 \pm 1,1$ & 0,68 \\
\hline $\mathrm{AUC}_{\mathrm{A}}(\mathrm{U})(\mathrm{N}=14)$ & $2227 \pm 162$ & $2122 \pm 173$ & 0,52 \\
\hline$A \cup C_{P}(U)(N=11)$ & $853 \pm 132$ & $972 \pm 91$ & 0,42 \\
\hline
\end{tabular}

$\overline{\text { FSB }}$ = fluxo sanguíneo basal; RV = resistência vascular; FSM = fluxo sanguíneo máximo; $A U C=$ área sob a curva; $A=$ antebraço; $P=$ perna. Valores = média \pm erro padrão.

Os valores obtidos antes das intervenções nas sessões controle e exercício foram comparados pelo teste t-Student para amostras repetidas. Não foi observada diferença significante nestes valores em nenhuma das variáveis analisadas.

5.3 Respostas durante a sessão de exercício

A tabela 7 apresenta as respostas cardiovasculares e a ocorrência de dor durante a execução da caminhada na sessão de exercício. Esses dados foram analisados pela ANOVA de um caminho. Em três indivíduos, não foi possível obter esses dados devido a problemas durante a coleta, de modo que os resultados representam 17 pacientes. 
Tabela 7 - Respostas cardiovasculares e a ocorrência de dor durante a execução da caminhada na sessão de exercício $(n=17)$.

\begin{tabular}{lcccc}
\hline & Repouso & $1^{\mathrm{a}}$ série & $5^{\mathrm{a}}$ série & $12^{\mathrm{a}}$ série \\
\hline $\mathrm{VO}_{2}\left(\mathrm{ml}^{\mathrm{kgg}}{ }^{-1} \cdot \mathrm{min}^{-1}\right)$ & $4,0 \pm 0,1$ & $12,0 \pm 0,8^{\mathrm{a}}$ & $14,9 \pm 0,5^{\mathrm{ab}}$ & $14,7 \pm 0,6^{\mathrm{ab}}$ \\
$\mathrm{VO}_{2}$ pico $(\%)$ & $22 \pm 2$ & $65 \pm 4^{\mathrm{a}}$ & $81 \pm 4^{\mathrm{ab}}$ & $79 \pm 4^{\mathrm{ab}}$ \\
$\mathrm{VO}_{2}$ LA (\%) & $32 \pm 2$ & $94 \pm 8^{\mathrm{a}}$ & $117 \pm 6^{\mathrm{ab}}$ & $114 \pm 6^{\mathrm{ab}}$ \\
$\mathrm{FC}$ (bpm) & $72 \pm 2$ & $94 \pm 3^{\mathrm{a}}$ & $99 \pm 4^{\mathrm{a}}$ & $101 \pm 4^{\mathrm{ab}}$ \\
$\mathrm{FC}$ pico (\%) & $60 \pm 3$ & $76 \pm 1^{\mathrm{a}}$ & $81 \pm 2^{\mathrm{a}}$ & $82 \pm 2^{\mathrm{ab}}$ \\
$\mathrm{FC}$ LD (\%) & ---- & $95 \pm 2$ & $100 \pm 1^{\mathrm{b}}$ & $102 \pm 1^{\mathrm{b}}$ \\
Dor na sessão (\%) & ----- & 47 & 94 & $100^{\mathrm{ab}}$
\end{tabular}

a Diferente do repouso; ${ }^{b}$ Diferente da $1^{\mathrm{a}}$ série $(\mathrm{P}<0,05)$. $\mathrm{VO}_{2}=$ consumo de oxigênio; FC = frequência cardíaca; $L A=$ limiar anaeróbico; $L D=$ limiar de dor. Valores $=$ média \pm erro padrão.

Durante o exercício, a $\mathrm{FC}$ e $\circ \mathrm{VO}_{2}$ aumentaram de forma significante na $1^{\mathrm{a}}, 5^{\mathrm{a}}$ e $12^{\mathrm{a}}$ séries. Durante todo o protocolo, a FC foi mantida na zona alvo $(\approx 100 \%$ do $\mathrm{VO}_{2}$ do LD). A partir da $5^{\mathrm{a}}$ série, os valores da $\mathrm{FC}$ e do $\mathrm{VO}_{2}$ se estabilizaram. Assim, a partir desta série, o exercício de caminhada foi realizado na intensidade acima do limiar anaeróbico ( $\approx 115 \%$ ), que correspondeu a aproximadamente $80 \%$ do $\mathrm{VO}_{2}$ pico e da FC pico. Além disso, o sintoma de dor nos membros inferiores foi relatado por quase todos os pacientes a partir da $5^{\underline{a}}$ série e, foi considerado tolerável, uma vez que todos foram capazes de realizar as 15 séries do exercício de caminhada.

\subsection{Respostas pós-exercício}

Para uma melhor visualização e compreensão dos resultados, as respostas às intervenções nas variáveis medidas no laboratório serão apresentadas de duas formas: 1) em tabelas apresentando os valores absolutos medidos pré e pós intervenção em cada sessão e 2) em figuras apresentando as respostas observadas (zero no valor pré e $\Delta$ = pós-pré no valor pós) em cada sessão. Nas variáveis ambulatoriais, serão apresentados apenas os valores absolutos obtidos após as intervenções nas duas sessões experimentais. 
5.4.1 Pressão arterial clínica e de 24 horas

A tabela 8 e a figura 5 apresentam as respostas das PAS, PAD e PAM medidas nas sessões controle e exercício. Para a análise inferencial dessas variáveis, foi aplicada a ANOVA de dois fatores para amostras repetidas, tendo como fatores principais a sessão (controle e exercício) e o momento (pré e pósintervenção).

Tabela 8 - Pressão arterial sistólica (PAS), pressão arterial diastólica (PAD) e pressão arterial média (PAM) medidas pré e pós-intervenção nas sessões experimentais: controle e exercício.

\begin{tabular}{lcccc}
\hline & \multicolumn{2}{c}{ Sessão Controle } & \multicolumn{2}{c}{ Sessão Exercício } \\
& Pré $(\mathrm{n}=20)$ & Pós $(\mathrm{n}=20)$ & Pré $(\mathrm{n}=20)$ & Pós $(\mathrm{n}=20)$ \\
\hline PAS $(\mathrm{mmHg})$ & $130 \pm 3$ & $138 \pm 4^{*}$ & $131 \pm 3$ & $127 \pm 4^{*} \dagger$ \\
PAD $(\mathrm{mmHg})$ & $76 \pm 1$ & $82 \pm 2^{*}$ & $77 \pm 2$ & $78 \pm 2 \dagger$ \\
PAM $(\mathrm{mmHg})$ & $94 \pm 2$ & $100 \pm 2^{*}$ & $95 \pm 2$ & $94 \pm 2 \dagger$ \\
\hline
\end{tabular}

* Diferente da pré-intervenção $(P<0,05)$. † Diferente da sessão controle $(P<0,05)$. Valores $=$ média \pm erro padrão. 

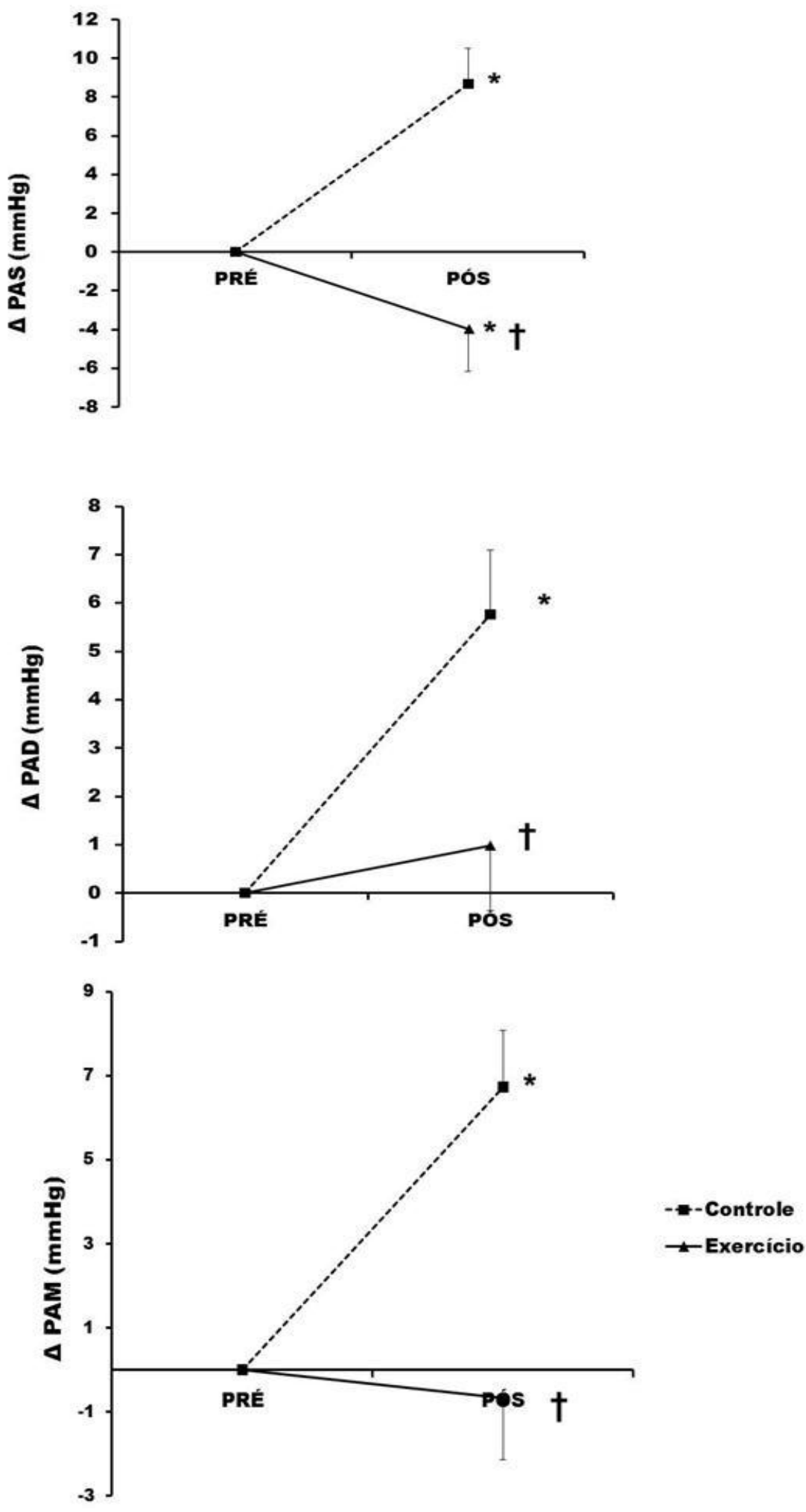

Figura 5 - Resposta $(\Delta)$ da pressão arterial sistólica (PAS), diastólica (PAD) e média (PAM) avaliadas nas sessões controle (linha tracejada) e exercício (linha contínua) ( $\mathrm{n}=20)$.

* Diferente da pré-intervenção $(P<0,05)$. $†$ Diferente da sessão controle $(P<0,05)$. Valores $=$ média \pm erro padrão. 
Houve interação significante entre os fatores sessão e momento para a PAS $(P=0,001)$, PAD $(P=0,01)$ e PAM $(P=0,01)$. Assim, a PAS aumentou significantemente após a sessão controle e diminuiu na sessão de exercício. Desta forma, no momento pós-intervenção, a PAS foi significantemente menor na sessão exercício do que na controle. Considerando-se a PAD e PAM, ambas aumentaram significantemente pós-intervenção na sessão controle e não se alteraram na sessão de exercício. Desta forma, no momento pós-intervenção, a PAD e a PAM foram significantemente menores na sessão de exercício que na controle.

As respostas da PAS, PAD, PAM e FC medidas na monitorização ambulatorial da pressão arterial e da FC nas duas sessões experimentais estão apresentadas na tabela 9. Não foi possível avaliar os dados em quatro pacientes. Em três deles, as medidas válidas foram menores que $80 \%$ das possíveis, demonstrando má qualidade da monitorização. O quarto paciente se recusou a realizar a avaliação em uma das sessões experimentais. Assim, esses dados foram analisados em 16 pacientes.

Os dados médios obtidos na monitorização ambulatorial nas duas sessões foram comparados pelo Teste $\mathrm{t}$ - Student para amostras repetidas. 
Tabela 9 - Média da pressão arterial sistólica (PAS), diastólica (PAD), média (PAM) e da frequência cardíaca (FC) obtidas no período de 24 horas, vigília e sono pós-intervenção nas sessões: controle e exercício $(n=16)$.

\begin{tabular}{lccc}
\hline & $\begin{array}{c}\text { Sessão Controle } \\
(\mathrm{N}=16)\end{array}$ & $\begin{array}{c}\text { Sessão Exercício } \\
(\mathrm{N}=16)\end{array}$ & $\mathrm{P}$ \\
\hline 24 horas & & & \\
PAS (mmHg) & $140 \pm 2$ & $141 \pm 3$ & 0,94 \\
PAD (mmHg) & $84 \pm 2$ & $84 \pm 2$ & 0,98 \\
PAM (mmHg) & $105 \pm 2$ & $105 \pm 2$ & 0,90 \\
FC (bpm) & $83 \pm 2$ & $85 \pm 2$ & 0,18 \\
Vigília & & & \\
PAS (mmHg) & $149 \pm 3$ & $149 \pm 3$ & 0,73 \\
PAD (mmHg) & $91 \pm 2$ & $90 \pm 2$ & 0,62 \\
PAM (mmHg) & $112 \pm 2$ & $111 \pm 2$ & 0,66 \\
FC (bpm) & $91 \pm 3$ & $92 \pm 2$ & 0,30 \\
Sono & & & 0,13 \\
PAS (mmHg) & & & \\
PAD (mmHg) & $126 \pm 2$ & $74 \pm 2$ & 0,94 \\
PAM (mmHg) & $72 \pm 2$ & $91 \pm 2$ & 0,41 \\
FC (bpm) & $91 \pm 2$ & & \\
\hline Valores & $68 \pm 2$ & & \\
\hline
\end{tabular}

Valores = média \pm erro padrão.

Não houve diferença significante nos valores médios da PAS, PAD, PAM e FC obtidos no período de 24 horas, vigília e sono após as intervenções nas as duas sessões experimentais.

O comportamento dessas variáveis avaliado hora a hora após as intervenções nas duas sessões experimentais está apresentado na figura 6. 

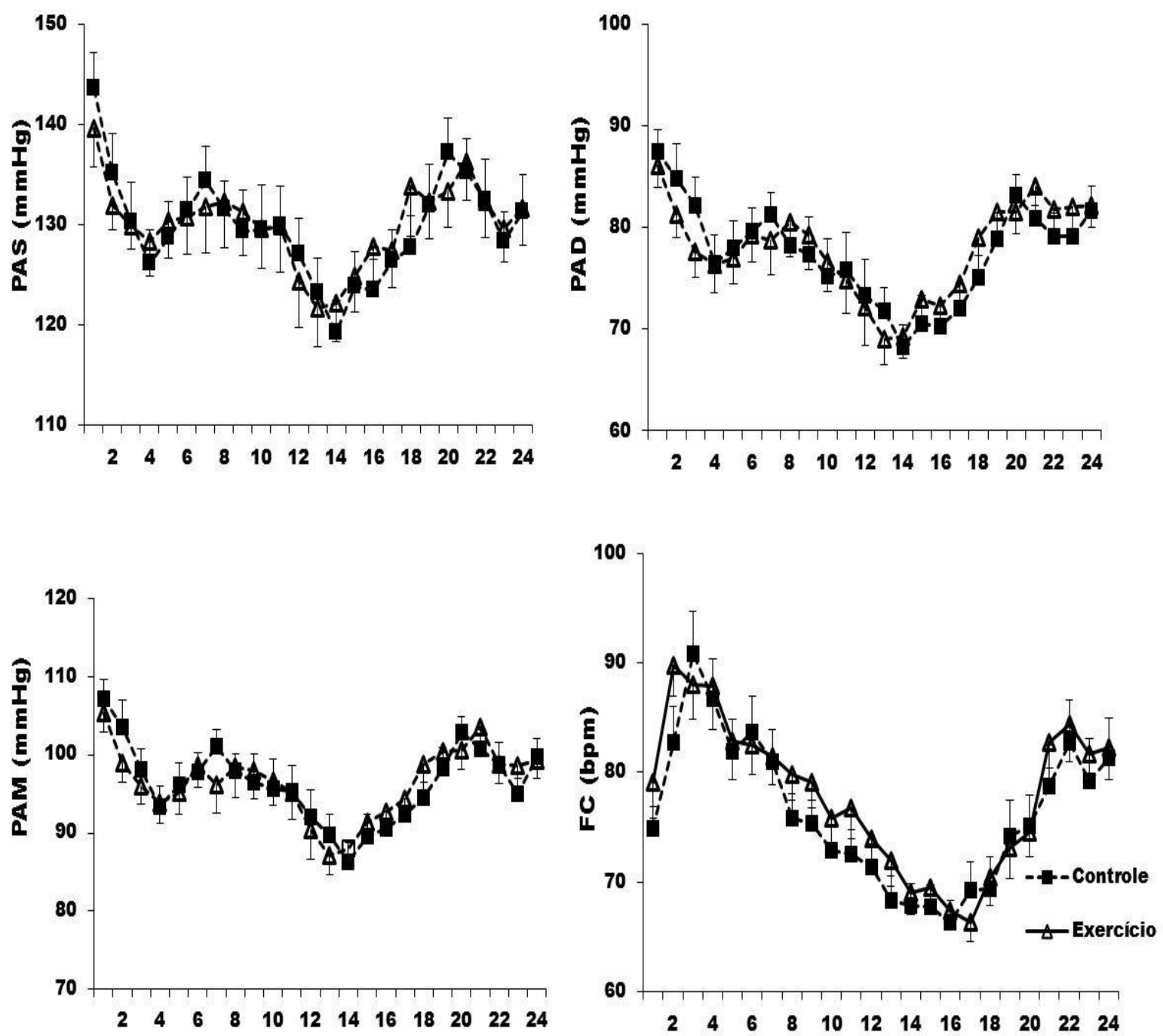

Figura 6 - Médias horárias da pressão arterial sistólica (PAS), diastólica (PAD), média (PAM) e da frequência cardíaca (FC) medidas após as intervenções nas duas sessões experimentais, controle (linha tracejada) e exercício (linha contínua) $(\mathrm{n}=16)$. Valores = média \pm erro padrão.

As médias horárias obtidas após as intervenções nas duas sessões experimentais foram comparadas pela ANOVA de dois fatores para amostras repetidas, tendo como fatores principais a sessão (controle e exercício) e o momento (hora a hora). Não foi observada nenhuma diferença significante nos valores horários da PAS, PAD, PAM e FC entre as duas sessões experimentais. 
5.4.2 Variáveis Hemodinâmicas Sistêmicas

As respostas dos determinantes hemodinâmicos da pressão arterial medidas nas duas sessões experimentais estão apresentadas na tabela 10 e na figura 7. A comparação entre as sessões (exercício e controle) e os momentos (pré e pósintervenção) foi feita pela ANOVA de dois fatores para amostras repetidas.

Tabela 10. Resistência vascular sistêmica (RVS), débito cardíaco (DC), volume sistólico (VS) e frequência cardíaca (FC) medidos pré e pós-intervenção nas sessões experimentais: controle e exercício.

\begin{tabular}{lcccc}
\hline & \multicolumn{2}{c}{ Sessão Controle } & \multicolumn{2}{c}{ Sessão Exercício } \\
& Pré $(\mathrm{n}=20)$ & Pós $(\mathrm{n}=20)$ & Pré $(\mathrm{n}=20)$ & Pós $(\mathrm{n}=20)$ \\
\hline RVS $(\mathrm{U})$ & $31,9 \pm 1,3$ & $36,0 \pm 1,9^{*}$ & $34,2 \pm 1,7$ & $35,9 \pm 1,2$ \\
DC $(\mathrm{l} / \mathrm{min})$ & $3,028 \pm 0,100$ & $2,927 \pm 0,130^{*}$ & $2,926 \pm 0,126$ & $2,780 \pm 0,122^{*}$ \\
FC $(\mathrm{bpm})$ & $66 \pm 2$ & $63 \pm 2^{*}$ & $65 \pm 2$ & $68 \pm 2 \dagger$ \\
VS $(\mathrm{ml})$ & $42,8 \pm 1,8$ & $45,3 \pm 1,9$ & $42,6 \pm 2,3$ & $39,2 \pm 2,1^{*} \dagger$ \\
\hline
\end{tabular}

* Diferente da pré-intervenção $(P<0,05)$. $†$ Diferente da sessão controle $(P<0,05)$. Valores $=$ média \pm erro padrão. 

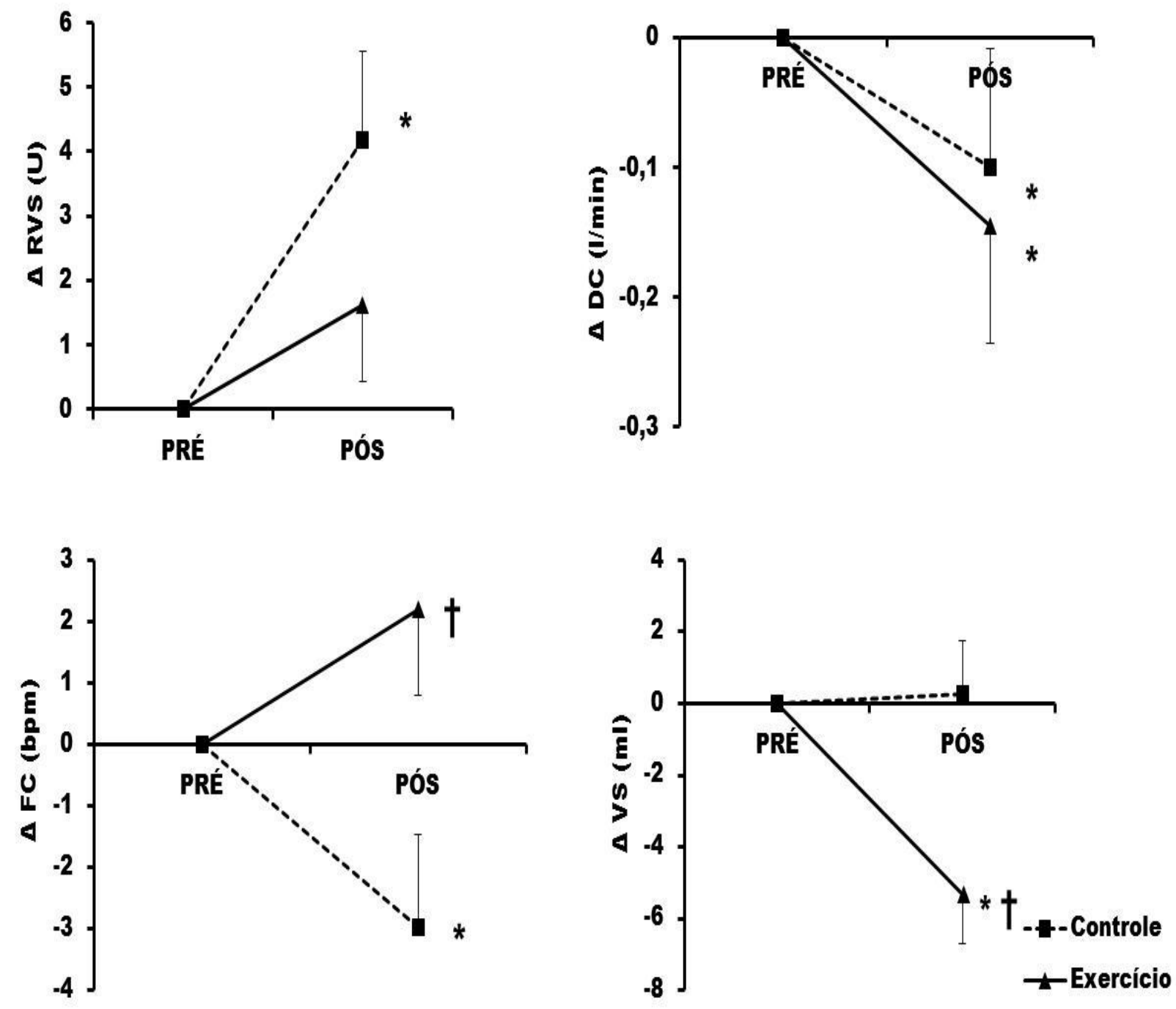

Figura 7. Resposta $(\Delta)$ da resistência vascular sistêmica (RVS), débito cardíaco (DC), frequência cardíaca (FC) e volume sistólico (VS) e avaliadas nas sessões controle (linha tracejada) e exercício (linha contínua) $(\mathrm{n}=20)$. . Diferente da pré-intervenção $(P<0,05)$. † Diferente da sessão controle $(P<0,05)$. Valores $=$ média \pm erro padrão.

Com relação à RVS, houve interação significante entre os fatores sessão e momento $(P=0,04)$. Assim, a RVS aumentou de forma significante na sessão controle e não se modificou na sessão exercício.

Como relação ao DC, não houve interação significante entre os fatores sessão e momento $(P>0,05)$. Contudo, houve efeito significante no fator momento $(P=0,04)$. Desta forma, o $D C$ diminuiu no período pós-intervenção em comparação ao período pré-intervenção, independentemente da sessão experimental analisada. 
Em relação à $\mathrm{FC}$, foi detectada interação significante entre os fatores sessão e o momento $(P=0,01)$, de modo que a $F C$ diminuiu no período pós-intervenção na sessão controle e não se modificou na sessão de exercício. Assim, no período pósintervenção, a FC estava maior na sessão de exercício que na controle.

Considerando-se o VS, também houve interação significante entre os fatores sessão e momento $(P=0,01)$. Porém, o VS não se alterou na sessão controle, mas diminuiu na sessão de exercício, de modo que, no período pós-intervenção, o VS estava menor na sessão de exercício que na controle.

\subsubsection{Variáveis Autonômicas}

As respostas dos parâmetros autonômicos avaliados nas duas sessões experimentais estão apresentadas na tabela 11 e na figura 8. A análise destes dados foi realizada pela ANOVA de dois fatores repetidos, tendo como fatores principais a sessão (exercício e controle) e o momento (pré e pós-intervenção). 
Tabela 11. Parâmetros autonômicos avaliados pelo modelo linear e não-linear de variabilidade da frequência cardíaca, pela variabilidade da pressão arterial e pela sensibilidade barorreflexa espontânea medidos no período pré e pósintervenção das sessões experimentais: controle e exercício.

\begin{tabular}{|c|c|c|c|c|}
\hline \multirow[b]{2}{*}{$\overline{R R}\left(m^{2}\right)(\mathrm{N}=14)$} & \multicolumn{2}{|c|}{ Sessão Controle } & \multicolumn{2}{|c|}{ Sessão Exercício } \\
\hline & $935 \pm 33$ & $1033 \pm 26^{*}$ & $944 \pm 37$ & $929 \pm 35 \dagger$ \\
\hline $\mathrm{VT}_{\mathrm{RR}}\left(\mathrm{ms}^{2}\right)(\mathrm{N}=14)$ & $1431 \pm 331$ & $2349 \pm 296^{*}$ & $1337 \pm 275$ & $1440 \pm 263 \dagger$ \\
\hline $\mathrm{BF}_{\mathrm{RR}}\left(\mathrm{ms}^{2}\right)(\mathrm{N}=14)$ & $319 \pm 79$ & $707 \pm 188^{*}$ & $182 \pm 28$ & $244 \pm 77 \dagger$ \\
\hline $\mathrm{AF}_{\mathrm{RR}}\left(\mathrm{ms}^{2}\right)(\mathrm{N}=14)$ & $133 \pm 31$ & $243 \pm 62^{*}$ & $122 \pm 33$ & $109 \pm 29 \dagger$ \\
\hline $\mathrm{BF}_{\mathrm{RR}}(\mathrm{un})(\mathrm{N}=14)$ & $59,7 \pm 5,9$ & $67,0 \pm 3,4$ & $56,7 \pm 4,7$ & $58,4 \pm 5,7$ \\
\hline$A F_{R R}(u n)(N=14)$ & $30,1 \pm 5,3$ & $24,5 \pm 3,1$ & $34,5 \pm 4,3$ & $30,1 \pm 4,1$ \\
\hline$B F / A F_{R R}(N=14)$ & $3,6 \pm 0,9$ & $4,5 \pm 1,2$ & $3,1 \pm 1,2$ & $3,7 \pm 1,4$ \\
\hline OV $(\%)(\mathrm{N}=13)$ & $30,4 \pm 3,8$ & $34,5 \pm 2,4$ & $36,0 \pm 3,2$ & $39,7 \pm 3,3$ \\
\hline $1 \mathrm{~V}(\%)(\mathrm{N}=13)$ & $47,6 \pm 1,9$ & $46,9 \pm 1,0$ & $47,5 \pm 2,0$ & $44,4 \pm 1,8$ \\
\hline $2 \mathrm{~V}(\%)(\mathrm{N}=13)$ & $22,0 \pm 2,6$ & $18,6 \pm 2,2$ & $16,4 \pm 1,9$ & $15,9 \pm 1,8$ \\
\hline$E S(N=13)$ & $3,4 \pm 0,1$ & $3,2 \pm 0,1$ & $3,2 \pm 0,1$ & $3,1 \pm 0,1$ \\
\hline $\mathrm{VT}_{\text {PAS }}\left(\mathrm{mmHg}^{2}\right) \quad(\mathrm{N}=10)$ & $35,9 \pm 5,7$ & $54,5 \pm 12,5$ & $51,3 \pm 9,4$ & $67,7 \pm 10,6$ \\
\hline $\mathrm{BF}_{\mathrm{PAS}}\left(\mathrm{mmHg}^{2}\right) \quad(\mathrm{N}=10)$ & $8,8 \pm 3,0$ & $12,3 \pm 5,6$ & $7,3 \pm 3,5$ & $5,9 \pm 2,2$ \\
\hline $\mathrm{VT}_{\mathrm{PAD}}\left(\mathrm{mmHg}^{2}\right)(\mathrm{N}=10)$ & $10,6 \pm 1,0$ & $18,1 \pm 5,2$ & $15,5 \pm 3,5$ & $20,5 \pm 3,4$ \\
\hline $\mathrm{BF}_{\mathrm{PAD}}\left(\mathrm{mmHg} \mathrm{g}^{2}\right)(\mathrm{N}=10)$ & $2,5 \pm 0,9$ & $2,6 \pm 1,4$ & $2,3 \pm 0,8$ & $2,6 \pm 1,2$ \\
\hline $\operatorname{SBR}(\mathrm{ms} / \mathrm{mmHg})(\mathrm{n}=9)$ & $7,7 \pm 0,9$ & $11,0 \pm 0,8^{*}$ & $6,1 \pm 1,1$ & $6,9 \pm 1,1 \dagger$ \\
\hline $\begin{array}{l}\text { RR = Intervalo R-R; VT } \\
\text { banda de alta frequê } \\
\text { variação, } 1 \mathrm{~V}=\text { apenas } \\
\text { Shannon, PAS = Pres } \\
\text { SBR = sensibilidade } \\
\text { Diferente da sessão con }\end{array}$ & $\Gamma$ = variância & sistólica; & a de baixa & $\begin{array}{l}\text { Jência; AF = } \\
=\text { nenhuma } \\
\text { Entropia de } \\
\text { al diastólica, } \\
\text { to }(P<0,05) . \dagger\end{array}$ \\
\hline
\end{tabular}



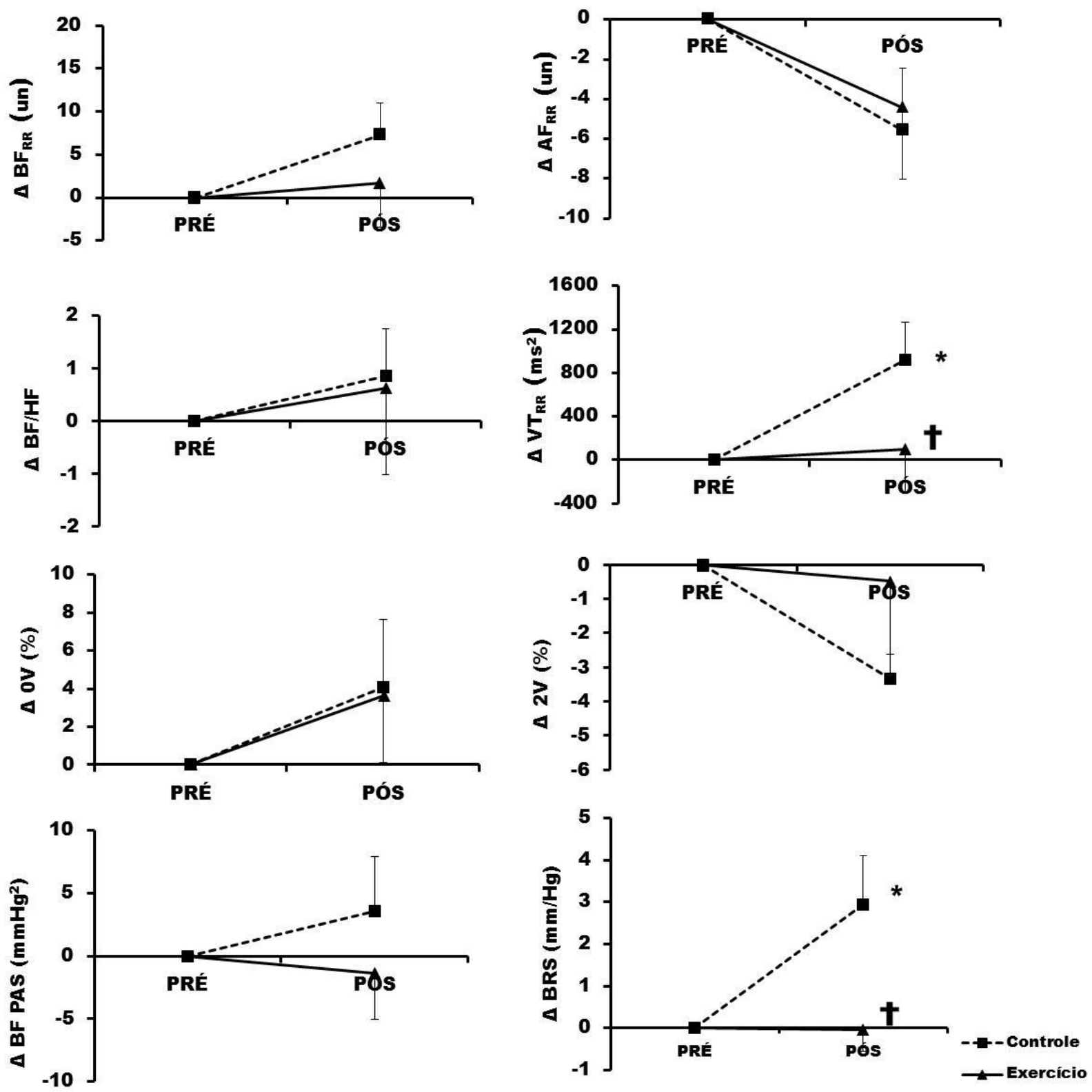

Figura 8 - Resposta $(\Delta)$ dos principais parâmetros autonômicos avaliados nas sessões controle (linha tracejada) e exercício (linha contínua).

$\mathbf{R R}=$ Intervalo R-R; VT = variância total; $B F$ = banda de baixa frequência; $A F=$ banda de alta frequência; $B F / A F=$ balanço simpato-vagal; PAS = Pressão arterial sistólica; $\mathrm{OV}=$ nenhuma variação, $2 \mathrm{~V}=$ duas variações, $\mathrm{SBR}=$ sensibilidade barorreflexa. * Diferente da pré-intervenção $(P<0,05) . \dagger$ Diferente da sessão controle $(P<0,05)$. Valores $=$ média \pm erro padrão.

Houve interação significante entre os fatores sessão e momento para o intervalo $R-R(P=0,001)$, a variância total do intervalo $R R(P=0,016)$ e para os valores absolutos da banda de alta $(P=0,04)$ e de baixa frequência $(P=0,03)$ da variabilidade do intervalo $\mathrm{RR}$ avaliados pelo método linear. Desta forma, os valores 
dessas variáveis aumentaram na sessão controle e não se alteraram na sessão de exercício, de modo que no período pós-intervenção eles estavam menores na sessão de exercício que na controle.

Com relação aos valores normalizados das bandas de baixa e alta frequência da variabilidade do intervalo $R R$, bem como o balanço simpatovagal, nenhum efeito ou interação significante foi detectado $(P>0,05)$. Desta forma, essas variáveis foram semelhantes entre as sessões e não se alteraram no período pós-intervenção em nenhuma das sessões experimentais.

Adicionalmente, não foi observado nenhum efeito ou interação significante na ANOVA para a análise da variabilidade da FC pelo método não-linear. Assim, a Entropia de Shannon, bem como os padrões de variação $0 \mathrm{~V}, 1 \mathrm{~V}$ e $2 \mathrm{~V}$ foram semelhantes entre as sessões e não se modificaram no período pós-intervenção em comparação com os valores pré-intervenção em nenhuma das sessões experimentais.

Com relação às variáveis de variabilidade da pressão arterial, também não foi observado nenhum efeito ou interação significante entre os fatores principais da ANOVA. Assim, essas variáveis foram semelhantes entre as sessões e não se alteraram no período pós-intervenção quando comparados ao período préintervenção em nenhuma das sessões experimentais.

Considerando-se a sensibilidade barorreflexa espontânea, houve interação significante entre os fatores sessão e momento $(P=0,03)$. Desta forma, o ganho médio do barrorreflexo aumentou de forma significante após a intervenção na sessão controle e não se modificou na sessão exercício, de modo que no período pós-intervenção, a sensibilidade barorreflexa estava menor na sessão exercício que na controle. 
5.4.4 Variáveis Vasculares

A tabela 12 e a figura 9 apresentam as respostas das variáveis vasculares medidas nas duas sessões experimentais. A comparação entre as sessões (exercício e controle) e os momentos (pré e pós-intervenção) foi feita pela ANOVA de dois fatores para amostras repetidas.

Tabela 12 - Fluxo sanguíneo basal (FSB), resistência vascular (RV), fluxo sanguíneo máximo pós-hiperemia (FSM) e área sob a curva de fluxos póshiperemia (AUC) medidos no membro inativo (antebraço - A) e ativo (perna P) nos períodos pré e pós-intervenção nas duas sessões experimentais: controle e exercício.

\begin{tabular}{lcccc} 
& \multicolumn{2}{c}{ Controle } & \multicolumn{2}{c}{ Exercício } \\
& Pré & Pós & Pré & Pós \\
\hline $\mathrm{FSB}_{\mathrm{A}}\left(\mathrm{ml} \cdot 100 \mathrm{ml}^{-1} \cdot \mathrm{min}^{-1}\right)(\mathrm{n}=14)$ & $2,3 \pm 0,2$ & $1,7 \pm 0,2^{*}$ & $2,3 \pm 0,4$ & $2,6 \pm 0,2 \dagger$ \\
$\mathrm{FSB}_{\mathrm{P}}\left(\mathrm{ml} .100 \mathrm{ml}^{-1} \cdot \mathrm{min}^{-1}\right)(\mathrm{n}=15)$ & $2,0 \pm 0,2$ & $1,8 \pm 0,2$ & $1,9 \pm 0,2$ & $2,1 \pm 0,2$ \\
& & & & \\
$\mathrm{RV}_{\mathrm{A}}(\mathrm{U})(\mathrm{N}=14)$ & $47,8 \pm 4,7$ & $67,2 \pm 6,4^{*}$ & $50,0 \pm 4,6$ & $46,0 \pm 4,7 \dagger$ \\
$\mathrm{RV}_{P}(\mathrm{U})(\mathrm{N}=15)$ & $50,9 \pm 3,9$ & $63,3 \pm 5,1^{*}$ & $57,9 \pm 5,5$ & $53,5 \pm 5,3 \dagger$ \\
& & & & \\
$\mathrm{FSM}_{\mathrm{A}}\left(\mathrm{ml} .100 \mathrm{ml}^{-1} \cdot \mathrm{min}^{-1}\right)(\mathrm{n}=12)$ & $26,4 \pm 1,7$ & $26,3 \pm 1,9$ & $27,0 \pm 1,9$ & $28,1 \pm 1,5$ \\
$\mathrm{FSM}_{\mathrm{P}}\left(\mathrm{ml} .100 \mathrm{ml}^{-1} \cdot \mathrm{min}^{-1}\right)(\mathrm{n}=13)$ & $7,6 \pm 0,9$ & $6,7 \pm 0,8$ & $7,1 \pm 1,1$ & $6,8 \pm 0,6$ \\
& & & & \\
$\mathrm{AUC}_{\mathrm{A}}(\mathrm{U})(\mathrm{n}=12)$ & $2264 \pm 185$ & $1923 \pm 202^{*}$ & $2190 \pm 195$ & $2045 \pm 103^{*}$ \\
$\mathrm{AUC}_{\mathrm{P}}(\mathrm{U})(\mathrm{n}=11)$ & $853 \pm 132$ & $1005 \pm 123$ & $972 \pm 91$ & $793 \pm 80$ \\
\hline
\end{tabular}

* Diferente da pré-intervenção $(\mathrm{P}<0,05)$. † Diferente da sessão controle $(\mathrm{P}<0,05)$. Valores $=$ média \pm erro padrão. 

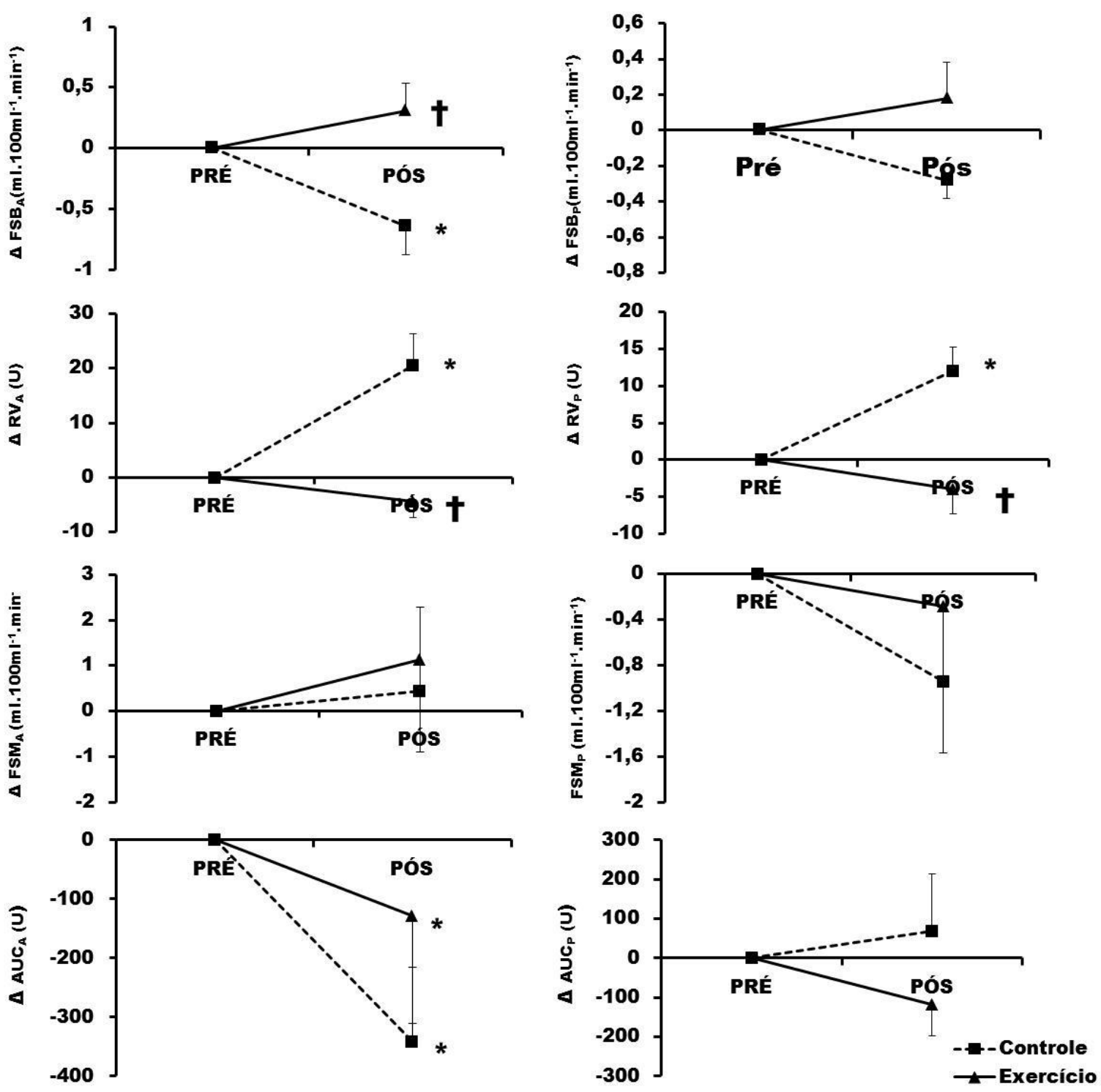

Figura 9 - Resposta $(\Delta)$ do fluxo sanguíneo basal (FSB), resistência vascular (RV), fluxo sanguíneo máximo pós-hiperemia (FSM) e área sob a curva de fluxos pós-hiperemia (AUC) medidos no membro inativo (antebraço - A) e ativo (perna- P) nas sessões controle (linha tracejada) e exercício (linha contínua). * Diferente da pré-intervenção $(P<0,05)$. $†$ Diferente da sessão controle $(P<0,05)$. Valores $=$ média \pm erro padrão

Considerando-se o fluxo sanguíneo basal, houve interação significante entre os fatores sessão e momento $(P=0,01)$ na região inativa (antebraço) e não houve efeito significante na região ativa, embora observa-se uma forte tendência $(P=0,06)$. Assim, o fluxo sanguíneo do antebraço diminuiu na sessão controle e não se alterou na sessão de exercício, de modo que após a intervenção, ele estava maior na sessão de exercício que na sessão controle. Por outro lado, o fluxo sanguíneo da perna foi semelhante entre as sessões e não se alterou de forma significante em 
nenhuma delas. Se a tendência for considerada, o comportamento do fluxo sanguíneo da perna foi semelhante ao do fluxo sanguíneo do braço.

Com relação à resistência vascular, houve interação significante entre os fatores sessão e momento tanto na região inativa (antebraço) $(P=0,01)$ quanto na ativa (perna) $(P=0,01)$. Assim, as resistências vasculares do antebraço e da perna aumentaram na sessão controle e não se alteraram após o exercício. Desta forma, no período pós-intervenção, as resistências vasculares do antebraço e da perna estavam menores na sessão exercício que na controle.

Considerando-se o fluxo máximo pós-hiperemia reativa, não foi detectada interação significante entre os fatores analisados pela ANOVA tanto para região inativa (antebraço) quanto para a ativa (perna). Desta forma, o fluxo máximo póshiperemia no antebraço e na perna foram semelhantes entre as sessões e não se modificaram no período pós-intervenção.

Com relação à área sob a curva de fluxos pós-hiperemia, também não foram observadas interações significantes entre os fatores analisados para ambas as regiões $(P>0,05)$. Contudo, houve efeito significante no fator momento para a região inativa (antebraço) $(P=0,02)$. Assim, a área sob a curva de fluxos pós-hiperemia no antebraço diminui no período pós-intervenção em comparação com o período préintervenção, independentemente da sessão experimental. Por outro lado, esta área para a perna foi semelhante entre as sessões e não se alterou de forma significante. 


\section{DISCUSSÃO}

Os principais resultados do presente estudo foram:

a) Uma sessão de caminhada realizada na FC do limiar de dor promoveu HPE de magnitude significante por 60 minutos pós-exercício em pacientes com $\mathrm{Cl}$. Este efeito hipotensor não perdurou nas horas subsequentes quando os pacientes retornaram a suas atividades cotidianas;

b) A HPE se deveu ao efeito do exercício impedindo o aumento da RVS que compensaria a redução do DC pós-exercício;

c) A redução do DC pós-exercício foi promovida pela diminuição do VS, que não foi compensada por um aumento da FC;

d) A resposta da FC pós-exercício se acompanhou de alterações nas variáveis de modulação autonômica cardiovascular no período pós-intervenção, que sugerem que o exercício prévio impediu o aumento da modulação vagal cardíaca;

e) O efeito do exercício prévio impedindo o aumento da RVS se acompanhou do impedimento do aumento da resistência vascular tanto da região ativa (perna) quanto da inativa (braço), sem modificação da resposta vasodilatadora. 


\subsection{Protocolo Experimental}

Observando-se os dados da amostra final do estudo, é possível verificar que os pacientes eram idosos, não obesos e apresentavam diversos fatores de risco associados à DAP. De fato, estudos que analisaram as características de pacientes com DAP verificaram que devido ao aumento da prevalência da doença com a idade, a maior parte dos pacientes tem mais que 60 anos (BENDERMACHER et al., 2006; NORGREN et al., 2007; PARMENTER et al., 2011). Além disso, a prevalência dos fatores de risco observados na presente investigação - hipertensão arterial 75\%, diabetes $20 \%$ e dislipidemia $80 \%$ é similar à observada por ISQUIERDO-PORRERA et al. (IZQUIERDO-PORRERA et al., 2000) que verificaram prevalência de hipertensão em $75 \%$, diabetes em $32 \%$, e dislipidemia em $82 \%$ dos indivíduos com DAP.

É interessante observar que a maioria dos pacientes incluídos no presente estudo apresentaram níveis médios de PAS e PAD em repouso, glicemia, triglicérides, colesterol total e suas frações considerados adequados. Assim, 75\% dos pacientes apresentavam PAS/PAD abaixo de 140/90 mmHg, 75\% glicemia abaixo de $126 \mathrm{mg} / \mathrm{dl}$, 85\% trigliceridemia abaixo de $200 \mathrm{mg} / \mathrm{dl}$, 85\% colesterol total abaixo de $240 \mathrm{mg} / \mathrm{dl}$, 85\% LDL-colesterol abaixo de $160 \mathrm{mg} / \mathrm{dl}$ e 60\% HDLcolesterol acima de $40 \mathrm{mg} / \mathrm{dl}$. Estes são os valores considerados como controlados pelas diretrizes de tratamento destas doenças (IV Diretriz Brasileira sobre Dislipidemias e Prevenção da Aterosclerose. Departamento de Aterosclerose da Sociedade Brasileira de Cardiologia 2007; Standards of medical care in diabetes-2011, 2011). Desta forma, do ponto de vista clínico, os pacientes, de maneira geral, apresentavam um bom controle dos fatores de risco associados à DAP.

Todos pacientes apresentaram valores de ITB de repouso inferiores a 0,90, apresentaram dor durante a caminhada e tiveram redução do ITB após o teste em esteira. Estes dados demonstram que os pacientes analisados efetivamente estavam no estágio II da doença (HIRSCH et al., 2006; NORGREN et al., 2007), uma vez que foi comprovada a presença de obstrução arterial no membro inferior e que esta obstrução prejudicava a atividade física. Com base nos dados anteriores, é possível verificar que a amostra apresentava as características necessárias para o estudo e também tinha características comuns a pacientes com DAP. 
Os valores médios da DIC e DTC observados na presente investigação foram de $297 \pm 38$ e $743 \pm 19 \mathrm{~m}$, respectivamente, e eles variaram de 80 a $440 \mathrm{~m}$ para a DIC e de 310 a 1260m para a DTC. Observa-se, portanto, uma variação bastante razoável na capacidade de caminhada entre os pacientes, o que é comumente observado nos estudos com esta população (PARMENTER et al., 2011). Em relação aos valores médios e sua comparação com outros estudos que utilizaram o mesmo teste máximo, os resultados da presente investigação foram maiores que os observados por TEW et al. (TEW et al., 2009) (DIC $=147 \pm 125 \mathrm{~m}$ e DTC $=496 \pm 250 \mathrm{~m}$ ) e por GARDNER et al. (GARDNER et al., 2000) (DIC=178 $\pm 22 \mathrm{~m}$ e DTC=389 $\pm 29 \mathrm{~m}$ ). Essa discrepância pode ser explicada pelos critérios de inclusão adotados, uma vez que, diferentemente dos outros estudos, na presente investigação não foram incluídos pacientes obesos e com presença de doença cardiovascular de maior gravidade.

Com relação à execução da caminhada, foi possível observar que o protocolo de treinamento escolhido foi seguido de forma adequada. Como programado, durante o esforço a FC foi mantida na FC do limiar de dor com variação de 4 bpm. Com este estímulo, a maioria dos pacientes apresentou sintomas de dor em quase todas as séries do esforço, mas esta dor foi considerada tolerável, uma vez que todos foram capazes de realizar todas as 15 séries de 2 min de caminhada. Adicionalmente, a caminhada realizada atingiu uma intensidade suficiente para estimular adaptações cardiovasculares e metabólicas, visto que ela estava acima do limiar anaeróbico, que é considerada a faixa ideal para se obter melhorias no sistema cardiovascular (HENRITZE et al., 1985). De fato, publicamos um artigo (CUCATO et al., 2013) que demonstra a viabilidade e a efetividade deste tipo de prescrição de caminhada em pacientes com Cl. Neste estudo, relatamos uma melhora de $104 \pm 141 \mathrm{~m}$ e $316 \pm 141 \mathrm{~m}$ na DIC e DTC, respectivamente, quando este treinamento foi realizado por 12 semanas com frequência de duas sessões semanais.

Outro aspecto a ser comentado em relação à realização do protocolo experimental é a aleatorização das sessões experimentais, que teve como objetivo impedir a possível influência de uma adaptação aos processos de medição, o que poderia acontecer se fosse adotada uma ordem fixa das sessões (THOMAS e NELSON, 2002). Foi possível observar que o sorteio da ordem de execução das sessões experimentais foi realizado com sucesso fazendo com que $50 \%$ dos pacientes da amostra iniciassem o protocolo experimental com cada sessão. 
Diante do exposto, observa-se que a execução do protocolo experimental atingiu os objetivos propostos. A amostra representou a população de pacientes com $\mathrm{Cl}$, de modo que os resultados podem ser extrapolados para pacientes com estas caraterísticas. Além disso, o protocolo foi realizado com cuidados experimentais adequados de modo que os resultados devem refletir os efeitos do exercício nesta população.

5.2 Efeito da Caminhada na Hipotensão Pós-Exercício em Pacientes com Claudicação Intermitente

Considerando-se a PAS, houve redução aos 60 minutos pós-exercício enquanto os pacientes estavam no laboratório. Neste momento, a redução líquida da PAS [calculada: (pós-exercício - pré-exercício) - (pós-controle - pré-controle) foi de $13 \pm 2 \mathrm{mmHg}$. Esses resultados são similares aos observados por CUCATO et al. (CUCATO et al., 2011) que relatou queda de $14 \pm 5 \mathrm{mmHg}$ na PAS após uma sessão de exercício de força em pacientes com $\mathrm{Cl}$. Além disso, estes resultados são um pouco maiores que os relatados em uma revisão sobre HPE aeróbico (MACDONALD, 2002), que observou redução média de $8 \mathrm{mmHg}$ em indivíduos normotensos e de $10 \mathrm{mmHg}$ em indivíduos hipertensos, ambos sem DAP. Um possível aspecto pode ser levantado para explicar a maior magnitude da HPE neste estudo. A maioria dos pacientes da presente investigação estava em uso de medicamentos anti-hipertensivos, sendo possível que o medicamento tenha um efeito aditivo ao exercício reduzindo mais a pressão arterial. Contudo, pelo nosso conhecimento, não existem estudos que avaliaram a HPE em indivíduos com e sem o uso de medicação.

Além da redução da PAS, o exercício de caminhada também promoveu efeito hipotensor na PAD, pois impediu o aumento desta pressão observado aos 60 minutos pós-intervenção na sessão controle. De fato, o efeito líquido desta redução foi de $5 \pm 2 \mathrm{mmHg}$, o que também está próximo ao observado por CUCATO et. (CUCATO et al., 2011) que verificaram $6 \pm 5 \mathrm{mmHg}$ de redução da PAD pós-exercício resistido em pacientes com $\mathrm{Cl}$ e de MACDONALD (MACDONALD, 2002) que relataram uma queda média de $7 \mathrm{mmHg}$ na PAD após o exercício aeróbico em 
normotensos e hipertensos. O aumento da PAS e da PAD na sessão controle pode parecer estranho a princípio, porém, ele pode ser explicado pelo fato das sessões terem sido conduzidas pela manhã, quando sabidamente, a pressão arterial aumenta (PANZA, EPSTEIN e QUYYUMI, 1991). O efeito hipotensor observado sobre a PAD também se revelou na PAM com uma redução líquida de $7 \pm 2 \mathrm{mmHg}$.

Desta forma, estes resultados permitem responder ao primeiro objetivo do estudo demonstrando que uma sessão de caminhada é capaz de promover a HPE em pacientes com $\mathrm{Cl}$.

O segundo aspecto investigado por este estudo diz respeito às características desta hipotensão, ou seja, sua magnitude e duração. Segundo KENNEY E SEALS (KENNEY e SEALS, 1993) para que a HPE tenha relevância clínica, ela deve ter magnitude significante e deve perdurar pela maior parte das horas do dia. Em relação à magnitude da queda da pressão arterial, como dito anteriormente, ela foi equivalente ou mesmo maior que a observada em outros estudos. Além disso, é sabido que reduções na ordem de $5 \mathrm{mmHg}$ diminuem a mortalidade por doença arterial coronariana em 9\% e por acidente vascular cerebral em 14\% (WHELTON et al., 2002). Desta forma, pode-se considerar que a magnitude da HPE foi clinicamente relevante.

A manutenção deste efeito hipotensor por um prolongado período de tempo pós-exercício foi avaliada no presente estudo a partir da monitorização ambulatorial da pressão arterial. Apesar da diminuição da pressão arterial no ambiente clínico por até 60 minutos pós-exercício, este efeito hipotensor não se manteve nas horas subsequentes, visto que as médias horárias da pressão arterial após as intervenções, bem como os valores médios dos períodos de 24 horas, vigília e sono pós-intervenções, foram semelhantes na sessão controle e de exercício. Esses resultados são similares aos dos estudos conduzido por SOMERS at al. (SOMERS et al., 1991) e RUECKERT et al. (RUECKERT et al., 1996) que avaliaram o efeito do exercício aeróbico em indivíduos hipertensos e observaram que a redução de pressão arterial ocorreu apenas no ambiente clínico e não se manteve em condições ambulatoriais. Resultados similares também foram observados em indivíduos com Cl após uma sessão de exercício resistido (RODRIGUES et al., 2013). Entretanto, outros estudos têm demonstrado efeito hipotensor do exercício aeróbico em condições ambulatoriais, que pode durar de 4 por até 16 horas (CARDOSO et al., 2010). 
Algumas hipóteses podem ser levantadas para explicar a ausência de manutenção da HPE no período ambulatorial nos pacientes com $\mathrm{Cl}$ apesar de grande efeito hipotensor no laboratório. A maioria dos pacientes do presente estudo estava com os níveis de pressão arterial controlados devido ao uso de medicamentos anti-hipertensivos. De fato, $60 \%$ dos pacientes apresentaram PAS/PAD no período de sono abaixo de 120/70 mmHg, respectivamente, que são considerados níveis limítrofes na monitorização ambulatorial (V Diretrizes Brasileiras de Monitoração Ambulatorial Da Pressão Arterial (MAPA V) e III Diretrizes de Monitoração Residencial da Pressão Arterial (MRPA III), 2011). É sabido que o efeito hipotensor do exercício é mais evidente em indivíduos com a presença de níveis de pressão arterial elevados (PESCATELLO et al., 2004; CARDOSO et al., 2010). Assim, é possível que o efeito hipotensor não tenha sido observado porque os níveis de pressão arterial estavam baixos. No entanto, os níveis de pressão arterial no ambiente clínico também estavam bem controlados e, mesmo assim, a HPE se manifestou de forma expressiva. Desta forma, outros fatores devem ter contribuído de forma mais expressiva nesta resposta. Neste sentido, é possível sugerir que no ambiente clínico, os pacientes estavam em repouso e, portanto, com ausência do sintoma de dor, o que pode ter permitido que o efeito hipotensor do exercício se manifestasse. Porém, quando os pacientes retornaram a suas atividades diárias, 0 que implica em locomoção, a dor nos membros inferiores se manifestou. Esta dor promovida pelo processo isquêmico aumenta a produção de espécies reativas de oxigênio e de agentes pró-inflamatórios, ativando reflexos pressores, que aumentam a atividade simpática e a pressão arterial (MULLER et al., 2012). De fato, durante a execução da caminhada em pacientes com $\mathrm{Cl}$, a pressão arterial aumenta progressivamente (BACCELLI et al., 1999). Assim, é possível que esse efeito das atividades cotidianas que promovem a dor tenha se contraposto ao efeito hipotensor do exercício, não permitindo que a HPE se mantivesse no ambiente ambulatorial.

Apesar da sessão de caminhada proposta neste estudo ter promovido HPE em pacientes com $\mathrm{Cl}$, a relevância clínica desta resposta parece ser pequena, visto que a magnitude do efeito hipotensor foi significante, mas este efeito não perdurou por um prolongado período de tempo. Entretanto, outros protocolos de exercício ou mesmo a associação do exercício a diferentes medicamentos pode potencializar o efeito hipotensor, aumentando sua duração e garantindo sua manutenção durante o período ambulatorial, o que precisa ser investigado no futuro. 
Outro aspecto interessante é que um estudo recente conduzido por LIU et al. (LIU et al., 2012) que observou em indivíduos pré-hipertensos, que a magnitude da redução da pressão arterial após uma única sessão de exercício aeróbico apresenta relação direta com a redução crônica desta pressão após um período de treinamento. Em outras palavras, indivíduos que apresentam maior HPE apresentam também maior redução da pressão arterial após um período de treinamento físico. Assim, se esta associação também ocorrer em pacientes com $\mathrm{Cl}$, o que ainda não foi investigado, a HPE poderá ser utilizada como uma estratégia clínica para identificar pacientes com maior possibilidade de apresentar benefícios cardiovasculares com a prática continua de caminhada. Estes aspectos levantam uma interessante linha de investigação para o futuro.

5.3 Mecanismos da Hipotensão Pós-Exercício de Caminhada em Pacientes com Claudicação Intermitente

Pelo nosso conhecimento, este foi o primeiro estudo que investigou os possíveis mecanismos mediadores da HPE em pacientes com $\mathrm{Cl}$. Considerando-se os principais determinantes hemodinâmicos da pressão arterial, o DC e a RVS, os resultados do presente estudo indicaram que, na amostra em geral, houve diminuição do DC tanto na sessão controle como na sessão de exercício. Porém, após a sessão controle, a redução do DC foi compensada por um aumento da RVS, que resultou em aumento da PAS e também da PAD. Por outro lado, após a sessão de caminhada, não houve aumento da RVS, de modo que a redução do $D C$ não foi compensada e, portanto, observou-se redução da PAS e manutenção da PAD, caracterizando o efeito hipotensor da caminhada. Diante desta análise, é possível dizer que a HPE de caminhada em pacientes com $\mathrm{Cl}$ se deveu ao efeito do exercício impedindo o aumento da RVS que compensaria a redução do DC. De fato, outros estudos (HAGBERG, MONTAIN e MARTIN, 1987; RUECKERT et al., 1996; BRANDAO RONDON et al., 2002) também observaram efeito semelhante do exercício aeróbico no DC e RVS, principalmente, em indivíduos idosos hipertensos.

Considerando-se a resposta da RVS, seu aumento numa situação de repouso pode parecer estranho a princípio, no entanto, ele pode ser explicado pelo fato das 
sessões experimentais terem sido realizadas no período da manhã (entre as 7 e 12 horas), de modo que o aumento poderia ser decorrente das alterações circadianas. Sabe-se que pela manhã, ocorre aumento dos níveis plasmáticos de catecolaminas e de angiotensina, o que aumenta a RVS (PANZA, EPSTEIN e QUYYUMI, 1991). É interessante observar que este aumento da RVS na sessão controle se acompanhou de aumento da resistência vascular do antebraço e da perna, sugerindo que, pelo menos em parte, este efeito se deve à vasoconstrição muscular em diferentes partes do corpo.

Como a sessão de exercício também foi realizada pela manhã, esperar-se-ia também um aumento da RVS após esta sessão devido aos ajustes circadianos. Em adição, após o exercício físico, o retorno venoso diminuiu, de modo que os receptores cardiopulmonares foram desativados, o que deveria aumentar a atividade nervosa simpática periférica e, consequentemente, a RVS (HALLIWILL, 2001). No entanto, os resultados deste estudo demonstraram que a RVS não aumentou após o exercício, o que sugere que o exercício agiu nos mecanismos de regulação cardiovascular periférica. Neste sentido, o exercício pode apresentar efeito simpatolítico pós-exercício (FLORAS et al., 1989; HARA e FLORAS, 1992; HALLIWILL, TAYLOR e ECKBERG, 1996). Diversos estudos demonstraram que uma sessão de exercício aeróbico é capaz de diminuir a atividade nervosa simpática periférica medida diretamente no nervo fibular pós-exercício (FLORAS et al., 1989; HARA e FLORAS, 1992; HALLIWILL, TAYLOR e ECKBERG, 1996; DICARLO, STAHL e BISHOP, 1997; BISQUOLO et al., 2005). Além disso, alguns autores (HALLIWILL, TAYLOR e ECKBERG, 1996) sugerem que a resposta vasoconstrictora está deprimida após o exercício. Assim, é possível que, no presente estudo, o exercício tenha impedido o aumento da atividade simpática periférica promovida pelo ritmo circadiano e pela desativação cardiopulmonar e tenha também reduzido à resposta vasoconstrictora à ativação simpática nos músculos periféricos, o que resultou na manutenção das resistências vasculares do antebraço e da perna pósexercício, garantindo a manutenção da RVS.

No presente estudo, no entanto, não foi possível observar nenhum efeito do exercício na variabilidade da pressão arterial, que é um marcador da modulação simpática vasomotora (Heart rate variability: standards of measurement, physiological interpretation and clinical use. Task Force of the European Society of Cardiology and the North American Society of Pacing and Electrophysiology, 1996). 
Alguns aspectos, entretanto, podem ser levantados para explicar esta ausência de efeito sobre a variabilidade da pressão arterial. Inicialmente, devido a problemas metodológicos, o número de sujeitos analisados nesta variável foi pequeno, o que pode ter reduzido o poder da análise estatística em detectar diferenças. Um segundo aspecto é que a análise da variabilidade da pressão arterial é uma ferramenta de avaliação mais global, que analisa a modulação simpática vasomotora para todo o organismo juntamente com a capacidade do vaso de responder a esta modulação, enquanto que a medida direta da atividade nervosa simpática no nervo fibular mede apenas a atividade simpática muscular para este território (Heart rate variability: standards of measurement, physiological interpretation and clinical use. Task Force of the European Society of Cardiology and the North American Society of Pacing and Electrophysiology, 1996; PAGANI et al., 1997; BRUNO et al., 2012). Desta forma, é provável que o exercício tenha impedido o aumento da atividade simpática muscular, o que resultou na manutenção da resistência vascular do antebraço e da perna, mas não tenha modificado a modulação simpática vasomotora para outras partes do organismo, o que foi avaliado pela variabilidade da pressão arterial. Esses dados corroboram com um estudo realizado por WILKINS et al. (WILKINS, MINSON e HALLIWILL, 2004) que também não observou alteração da modulação simpática vasomotora após o exercício aeróbico quando esta foi avaliada pela variabilidade da pressão arterial.

Cabe ainda ressaltar que o exercício prévio, embora tenha impedido o aumento da resistência vascular de antebraço e perna, não modificou a função vasodilatadora nestas regiões. Em outras populações sem DAP, alguns estudos (BOUSQUET-SANTOS, SOARES e NOBREGA, 2005; CURRIE, MCKELVIE e MACDONALD, 2012) observaram aumento da capacidade vasodilatadora no período pós-exercício aeróbico. Contudo, apesar do exercício físico estimular a liberação de substâncias vasodilatadoras durante a sua execução, tais como óxido nítrico, prostaglandinas, histaminas e outras (THOMAS e SEGAL, 2004), pacientes com $\mathrm{Cl}$ apresentam aumento da síntese de marcadores pró-inflamatórios após a realização de caminhada (SIGNORELLI et al., 2003). Desta forma, no período pósexercício, é possível que o balanço entre a liberação de substâncias vasodilatadoras e vasoconstritoras nos pacientes com $\mathrm{Cl}$ tenha resultado no impedimento da vasoconstrição, mas não tenha sido capaz de potencializar a resposta vasodilatadora a estímulos. 
Considerando-se a redução do DC, é interessante observar que apesar desta diminuição ser semelhante após as duas sessões experimentais, ela se deveu a mecanismos diferentes em cada sessão. Após a sessão controle, a redução do DC ocorreu em função da diminuição da FC, enquanto que após a sessão de exercício, ela se deveu à diminuição do VS. Assim, a caminhada diminuiu o DC a partir da redução do VS. Estes resultados também já foram relatados em vários estudos envolvendo outras populações e o exercício aeróbico, como jovens normotensos (SENITKO, CHARKOUDIAN e HALLIWILL, 2002; DUJIC et al., 2006) e idosos hipertensos (HAGBERG, MONTAIN e MARTIN, 1987; BRANDAO RONDON et al., 2002).

Os mecanismos responsáveis pela redução do VS após o exercício não fazem parte do escopo deste estudo, mas podem ser hipotetizados. O aumento da pós-carga, a redução da pré-carga e a redução da contratilidade cardíaca podem estar envolvidos numa redução de VS. No entanto, o aumento da pós-carga não parece ser uma explicação plausível no presente estudo, uma vez que a RVS não aumentou na sessão de exercício. A redução da contratilidade cardíaca também não aparece ser adequada, uma vez que BRANDÃO RONDON et al (BRANDAO RONDON et al., 2002) analisando o efeito de 45 min de exercício aeróbico em 50\% do $\mathrm{VO}_{2}$ pico em indivíduos idosos hipertensos não observaram alterações expressivas na fração de ejeção no período pós-exercício. Desta forma, a hipótese mais provável é a diminuição da pré-carga. De fato, um estudo conduzido por HALLIWILL et (HALLIWILL, MINSON e JOYNER, 2000) observou que após o exercício físico aeróbico houve redução da pressão venosa central, refletindo em uma redução do retorno venoso que explicaria a diminuição do VS. Esta redução da pré-carga pode ser atribuída à redução do volume plasmático ou ao aumento da complacência venosa. A redução do volume plasmático parece não ser uma explicação adequada, pois um estudo conduzido por nosso grupo observou que o volume plasmático retornou aos valores pré-exercício alguns minutos após o exercício (LOBO, 2011), enquanto que a HPE perdurou por um tempo mais prolongado. Assim, a redução da pré-carga deve ser mediada pelo aumento da complacência venosa, o que já foi sugerido por outros autores (GREEN et al., 2011).

$\mathrm{Na}$ sessão controle, a redução do DC se deveu à diminuição da FC. Analisando-se as respostas hemodinâmicas e autonômicas observadas nesta sessão, é possível sugerir que o aumento da pressão arterial que ocorreu com o 
passar do tempo nesta sessão deve ter estimulado os barorreceptores arteriais, promovendo modificação na modulação autonômica cardíaca (CHEN e BONHAM, 2010), o que no presente estudo foi evidenciado pelo aumento da variância total e dos componentes absolutos das bandas de baixa e alta frequência da variabilidade da FC. O aumento destes índices indica uma modificação da modulação autonômica cardíaca em direção ao predomínio parassimpático (Heart rate variability: standards of measurement, physiological interpretation and clinical use. Task Force of the European Society of Cardiology and the North American Society of Pacing and Electrophysiology, 1996). Estes efeitos devem ter sido potencializados pelo aumento da sensibilidade barorreflexa nesta sessão e resultaram na redução da FC.

Diferentemente, após a sessão de exercício, a FC não se modificou, mas deixou de diminuir como observado na sessão controle, o que implica que a caminhada teve um efeito estimulador sobre a FC. Um possível mecanismo para esta resposta é o fato do exercício prévio ter reduzido a pressão arterial, o que deve ter desativado o barorreflexo, estimulando a aumento da modulação simpática e reduzindo a modulação vagal cardíaca (CHANDLER, RODENBAUGH e DICARLO, 1998). Outro aspecto é que a redução do retorno venoso pode ter desativado o receptores cardiopulmonares, causando a mesma alteração autonômica cardíaca (BROWN et al., 2003). Estes efeitos devem ter impedido as modificações autonômicas observadas na sessão controle, de modo que a variância total e os poderes absolutos das bandas de baixa e alta frequência da variabilidade da FC deixaram de aumentar, impedindo a redução da FC. A resposta de manutenção da FC após uma sessão de exercício aeróbico foi relatada por alguns autores (RUECKERT et al., 1996; MACDONALD et al., 2002), mas difere da resposta observada por outros que verificaram aumento significante da FC no período de recuperação pós-exercício (FLORAS et al., 1989; CLEROUX et al., 1992; POBER, BRAUN e FREEDSON, 2004; LIU et al., 2012). Alguns fatores, como a intensidade do exercício pode explicar estas diferenças. Aumentos da modulação simpática cardíaca e da FC no período pós-exercício têm sido relatados após exercícios de intensidade mais elevada (JAMES et al., 2012). No presente estudo, o exercício foi realizado numa intensidade correspondente ao primeiro limiar ventilatório, o que corresponde a uma intensidade leve (HENRITZE et al., 1985) e, por este motivo, a FC pode não ter permanecido elevada no período de recuperação, mas deixou de diminuir. 


\subsection{Limitações do Estudo}

Como todas as investigações, este estudo apresenta algumas limitações que devem ser consideradas na interpretação e extrapolação de seus resultados. Todos os pacientes que participaram do estudo eram do gênero masculino e se encontravam no estágio II da DAP, de modo que estes resultados não podem ser extrapolados para pacientes do gênero feminino e em outros estágios da doença (assintomáticos e estágio III e IV). Não foram incluídos pacientes em uso de medicamentos que poderiam afetar as respostas da avaliação da variabilidade da frequência FC e da pressão arterial, tais como beta-bloqueadores, bloqueadores de canal de cálcio não-dihidropiridinos e vasodilatadores periféricos, de modo que os resultados não podem ser extrapolados para pacientes com $\mathrm{Cl}$ em uso dessas medicações. Além disso, os pacientes estavam em uso de diferentes tipos de medicamento, o que pode ter afetado as resposta e não permite avaliar a interação entre o exercício e nenhuma classe específica de medicamento. Porém, os pacientes como DAP têm várias comorbidades e, normalmente, recebem medicamentos diferentes para cada uma delas (DOBESH, STACY e PERSSON, 2009). Assim, o fato da amostra receber diferentes medicamentos aumenta a aplicabilidade prática dos resultados.

Este estudo envolveu um protocolo de exercício em esteira com duração de 30 min e realizado de forma intervalada com uma relação esforço pausa de 2 para 2 min e com uma intensidade baseada na FC do limiar de dor. Os resultados, portanto, são válidos para este protocolo de treinamento, de modo que outros protocolos precisam ser testados.

Devido a problemas metodológicos, o número de sujeitos analisados para as variáveis autonômicas foi menor que para as variáveis hemodinâmicas, o que pode ter reduzido o poder da análise estatística em detectar diferenças para essas variáveis. Este aspecto pode ter influenciado a análise da banda de baixa frequência normalizada, visto que esta variável não apresentou modificação significante apesar da banda de baixa frequência absoluta e da variância total, que também espelham a modulação vagal, terem apresentado diferenças significantes entre as sessões. Cabe ainda ressaltar que a avaliação do controle autonômico para o coração e 
vasos foi realizada de forma indireta, utilizando sinais de pressão arterial e FC, o que possibilita a avaliação da modulação e não a atividade desses sistemas.

Adicionalmente, também na avalição das variáveis vasculares, o número de sujeitos foi menor que nas variáveis hemodinâmicas. Este aspecto parece ter influenciado apenas a avaliação do fluxo sanguíneo da perna, visto que a resistência vascular nesta região diferiu entre as sessões, mas este efeito não pode ser observado no fluxo apesar de haver uma tendência a significância $(p=0,06)$.

\section{CONCLUSÃO}

Em pacientes com Cl, uma sessão de caminhada foi capaz de promover HPE por 60 min no ambiente clínico, que não se manteve nas horas subsequentes em condições ambulatoriais. O efeito hipotensor se associou ao efeito do exercício impedindo o aumento da RVS que compensaria a redução do DC promovida pela diminuição do VS. O efeito do exercício sobre a resistência vascular foi verificado tanto na região ativa quanto inativa. Além disso, o efeito hipotensor do exercício se acompanhou de um efeito sobre a modulação parassimpática cardíaca, impedindo seu aumento ao longo do tempo e, consequentemente, impedindo a redução da FC apesar da diminuição do VS. 


\section{REFERENCIAS}

ABOYANS, V., CRIQUI, M. H., ABRAHAM, P., ALLISON, M. A., CREAGER, M. A., DIEHM, C., FOWKES, F. G., HIATT, W. R., JONSSON, B., LACROIX, P., MARIN, B., MCDERMOTT, M. M., NORGREN, L., PANDE, R. L., PREUX, P. M., STOFFERS, H. E. e TREAT-JACOBSON, D. Measurement and Interpretation of the Ankle-Brachial Index: A Scientific Statement From the American Heart Association. Circulation, v. 126, n. 24, p. 2890-909, 2012.

ANUNCIAÇÃO, P. G. e POLITO, M. D. Hipotensão Pós-exercício em Indivíduos Hipertensos: uma Revisão. Arq Bras Cardiol, v. 96, n., p. e100-e9, 2011.

ARAUJO, E. A. (2007). Respostas hemodinâmicas e autonômicas pós-exercício: influência da massa muscular, da intensidade relativa e do gasto energético total do exercício. Departamento de Biodinâmica do Movimento do Corpo Humano. Sâo Paulo, Escola de Educação Física e Esporte da Universidade de São Paulo, São Paulo. Mestrado.

BACCELLI, G., REGGIANI, P., MATTIOLI, A., CORBELLINI, E., GARDUCCI, S. e CATALANO, M. The exercise pressor reflex and changes in radial arterial pressure and heart rate during walking in patients with arteriosclerosis obliterans. Angiology, v. 50, n. 5, p. 361-74, 1999.

BARRETT-O'KEEFE, Z., KAPLON, R. E. e HALLIWILL, J. R. Sustained postexercise vasodilatation and histamine-receptor activation following small muscle-mass exercise in humans. Exp Physiol, v. 98, n. 1, p. 268-77, 2013.

BENDERMACHER, B. L., WILLIGENDAEL, E. M., TEIJINK, J. A. e PRINS, M. H. Supervised exercise therapy versus non-supervised exercise therapy for intermittent claudication. Cochrane Database Syst Rev, v. n. 2, p. CD005263, 2006.

BENNETT, T., WILCOX, R. G. e MACDONALD, I. A. Post-exercise reduction of blood pressure in hypertensive men is not due to acute impairment of baroreflex function. Clin Sci (Lond), v. 67, n. 1, p. 97-103, 1984.

BERGER, J. S., KRANTZ, M. J., KITTELSON, J. M. e HIATT, W. R. Aspirin for the prevention of cardiovascular events in patients with peripheral artery disease: a meta-analysis of randomized trials. JAMA, v. 301, n. 18, p. 1909-19, 2009.

BHATT, D. L., STEG, P. G., OHMAN, E. M., HIRSCH, A. T., IKEDA, Y., MAS, J. L., GOTO, S., LIAU, C. S., RICHARD, A. J., ROTHER, J. e WILSON, P. W. International prevalence, recognition, and treatment of cardiovascular risk factors in outpatients with atherothrombosis. JAMA, v. 295, n. 2, p. 180-9, 2006.

BISQUOLO, V. A., CARDOSO, C. G., JR., ORTEGA, K. C., GUSMAO, J. L., TINUCCI, T., NEGRAO, C. E., WAJCHENBERG, B. L., MION, D., JR. e FORJAZ, C. L. Previous exercise attenuates muscle sympathetic activity and 
increases blood flow during acute euglycemic hyperinsulinemia. J Appl Physiol, v. 98, n. 3, p. 866-71, 2005.

BLANCHARD, B. E., TSONGALIS, G. J., GUIDRY, M. A., LABELLE, L. A., POULIN, M., TAYLOR, A. L., MARESH, C. M., DEVANEY, J., THOMPSON, P. D. e PESCATELLO, L. S. RAAS polymorphisms alter the acute blood pressure response to aerobic exercise among men with hypertension. Eur $\mathbf{J}$ Appl Physiol, v. 97, n. 1, p. 26-33, 2006.

BOULTON, A. J., VINIK, A. I., AREZZO, J. C., BRIL, V., FELDMAN, E. L., FREEMAN, R., MALIK, R. A., MASER, R. E., SOSENKO, J. M. e ZIEGLER, D. Diabetic neuropathies: a statement by the American Diabetes Association. Diabetes Care, v. 28, n. 4, p. 956-62, 2005.

BOUSQUET-SANTOS, K., SOARES, P. P. e NOBREGA, A. C. Subacute effects of a maximal exercise bout on endothelium-mediated vasodilation in healthy subjects. Braz J Med Biol Res, v. 38, n. 4, p. 621-7, 2005.

BRANDAO RONDON, M. U., ALVES, M. J., BRAGA, A. M., TEIXEIRA, O. T., BARRETTO, A. C., KRIEGER, E. M. e NEGRAO, C. E. Postexercise blood pressure reduction in elderly hypertensive patients. J Am Coll Cardiol, v. 39, n. 4, p. 676-82, 2002.

BREVETTI, G., SCHIANO, V. e CHIARIELLO, M. Endothelial dysfunction: a key to the pathophysiology and natural history of peripheral arterial disease? Atherosclerosis, v. 197, n. 1, p. 1-11, 2008.

BROWN, C. M., HECHT, M. J., NEUNDORFER, B. e HILZ, M. J. Effects of lower body negative pressure on cardiac and vascular responses to carotid baroreflex stimulation. Physiol Res, v. 52, n. 5, p. 637-45, 2003.

BRUNO, R. M., GHIADONI, L., SERAVALLE, G., DELL'ORO, R., TADDEI, S. e GRASSI, G. Sympathetic regulation of vascular function in health and disease. Front Physiol, v. 3, n., p. 284, 2012.

CARDOSO, C. G., JR. (2005). Efeito da massa muscular exercitada sobre as respostas hemodinâmicas pós-exercício. Departamento de Biodinâmica do Movimento do Corpo Humano. São Paulo, Escola de Educação Física e Esporte da Universidade de São Paulo, São Paulo. Mestrado.

CARDOSO, C. G., JR., GOMIDES, R. S., QUEIROZ, A. C., PINTO, L. G., DA SILVEIRA LOBO, F., TINUCCI, T., MION, D., JR. e DE MORAES FORJAZ, C. L. Acute and chronic effects of aerobic and resistance exercise on ambulatory blood pressure. Clinics (Sao Paulo), v. 65, n. 3, p. 317-25, 2010.

CHANDLER, M. P., RODENBAUGH, D. W. e DICARLO, S. E. Arterial baroreflex resetting mediates postexercise reductions in arterial pressure and heart rate. Am J Physiol, v. 275, n. 5 Pt 2, p. H1627-34, 1998. 
CHEHUEN, M. R., CUCATO, G. G. e FORJAZ, C. L. M. Caminhada e risco cardiovascular em pacientes com claudicação intermitente: uma revisão de literatura. Rev Soc Cardiol Estado de São Paulo, v. 22, n. 4 Supl A, p. 3-6, 2012.

CHEN, C. Y. e BONHAM, A. C. Postexercise hypotension: central mechanisms. Exerc Sport Sci Rev, v. 38, n. 3, p. 122-7, 2010.

CHODZKO-ZAJKO, W. J., PROCTOR, D. N., FIATARONE SINGH, M. A., MINSON, C. T., NIGG, C. R., SALEM, G. J. e SKINNER, J. S. American College of Sports Medicine position stand. Exercise and physical activity for older adults. Med Sci Sports Exerc, v. 41, n. 7, p. 1510-30, 2009.

CleRouX, J., KOUAME, N., NADEAU, A., COULOMBE, D. e LACOURCIERE, Y. Aftereffects of exercise on regional and systemic hemodynamics in hypertension. Hypertension, v. 19, n. 2, p. 183-91, 1992.

CleROUX, J., KOUAME, N., NADEAU, A., COULOMBE, D. e LACOURCIERE, Y. Baroreflex regulation of forearm vascular resistance after exercise in hypertensive and normotensive humans. Am J Physiol, v. 263, n. 5 Pt 2, p. H1523-31, 1992.

CRIQUI, M. H., LANGER, R. D., FRONEK, A., FEIGELSON, H. S., KLAUBER, M. R., MCCANN, T. J. e BROWNER, D. Mortality over a period of 10 years in patients with peripheral arterial disease. N Engl J Med, v. 326, n. 6, p. 381-6, 1992.

CRIQUI, M. H., VARGAS, V., DENENBERG, J. O., HO, E., ALLISON, M., LANGER, R. D., GAMST, A., BUNDENS, W. P. e FRONEK, A. Ethnicity and peripheral arterial disease: the San Diego Population Study. Circulation, v. 112, n. 17, p. 2703-7, 2005.

CUCATO, G. G., CHEHUEN, M. R., COSTA, L. A. R., RITTI-DIAS, R. M., WOLOSKER, N., SAXTON, J. M. e FORJAZ, C. L. M. Exercise prescription using heart rate at the onset of claudication pain in patients with intermittent claudication. Clinics (Sao Paulo), 2013. No Prelo.

CUCATO, G. G., RITTI-DIAS, R. M., WOLOSKER, N., SANTAREM, J. M., JACOB FILHO, W. e FORJAZ, C. L. Post-resistance exercise hypotension in patients with intermittent claudication. Clinics (Sao Paulo), v. 66, n. 2, p. 221-6, 2011.

CURRIE, K. D., MCKELVIE, R. S. e MACDONALD, M. J. Flow-mediated dilation is acutely improved after high-intensity interval exercise. Med Sci Sports Exerc, v. 44, n. 11, p. 2057-64, 2012.

DICARLO, S. E., STAHL, L. K. e BISHOP, V. S. Daily exercise attenuates the sympathetic nerve response to exercise by enhancing cardiac afferents. Am $\mathbf{J}$ Physiol, v. 273, n. 3 Pt 2, p. H1606-10, 1997. 
DOBESH, P. P., STACY, Z. A. e PERSSON, E. L. Pharmacologic therapy for intermittent claudication. Pharmacotherapy, v. 29, n. 5, p. 526-53, 2009.

DUJIC, Z., IVANCEV, V., VALIC, Z., BAKOVIC, D., MARINOVIC-TERZIC, I., ETEROVIC, D. e WISLOFF, U. Postexercise hypotension in moderately trained athletes after maximal exercise. Med Sci Sports Exerc, v. 38, n. 2, p. 318-22, 2006.

EICHER, J. D., MARESH, C. M., TSONGALIS, G. J., THOMPSON, P. D. e PESCATELLO, L. S. The additive blood pressure lowering effects of exercise intensity on post-exercise hypotension. Am Heart J, v. 160, n. 3, p. 513-20, 2010.

ENDO, M. Y., SHIMADA, K., MIURA, A. e FUKUBA, Y. Peripheral and central vascular conductance influence on post-exercise hypotension. J Physiol Anthropol, v. 31, p. 32, 2012.

FLORAS, J. S., SINKEY, C. A., AYLWARD, P. E., SEALS, D. R., THOREN, P. N. e MARK, A. L. Postexercise hypotension and sympathoinhibition in borderline hypertensive men. Hypertension, v. 14, n. 1, p. 28-35, 1989.

FLORAS, J. S. e WESCHE, J. Haemodynamic contributions to post-exercise hypotension in young adults with hypertension and rapid resting heart rates. $\mathbf{J}$ Hum Hypertens, v. 6, n. 4, p. 265-9, 1992.

FONTAINE, R., KIM, M. e KIENY, R. [Surgical treatment of peripheral circulation disorders.]. Helv Chir Acta, v. 21, n. 5-6, p. 499-533, 1954.

FOOT, D. K., LEWIS, R. P., PEARSON, T. A. e BELLER, G. A. Demographics and cardiology, 1950-2050. J Am Coll Cardiol, v. 35, n. 5 Suppl B, p. 66B-80B, 2000.

FORJAZ, C. L., CARDOSO, C. G., JR., REZK, C. C., SANTAELLA, D. F. e TINUCCI, T. Postexercise hypotension and hemodynamics: the role of exercise intensity. J Sports Med Phys Fitness, v. 44, n. 1, p. 54-62, 2004.

FORJAZ, C. L., MATSUDAIRA, Y., RODRIGUES, F. B., NUNES, N. e NEGRAO, C. $E$. Post-exercise changes in blood pressure, heart rate and rate pressure product at different exercise intensities in normotensive humans. Braz $\mathbf{J}$ Med Biol Res, v. 31, n. 10, p. 1247-55, 1998.

FORJAZ, C. L., RAMIRES, P. R., TINUCCI, T., ORTEGA, K. C., SALOMAO, H. E., IGNES, E. C., WAJCHENBERG, B. L., NEGRAO, C. E. e MION, D., JR. Postexercise responses of muscle sympathetic nerve activity and blood flow to hyperinsulinemia in humans. J Appl Physiol, v. 87, n. 2, p. 824-9, 1999.

FORJAZ, C. L., SANTAELLA, D. F., REZENDE, L. O., BARRETTO, A. C. e NEGRAO, C. E. Effect of exercise duration on the magnitude and duration of post-exercise hypotension. Arq Bras Cardiol, v. 70, n. 2, p. 99-104, 1998. 
FORJAZ, C. L., TINUCCI, T., ORTEGA, K. C., SANTAELLA, D. F., MION, D., JR. e NEGRAO, C. E. Factors affecting post-exercise hypotension in normotensive and hypertensive humans. Blood Press Monit, v. 5, n. 5-6, p. 255-62, 2000.

FORJAZ, C. L. D. M. (2007). Hipotensão Pós-Exercício: caracterização, fatores de influência e mecanismos. Departamento de Biodinâmica do Movimento do Corpo Humano. São Paulo, Escola de Educação Física e Esporte da Universidade de São Paulo, São Paulo. Livre Docência.

FORJAZ, C. L. M., SANTAELLA, D. F., BARRETO, A. C. P. e NEGRAO, C. E. A duração do exercício determina a magnitude e a duração da hipotensão pósexercício. Arq Bras Cardiol, v. 70, n. 2, p. 99-104, 1998.

GARDNER, A. W., KATZEL, L. I., SORKIN, J. D., KILLEWICH, L. A., RYAN, A., FLINN, W. R. e GOLDBERG, A. P. Improved functional outcomes following exercise rehabilitation in patients with intermittent claudication. J Gerontol A Biol Sci Med Sci, v. 55, n. 10, p. M570-7, 2000.

GARDNER, A. W. e MONTGOMERY, P. S. Comparison of three blood pressure methods used for determining ankle/brachial index in patients with intermittent claudication. Angiology, v. 49, n. 9, p. 723-8, 1998.

GARDNER, A. W., MONTGOMERY, P. S. e AFAQ, A. Exercise performance in patients with peripheral arterial disease who have different types of exertional leg pain. J Vasc Surg, v. 46, n. 1, p. 79-86, 2007.

GARDNER, A. W., MONTGOMERY, P. S., FLINN, W. R. e KATZEL, L. I. The effect of exercise intensity on the response to exercise rehabilitation in patients with intermittent claudication. J Vasc Surg, v. 42, n. 4, p. 702-9, 2005.

GARDNER, A. W. e POEHLMAN, E. T. Exercise rehabilitation programs for the treatment of claudication pain. A meta-analysis. JAMA, v. 274, n. 12, p. 97580, 1995.

GARDNER, A. W., RITTI-DIAS, R. M., STONER, J. A., MONTGOMERY, P. S., SCOTT, K. J. e BLEVINS, S. M. Walking economy before and after the onset of claudication pain in patients with peripheral arterial disease. J Vasc Surg, v. 51, n. 3, p. 628-33, 2010.

GARDNER, A. W., SKINNER, J. S., CANTWELL, B. W. e SMITH, L. K. Progressive vs single-stage treadmill tests for evaluation of claudication. Med Sci Sports Exerc, v. 23, n. 4, p. 402-8, 1991.

GOERNIG, M., SCHROEDER, R., ROTH, T., TRUEBNER, S., PALUTKE, I., FIGULLA, H. R., LEDER, U. e VOSS, A. Peripheral arterial disease alters heart rate variability in cardiovascular patients. Pacing Clin Electrophysiol, v. 31, n. 7, p. 858-62, 2008.

GOLBIDI, S. e LAHER, I. Exercise and the cardiovascular system. Cardiol Res Pract, v. 2012, p. 210852, 2012. 
GREEN, D. J., SPENCE, A., HALLIWILL, J. R., CABLE, N. T. e THIJSSEN, D. H. Exercise and vascular adaptation in asymptomatic humans. Exp Physiol, v. 96, n. 2, p. 57-70, 2011.

GRIZZO CUCATO, G., DE MORAES FORJAZ, C. L., KANEGUSUKU, H., DA ROCHA CHEHUEN, M., RIANI COSTA, L. A., WOLOSKER, N., KALIL FILHO, R., DE FATIMA NUNES MARUCCI, M. e MENDES RITTI-DIAS, R. Effects of walking and strength training on resting and exercise cardiovascular responses in patients with intermittent claudication. Vasa, v. 40, n. 5, p. 3907, 2011.

HAGBERG, J. M., MONTAIN, S. J. e MARTIN, W. H., 3RD. Blood pressure and hemodynamic responses after exercise in older hypertensives. $J$ Appl Physiol, v. 63, n. 1, p. 270-6, 1987.

HALLIWILL, J. R. Mechanisms and clinical implications of post-exercise hypotension in humans. Exerc Sport Sci Rev, v. 29, n. 2, p. 65-70, 2001.

HALLIWILL, J. R., BUCK, T. M., LACEWELL, A. N. e ROMERO, S. A. Postexercise hypotension and sustained postexercise vasodilatation: what happens after we exercise? Exp Physiol, v. 98, n. 1, p. 7-18, 2013.

HALLIWILL, J. R., DIETZ, N. M. e JOYNER, M. J. Active vasodilation during fainting: a hypothesis revisited. Clin Auton Res, v. 6, n. 4, p. 233-6, 1996.

HALLIWILL, J. R., MINSON, C. T. e JOYNER, M. J. Effect of systemic nitric oxide synthase inhibition on postexercise hypotension in humans. J Appl Physiol, v. 89 , n. 5 , p. $1830-6,2000$.

HALLIWILL, J. R., TAYLOR, J. A. e ECKBERG, D. L. Impaired sympathetic vascular regulation in humans after acute dynamic exercise. J Physiol, v. 495 ( Pt 1), n., p. 279-88, 1996.

HALLIWILL, J. R., TAYLOR, J. A., HARTWIG, T. D. e ECKBERG, D. L. Augmented baroreflex heart rate gain after moderate-intensity, dynamic exercise. Am J Physiol, v. 270, n. 2 Pt 2, p. R420-6, 1996.

HALTMAYER, M., MUELLER, T., HORVATH, W., LUFT, C., POELZ, W. e HAIDINGER, D. Impact of atherosclerotic risk factors on the anatomical distribution of peripheral arterial disease. Int Angiol, v. 20, n. 3, p. 200-7, 2001.

HARA, K. e FLORAS, J. S. Effects of naloxone on hemodynamics and sympathetic activity after exercise. J Appl Physiol, v. 73, n. 5, p. 2028-35, 1992.

Heart rate variability: standards of measurement, physiological interpretation and clinical use. Task Force of the European Society of Cardiology and the North American Society of Pacing and Electrophysiology. Circulation, v. 93, n. 5, p. 1043-65, 1996. 
HENRITZE, J., WELTMAN, A., SCHURRER, R. e BARLOW, K. Effects of training at and above the lactate threshold on the lactate threshold and maximal oxygen uptake. Eur J Appl Physiol Occup Physiol., v. 54, n., p. 84-8, 1985.

HIGASHI, Y. e YOSHIZUMI, M. New methods to evaluate endothelial function: method for assessing endothelial function in humans using a strain-gauge plethysmography: nitric oxide-dependent and -independent vasodilation. J Pharmacol Sci, v. 93, n. 4, p. 399-404, 2003.

HIRSCH, A. T., HASKAL, Z. J., HERTZER, N. R., BAKAL, C. W., CREAGER, M. A., HALPERIN, J. L., HIRATZKA, L. F., MURPHY, W. R., OLIN, J. W., PUSCHETT, J. B., ROSENFIELD, K. A., SACKS, D., STANLEY, J. C., TAYLOR, L. M., JR., WHITE, C. J., WHITE, J., WHITE, R. A., ANTMAN, E. M., SMITH, S. C., JR., ADAMS, C. D., ANDERSON, J. L., FAXON, D. P., FUSTER, V., GIBBONS, R. J., HUNT, S. A., JACOBS, A. K., NISHIMURA, R., ORNATO, J. P., PAGE, R. L. e RIEGEL, B. ACC/AHA 2005 Practice Guidelines for the management of patients with peripheral arterial disease (lower extremity, renal, mesenteric, and abdominal aortic): a collaborative report from the American Association for Vascular Surgery/Society for Vascular Surgery, Society for Cardiovascular Angiography and Interventions, Society for Vascular Medicine and Biology, Society of Interventional Radiology, and the ACC/AHA Task Force on Practice Guidelines (Writing Committee to Develop Guidelines for the Management of Patients With Peripheral Arterial Disease): endorsed by the American Association of Cardiovascular and Pulmonary Rehabilitation; National Heart, Lung, and Blood Institute; Society for Vascular Nursing; TransAtlantic Inter-Society Consensus; and Vascular Disease Foundation. Circulation, v. 113, n. 11, p. e463-654, 2006.

HOFFMANN, P., DELLE, M. e THOREN, P. Role of opioid receptors in the longlasting blood pressure depression after electric muscle stimulation in the hind leg of the rat. Acta Physiol Scand, v. 140, n. 2, p. 191-8, 1990.

HOWARD, M. G. e DICARLO, S. E. Reduced vascular responsiveness after a single bout of dynamic exercise in the conscious rabbit. J Appl Physiol, v. 73, n. 6, p. 2662-7, 1992.

IRIBARREN, C., SIDNEY, S., STERNFELD, B. e BROWNER, W. S. Calcification of the aortic arch: risk factors and association with coronary heart disease, stroke, and peripheral vascular disease. JAMA, v. 283, n. 21, p. 2810-5, 2000.

IV Diretriz Brasileira sobre Dislipidemias e Prevenção da Aterosclerose. Departamento de Aterosclerose da Sociedade Brasileira de Cardiologia Arq Bras Cardiol, v. 88, n. Suplemento 1, p. 1-19, 2007.

IZQUIERDO-PORRERA, A. M., GARDNER, A. W., POWELL, C. C. e KATZEL, L. I. Effects of exercise rehabilitation on cardiovascular risk factors in older patients with peripheral arterial occlusive disease. J Vasc Surg, v. 31, n. 4, p. 670-7, 2000. 
JAMES, D. V., MUNSON, S. C., MALDONADO-MARTIN, S. e DE STE CROIX, M. B. Heart rate variability: effect of exercise intensity on postexercise response. Res Q Exerc Sport, v. 83, n. 4, p. 533-9, 2012.

JONES, H., TAYLOR, C. E., LEWIS, N. C., GEORGE, K. e ATKINSON, G. Postexercise blood pressure reduction is greater following intermittent than continuous exercise and is influenced less by diurnal variation. Chronobiol Int, v. 26, n. 2, p. 293-306, 2009.

JONES, N. L., CAMPBELL, E. J., MCHARDY, G. J., HIGGS, B. E. e CLODE, M. The estimation of carbon dioxide pressure of mixed venous blood during exercise. Clin Sci, v. 32, n. 2, p. 311-27, 1967.

JUNGERSTEN, L., AMBRING, A., WALL, B. e WENNMALM, A. Both physical fitness and acute exercise regulate nitric oxide formation in healthy humans. J Appl Physiol, v. 82, n. 3, p. 760-4, 1997.

KENNEY, M. J. e SEALS, D. R. Postexercise hypotension. Key features, mechanisms, and clinical significance. Hypertension, v. 22, n. 5, p. 653-64, 1993.

LA ROVERE, M. T., PINNA, G. D. e RACZAK, G. Baroreflex sensitivity: measurement and clinical implications. Ann Noninvasive Electrocardiol, v. 13, n. 2, p. 191-207, 2008.

LEGRAMANTE, J. M., GALANTE, A., MASSARO, M., ATTANASIO, A., RAIMONDI, G., PIGOZZI, F. e IELLAMO, F. Hemodynamic and autonomic correlates of postexercise hypotension in patients with mild hypertension. Am J Physiol Regul Integr Comp Physiol, v. 282, n. 4, p. R1037-43, 2002.

LIU, S., GOODMAN, J., NOLAN, R., LACOMBE, S. e THOMAS, S. G. Blood pressure responses to acute and chronic exercise are related in prehypertension. Med Sci Sports Exerc, v. 44, n. 9, p. 1644-52, 2012.

LOBO, F. S. (2011). Efeito da hidratação na resposta da pressão arterial pósexercício e seus mecanismos. Departamento de Biodinâmica do Movimento do Corpo Humano. São Paulo, Escola de Educação Física e Esporte da Universidade de São Paulo, São Paulo. Mestrado.

LOCKWOOD, J. M., PRICHER, M. P., WILKINS, B. W., HOLOWATZ, L. A. e HALLIWILL, J. R. Postexercise hypotension is not explained by a prostaglandin-dependent peripheral vasodilation. J Appl Physiol, v. 98, n. 2, p. 447-53, 2005.

LOCKWOOD, J. M., WILKINS, B. W. e HALLIWILL, J. R. H1 receptor-mediated vasodilatation contributes to postexercise hypotension. J Physiol, v. 563, n. Pt 2, p. 633-42, 2005.

MACDONALD, J. R. Potential causes, mechanisms, and implications of post exercise hypotension. J Hum Hypertens, v. 16, n. 4, p. 225-36, 2002. 
MACDONALD, J. R., MACDOUGALL, J. D. e HOGBEN, C. D. The effects of exercising muscle mass on post exercise hypotension. J Hum Hypertens, v. 14 , n. 5, p. 317-20, 2000.

MACDONALD, J. R., MACDOUGALL, J. D., INTERISANO, S. A., SMITH, K. M., MCCARTNEY, N., MOROZ, J. S., YOUNGLAI, E. V. e TARNOPOLSKY, M. A. Hypotension following mild bouts of resistance exercise and submaximal dynamic exercise. Eur J Appl Physiol Occup Physiol, v. 79, n. 2, p. 148-54, 1999.

MACDONALD, J. R., ROSENFELD, J. M., TARNOPOLSKY, M. A., HOGBEN, C. D., BALLANTYNE, C. S. e MACDOUGALL, J. D. Post exercise hypotension is not mediated by the serotonergic system in borderline hypertensive individuals. $\mathbf{J}$ Hum Hypertens, v. 16, n. 1, p. 33-9, 2002.

MAHONEY, E. M., WANG, K., KEO, H. H., DUVAL, S., SMOLDEREN, K. G., COHEN, D. J., STEG, G., BHATT, D. L. e HIRSCH, A. T. Vascular hospitalization rates and costs in patients with peripheral artery disease in the United States. Circ Cardiovasc Qual Outcomes, v. 3, n. 6, p. 642-51, 2010.

MAKDISSE, M., PEREIRA ADA, C., BRASIL DDE, P., BORGES, J. L., MACHADOCOELHO, G. L., KRIEGER, J. E., NASCIMENTO NETO, R. M. e CHAGAS, A. C. Prevalence and risk factors associated with peripheral arterial disease in the Hearts of Brazil Project. Arq Bras Cardiol, v. 91, n. 6, p. 370-82, 2008.

MANNARINO, E., PASQUALINI, L., INNOCENTE, S., SCRICCIOLO, V., RIGNANESE, A. e CIUFFETTI, G. Physical training and antiplatelet treatment in stage II peripheral arterial occlusive disease: alone or combined? Angiology, v. 42, n. 7, p. 513-21, 1991.

MAZARI, F. A., KHAN, J. A., CARRADICE, D., SAMUEL, N., ABDUL RAHMAN, M. N., GULATI, S., LEE, H. L., MEHTA, T. A., MCCOLLUM, P. T. e CHETTER, I. C. Randomized clinical trial of percutaneous transluminal angioplasty, supervised exercise and combined treatment for intermittent claudication due to femoropopliteal arterial disease. Br J Surg, v. 99, n. 1, p. 39-48, 2012.

MCCORD, J. L., BEASLEY, J. M. e HALLIWILL, J. R. H2-receptor-mediated vasodilation contributes to postexercise hypotension. J Appl Physiol, v. 100, n. 1, p. 67-75, 2006.

MEIJER, W. T., COST, B., BERNSEN, R. M. e HOES, A. W. Incidence and management of intermittent claudication in primary care in The Netherlands. Scand J Prim Health Care, v. 20, n. 1, p. 33-4, 2002.

MULLER, M. D., DREW, R. C., BLAHA, C. A., MAST, J. L., CUI, J., REED, A. B. e SINOWAY, L. I. Oxidative Stress Contributes to the Augmented Exercise Pressor Reflex in Peripheral Arterial Disease Patients. J Physiol, 2012. 
MURABITO, J. M., D'AGOSTINO, R. B., SILBERSHATZ, H. e WILSON, W. F. Intermittent claudication. A risk profile from The Framingham Heart Study. Circulation, v. 96, n. 1, p. 44-9, 1997.

NEW, K. J., REILLY, M. E., TEMPLETON, K., ELLIS, G., JAMES, P. E., MCENENY, J., PENNEY, M., HOOPER, J., HULLIN, D., DAVIES, B. e BAILEY, D. M. Free radical-mediated lipid peroxidation and systemic nitric oxide bioavailability: implications for postexercise hemodynamics. Am J Hypertens, v. 26, n. 1, p. 126-34, 2013.

NICHOLSON, C. D., ANGERSBACH, D. e WILKE, R. The effect of physical training on rat calf muscle, oxygen tension, blood flow, metabolism and function in an animal model of chronic occlusive peripheral vascular disease. Int $\mathbf{J}$ Sports Med, v. 13, n. 1, p. 60-4, 1992.

NORGREN, L., HIATT, W. R., DORMANDY, J. A., NEHLER, M. R., HARRIS, K. A., FOWKES, F. G. e RUTHERFORD, R. B. Inter-society consensus for the management of peripheral arterial disease. Int Angiol, v. 26, n. 2, p. 81-157, 2007.

Normas de Orientação Clínica para Prevenção, Diagnóstico e Tratamento da Doença Arterial Obstrutiva Periférica (DAOP) (2005). Jornal Vascular Brasileiro - Cirurgia Vascular, Endovascular e Angiologia. 4: S 222-38.

NOSE, H., MACK, G. W., SHI, X. R. e NADEL, E. R. Role of osmolality and plasma volume during rehydration in humans. J Appl Physiol, v. 65, n. 1, p. 325-31, 1988.

OLAMAEI, N., DUPUIS, J., NGO, Q., FINNERTY, V., VO THANG, T. T., AUTHIER, S., KHAIRY, P. e HAREL, F. Characterization and reproducibility of forearm arterial flow during reactive hyperemia. Physiol Meas, v. 31, n. 6, p. 763-73, 2010.

PAGANI, M., MONTANO, N., PORTA, A., MALLIANI, A., ABBOUD, F. M., BIRKETT, C. e SOMERS, V. K. Relationship between spectral components of cardiovascular variabilities and direct measures of muscle sympathetic nerve activity in humans. Circulation, v. 95, n. 6, p. 1441-8, 1997.

PANZA, J. A., EPSTEIN, S. E. e QUYYUMI, A. A. Circadian variation in vascular tone and its relation to alpha-sympathetic vasoconstrictor activity. $\mathbf{N}$ Engl $\mathbf{J}$ Med, v. 325, n. 14, p. 986-90, 1991.

PARMENTER, B. J., RAYMOND, J., DINNEN, P. e SINGH, M. A. A systematic review of randomized controlled trials: Walking versus alternative exercise prescription as treatment for intermittent claudication. Atherosclerosis, v. 218, n. 1, p. 1-12, 2011.

PESCATELLO, L. S., FARGO, A. E., LEACH, C. N., JR. e SCHERZER, H. H. Shortterm effect of dynamic exercise on arterial blood pressure. Circulation, v. 83, n. 5, p. 1557-61, 1991. 
PESCATELLO, L. S., FRANKLIN, B. A., FAGARD, R., FARQUHAR, W. B., KELLEY, G. A. e RAY, C. A. American College of Sports Medicine position stand. Exercise and hypertension. Med Sci Sports Exerc, v. 36, n. 3, p. 533-53, 2004.

PESCATELLO, L. S., GUIDRY, M. A., BLANCHARD, B. E., KERR, A., TAYLOR, A. L., JOHNSON, A. N., MARESH, C. M., RODRIGUEZ, N. e THOMPSON, P. D. Exercise intensity alters postexercise hypotension. J Hypertens, v. 22, n. 10, p. 1881-8, 2004.

PIEPOLI, M., COATS, A. J., ADAMOPOULOS, S., BERNARDI, L., FENG, Y. H., CONWAY, J. e SLEIGHT, P. Persistent peripheral vasodilation and sympathetic activity in hypotension after maximal exercise. J Appl Physiol, v. 75, n. 4, p. 1807-14, 1993.

POBER, D. M., BRAUN, B. e FREEDSON, P. S. Effects of a single bout of exercise on resting heart rate variability. Med Sci Sports Exerc, v. 36, n. 7, p. 1140-8, 2004.

PORTA, A., GUZZETTI, S., MONTANO, N., FURLAN, R., PAGANI, M., MALLIANI, A. e CERUTTI, S. Entropy, entropy rate, and pattern classification as tools to typify complexity in short heart period variability series. IEEE Trans Biomed Eng, v. 48, n. 11, p. 1282-91, 2001.

PRICHER, M. P., HOLOWATZ, L. A., WILLIAMS, J. T., LOCKWOOD, J. M. e HALLIWILL, J. R. Regional hemodynamics during postexercise hypotension. I. Splanchnic and renal circulations. J Appl Physiol, v. 97, n. 6, p. 2065-70, 2004.

QUEIROZ, A. C., GAGLIARDI, J. F., FORJAZ, C. L. e REZK, C. C. Clinic and ambulatory blood pressure responses after resistance exercise. J Strength Cond Res, v. 23, n. 2, p. 571-8, 2009.

QUEIROZ, A. C., REZK, C. C., TEIXEIRA, L., TINUCCI, T., MION, D. e FORJAZ, C. L. Gender Influence on Post-resistance Exercise Hypotension and Hemodynamics. Int J Sports Med, 2013.

QUINN, T. J. Twenty-four hour, ambulatory blood pressure responses following acute exercise: impact of exercise intensity. J Hum Hypertens, v. 14, n. 9, p. 54753, 2000.

REGENSTEINER, J. G., WARE, J. E., JR., MCCARTHY, W. J., ZHANG, P., FORBES, W. P., HECKMAN, J. e HIATT, W. R. Effect of cilostazol on treadmill walking, community-based walking ability, and health-related quality of life in patients with intermittent claudication due to peripheral arterial disease: meta-analysis of six randomized controlled trials. J Am Geriatr Soc, v. 50, n. 12, p. 1939-46, 2002.

REZK, C. C., MARRACHE, R. C., TINUCCI, T., MION, D., JR. e FORJAZ, C. L. Postresistance exercise hypotension, hemodynamics, and heart rate variability: 
influence of exercise intensity. Eur J Appl Physiol, v. 98, n. 1, p. 105-12, 2006.

RITTI-DIAS, R. M., DE MORAES FORJAZ, C. L., CUCATO, G. G., COSTA, L. A., WOLOSKER, N. e DE FATIMA NUNES MARUCCI, M. Pain threshold is achieved at intensity above anaerobic threshold in patients with intermittent claudication. J Cardiopulm Rehabil Prev, v. 29, n. 6, p. 396-401, 2009.

RITTI-DIAS, R. M., WOLOSKER, N., DE MORAES FORJAZ, C. L., CARVALHO, C. R., CUCATO, G. G., LEAO, P. P. e DE FATIMA NUNES MARUCCI, M. Strength training increases walking tolerance in intermittent claudication patients: randomized trial. J Vasc Surg, v. 51, n. 1, p. 89-95, 2010.

RODRIGUES, L. B. C. C. (2011). Respostas cardiovasculares clínicas e ambulatoriais após o exercício físico de força em indivíduos com doença arterial periférica. . Programa Associado de Pós-graduação em Educação Física UPE/UFPB. Recife, Escola Superior de Educação Física, Universidade de Pernambuco. Mestrado.

RODRIGUES, L. B. C. C., FORJAZ, C. L. M., LIMA, A. H. R. A., MIRANDA, A. S., RODRIGUES, S. L. C., CARDOSO JR, C. G., FILHO, D. S. M. F., MONTEIRO, F. M., GOMES, S. L., GARDNER, A. W., PRADO, W. L. e RITTIDIAS, R. M. A single bout of resistance exercise does not modify cardiovascular responses during daily activities in patients with peripheral artery disease Blood Press Monit., 2013. No Prelo.

RUECKERT, P. A., SLANE, P. R., LILLIS, D. L. e HANSON, P. Hemodynamic patterns and duration of post-dynamic exercise hypotension in hypertensive humans. Med Sci Sports Exerc, v. 28, n. 1, p. 24-32, 1996.

SANTAELLA, D. F., ARAUJO, E. A., ORTEGA, K. C., TINUCCI, T., MION, D., JR., NEGRAO, C. E. e DE MORAES FORJAZ, C. L. Aftereffects of exercise and relaxation on blood pressure. Clin J Sport Med, v. 16, n. 4, p. 341-7, 2006.

SELVIN, E. e ERLINGER, T. P. Prevalence of and risk factors for peripheral arterial disease in the United States: results from the National Health and Nutrition Examination Survey, 1999-2000. Circulation, v. 110, n. 6, p. 738-43, 2004.

SENITKO, A. N., CHARKOUDIAN, N. e HALLIWILL, J. R. Influence of endurance exercise training status and gender on postexercise hypotension. $\mathbf{J}$ Appl Physiol, v. 92, n. 6, p. 2368-74, 2002.

SHI, X., POTTS, J. T., FORESMAN, B. H. e RAVEN, P. B. Carotid baroreflex responsiveness to lower body positive pressure-induced increases in central venous pressure. Am J Physiol, v. 265, n. 3 Pt 2, p. H918-22, 1993.

SIGNORELLI, S. S., MAZZARINO, M. C., DI PINO, L., MALAPONTE, G., PORTO, C., PENNISI, G., MARCHESE, G., COSTA, M. P., DIGRANDI, D., CELOTTA, G. e VIRGILIO, V. High circulating levels of cytokines (IL-6 and TNFalpha), adhesion molecules (VCAM-1 and ICAM-1) and selectins in patients with 
peripheral arterial disease at rest and after a treadmill test. Vasc Med, v. 8, n. 1, p. 15-9, 2003.

SIGNORELLI, S. S., MAZZARINO, M. C., SPANDIDOS, D. A. e MALAPONTE, G. Proinflammatory circulating molecules in peripheral arterial disease. Int $\mathbf{J}$ Mol Med, v. 20, n. 3, p. 279-86, 2007.

SOMERS, V. K., CONWAY, J., COATS, A., ISEA, J. e SLEIGHT, P. Postexercise hypotension is not sustained in normal and hypertensive humans. Hypertension, v. 18, n. 2, p. 211-5, 1991.

SPRONK, S., WHITE, J. V., BOSCH, J. L. e HUNINK, M. G. Impact of claudication and its treatment on quality of life. Semin Vasc Surg, v. 20, n. 1, p. 3-9, 2007.

Standards of medical care in diabetes--2011. Diabetes Care, v. 34 Suppl 1, n., p. S11-61, 2011.

STEG, P. G., BHATT, D. L., WILSON, P. W., D'AGOSTINO, R., SR., OHMAN, E. M., ROTHER, J., LIAU, C. S., HIRSCH, A. T., MAS, J. L., IKEDA, Y., PENCINA, M. J. e GOTO, S. One-year cardiovascular event rates in outpatients with atherothrombosis. JAMA, v. 297, n. 11, p. 1197-206, 2007.

TAN, K. H., COTTERRELL, D., SYKES, K., SISSONS, G. R., DE COSSART, L. e EDWARDS, P. R. Exercise training for claudicants: changes in blood flow, cardiorespiratory status, metabolic functions, blood rheology and lipid profile. Eur J Vasc Endovasc Surg, v. 20, n. 1, p. 72-8, 2000.

TEIXEIRA, L., RITTI-DIAS, R. M., TINUCCI, T., MION JUNIOR, D. e FORJAZ, C. L. Post-concurrent exercise hemodynamics and cardiac autonomic modulation. Eur J Appl Physiol, v. 111, n. 9, p. 2069-78, 2011.

TEW, G., NAWAZ, S., ZWIERSKA, I. e SAXTON, J. M. Limb-specific and crosstransfer effects of arm-crank exercise training in patients with symptomatic peripheral arterial disease. Clin Sci (Lond), v. 117, n. 12, p. 405-13, 2009.

THOMAS, G. D. e SEGAL, S. S. Neural control of muscle blood flow during exercise. J Appl Physiol, v. 97, n. 2, p. 731-8, 2004.

THOMAS, J. R. e NELSON, J. R. (2002). Métodos de pesquisa em atividade física. São Paulo, Artmed.

URAKAWA, K. e YOKOYAMA, K. Music can enhance exercise-induced sympathetic dominancy assessed by heart rate variability. Tohoku J Exp Med, v. 206, n. 3, p. 213-8, 2005.

V Diretrizes Brasileiras de Monitoração Ambulatorial Da Pressão Arterial (MAPA V) e III Diretrizes de Monitoração Residencial da Pressão Arterial (MRPA III). Arq Bras Cardiol, v. 97, n. 3 supl.3, p. 1-24, 2011. 
VI Diretrizes Brasileiras de Hipertensão. Arq Bras Cardiol, v. 95, n., p. 1-51, 2010.

WALLACE, J. P., BOGLE, P. G., KING, B. A., KRASNOFF, J. B. e JASTREMSKI, C. A. A comparison of 24-h average blood pressures and blood pressure load following exercise. American Journal of Hypertension, v. 10, n. 7 Pt 1, p. 728-34, 1997.

WALLACE, J. P., BOGLE, P. G., KING, B. A., KRASNOFF, J. B. e JASTREMSKI, C. $A$. The magnitude and duration of ambulatory blood pressure reduction following acute exercise. J Hum Hypertens, v. 13, n. 6, p. 361-6, 1999.

WHELTON, P. K., HE, J., APPEL, L. J., CUTLER, J. A., HAVAS, S., KOTCHEN, T. A., ROCCELLA, E. J., STOUT, R., VALLBONA, C., WINSTON, M. C. e KARIMBAKAS, J. Primary prevention of hypertension: clinical and public health advisory from The National High Blood Pressure Education Program. JAMA, v. 288, n. 15, p. 1882-8, 2002.

WILCOX, R. G., BENNETT, T., BROWN, A. M. e MACDONALD, I. A. Is exercise good for high blood pressure? Br Med J (Clin Res Ed), v. 285, n. 6344, p. 767-9, 1982.

WILKINS, B. W., MINSON, C. T. e HALLIWILL, J. R. Regional hemodynamics during postexercise hypotension. II. Cutaneous circulation. J Appl Physiol, v. 97, n. 6, p. 2071-6, 2004.

WILKINSON, I. B. e WEBB, D. J. Venous occlusion plethysmography in cardiovascular research: methodology and clinical applications. $\mathbf{B r} \mathbf{J}$ Clin Pharmacol, v. 52, n. 6, p. 631-46, 2001.

WOLOSKER, N., NAKANO, L., DUARTE, F. H., DE LUCIA, N. e LEAO, P. P. Peroneal artery approach for angioplasty of the superficial femoral artery: a case report. Vasc Endovascular Surg, v. 37, n. 2, p. 129-33, 2003.

WOLOSKER, N., NAKANO, L., ROSOKY, R. A. e PUECH-LEAO, P. Evaluation of walking capacity over time in 500 patients with intermittent claudication who underwent clinical treatment. Arch Intern Med, v. 163, n. 19, p. 2296-300, 2003.

WOLOSKER, N., ROSOKY, R. A., NISHINARI, K. e NAKANO, L. Use of arteriography for the initial evaluation of patients with intermittent lower limb claudication. Sao Paulo Med J, v. 119, n. 2, p. 59-61, 2001.

ZAGURA, M., SERG, M., KAMPUS, P., ZILMER, M., EHA, J., UNT, E., LIEBERG, J., COCKCROFT, J. R. e KALS, J. Aortic stiffness and vitamin $D$ are independent markers of aortic calcification in patients with peripheral arterial disease and in healthy subjects. Eur J Vasc Endovasc Surg, v. 42, n. 5, p. 689-95, 2011.

ZERATI, A. E., WOLOSKER, N., AYZIN ROSOKY, R. M., FERNANDES SAES, G., RAGAZZO, L. e PUECH-LEAO, P. Prevalence of metabolic syndrome in 
patients with intermittent claudication and its correlation with the segment of arterial obstruction. Angiology, v. 61, n. 8, p. 784-8, 2010. 


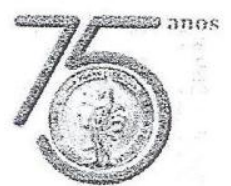

\section{UNIVERSIDADE DE SÃO PAULO ESCOLA DE EDUCAÇÃO FÍSICA E ESPORTE}

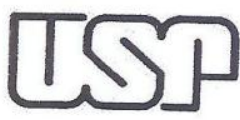

\section{Of. CEP00809/EEFE/06022009}

São Paulo, 06 de fevereiro de 2009.

Senhora Pesquisadora,

O Comitê de Ética em Pesquisa (CEP) da Escola de Educação Física e Esporte da Universidade de São Paulo, em reunião ordinária realizada em 05 de fevereiro de 2009, aprovou o Protocolo 2008/55 - "Respostas cardiovasculares agudas e crônicas ao exercício físico em indivíduos com claudicação intermitente", sob sua responsabilidade.

Atenciosamente,

Ilma. Sra

Profa. Dra. Cláudia Forjaz

EEFEUSP - EFB 
Data: Mon, 1 Feb 2010 16:55:42 -0200 [01-02-10 16:55 16:55:42 EST]

De: aezerati@uol.com.br

Para: "cucato@usp.br"<cucato@usp.br>

Assunto: Fwd: alerta automático CAPPesq

Mensagem original

De: CAPPesq < cappesq@hcnet.usp.br >

Para: Investigador < aezerati@uol.com.br >

Assunto: alerta automático CAPPesq

Enviada: 01/02/2010 13:20

CAPPesq

Prezado Investigador,

Você está recebendo um alerta automático do Sistema Gestão da Pesquisa.

Seu registro online $n^{\circ} 4344$, protocolo CAPPesq $n^{\circ} 1179 / 09$ passou para o status: APROVADO na Comissão de Ética para Análise de Projetos de Pesquisa (CAPPesq) do HCFMUSP.

Motivo:

Acesse: http://mww.hcnet. usp.br/adm/dc/napesq/DiretoriaClinica/

Atenciosamente,

Comissåo de Ética para Análise de Projetos de Pesquisa - CAPPesq

Diretoria Clínica - HCFMUSP 